\title{
Left Ventricular Mechanoenergetics in Small Animals
}

\author{
M. TAKAKI \\ Department of Physiology II, Nara Medical University, 840 Shijo-cho, Kashihara, Nara, 634-8521 Japan
}

\begin{abstract}
Studies on left ventricular mechanical work and energetics in rat and mouse hearts are reviewed. First, left ventricular linear endsystolic pressure-volume relation (ESPVR) and curved end-diastolic pressure-volume relation (EDPVR) in canine hearts and left ventricular curved ESPVR and curved EDPVR in rat hearts are reviewed. Second, as an index for total mechanical energy per beat in rat hearts as in canine hearts, a systolic pressure-volume area (PVA) is proposed. By the use of our original system for measuring continuous oxygen consumption for rat left ventricular mechanical work, the linear left ventricular myocardial oxygen consumption per beat $\left(\mathrm{VO}_{2}\right)$-PVA relation is obtained as in canine hearts. The slope of $\mathrm{VO}_{2}$-PVA relation (oxygen cost of PVA) indicates a ratio of chemomechanical energy transduction. $\mathrm{VO}_{2}$ intercept (PVA-independ-
\end{abstract}

ent $\mathrm{VO}_{2}$ ) indicates the summation of oxygen consumption for $\mathrm{Ca}^{2+}$ handling in excitation-contraction coupling and for basal metabolism. An equivalent maximal elastance (eEmax) is proposed as a new left ventricular contractility index based on PVA at the midrange left ventricular volume. The slope of the linear relation between PVA-independent $\mathrm{VO}_{2}$ and eEmax (oxygen cost of eEmax) indicates changes in oxygen consumption for $\mathrm{Ca}^{2+}$ handling in excitation-contraction coupling per unit changes in left ventricular contractility. The key framework of $\mathrm{VO}_{2}$-PVA-eEmax can give us a better understanding for the biology and mechanisms of physiological and various failing rat heart models in terms of mechanical work and energetics. [The Japanese Journal of Physiology 54: 175207, 2004]

Key words: rat, left ventricle, oxygen consumption per beat $\left(\mathrm{VO}_{2}\right)$, systolic pressure-volume area (PVA), sarcoplasmic reticulum $\mathrm{Ca}^{2+}$ ATPase (SERCA2a), equivalent Emax (eEmax).

\section{Introduction}

We have proposed the two key mechanoenergetic indexes: "oxygen $\left(\mathrm{O}_{2}\right)$ cost of mechanical energy (PVA)" and " $\mathrm{O}_{2}$ cost of contractility (Emax)." These two $\mathrm{O}_{2}$ costs are proved to be relatively constant under various physiological conditions, but they may alter under pathophysiological conditions such as myocardial stunning and acidosis. We consider that the analyses of these two costs will greatly facilitate a better understanding of cardiac mechanoenergetics of both normal and failing hearts. The heart maintains its pumping action by converting chemical energy contained in metabolic substrates into mechanical energy and work [1]. ATP is the final source of chemical energy for a mechanical contraction of the muscle [1-3]. Cardiac energy metabolism is normally aerobic, i.e., consum- ing $\mathrm{O}_{2}$; most ATP is produced by oxidative phosphorylation in mitochondria in myocardium. Therefore cardiac oxygen consumption is virtually equivalent to the total energy utilization of the heart $\left(1 \mathrm{ml} \mathrm{O}_{2}=20 \mathrm{~J}\right)[4,5]$.

ATP is used in myocardium by three major ATPases: $\mathrm{Na}^{+}-\mathrm{K}^{+}$-ATPase at the sarcolemma, $\mathrm{Ca}^{2+}$-ATPase at the sarcoplasmic reticulum (SR), and myosin ATPase at the contractile element [5]. The $\mathrm{Na}^{+}-\mathrm{K}^{+}$-ATPase is related to both $\mathrm{Na}^{+}$and $\mathrm{K}^{+}$handling in the electrical activation of the sarcolemma and to $\mathrm{Na}^{+}$handling coupled with $\mathrm{Na}^{+}-\mathrm{Ca}^{2+}$ and $\mathrm{Na}^{+}-\mathrm{H}^{+}$exchanges. The $\mathrm{Ca}^{2+}$-ATPase is related to $\mathrm{Ca}^{2+}$ handling in the excitation-contraction (EC) coupling for the activation of contraction and its relaxation. The myosin ATPase is related to cross-bridge cycling for mechanical contraction [5]. The mechanical loading, excitation rate,

Received on March 1, 2004; accepted on June 7, 2004

Correspondence should be addressed to: Miyako Takaki, Ph.D., Department of Physiology II, Nara Medical University, 840 Shijo-cho, Kashihara, Nara, 634-8521 Japan. Tel: +81-744-29-8829, Fax: +81-744-23-4696, Email: mtakaki@naramed-u.ac.jp 
and inotropic conditions of the heart are known to affect the rate and amount of ATP hydrolysis by these ATPase and thus myocardial oxygen consumption [3, 4]. However, their quantitative relations in normal and failing hearts would be different [6].

In this review, we summarize recent studies, including ours, especially focusing on small animal hearts analyzed mainly at the whole heart, and also at the myocardium slice, by an application of the two key indexes: the $\mathrm{O}_{2}$ cost of mechanical energy (pressurevolume area, PVA) and the $\mathrm{O}_{2}$ cost of equivalent Emax (an index of left ventricular contractility, eEmax for rat hearts). These two $\mathrm{O}_{2}$ costs have been shown to be relatively constant under various physiological and pathological conditions [7-11], but to be altered under intracoronary infusion of sodium nitroprusside [12] or barium [13]. We consider that the analyses of these two costs will greatly facilitate a better understanding of cardiac mechanoenergetics of normal and failing hearts.

\section{Definition and analyses of left ventricular function in canine and rabbit hearts}

\section{(1) Time-varying elastance model}

When the Hill two-element model is used to calculate the energy costs of external and internal work, the energy costs of work are 1:3, respectively, in regard to external work and internal work. This leads to the general contention that internal work is three times more costy than external work [14]. However, it is not easily conceivable how the contractile element could discriminate external work from internal work and perform these two types of work with different energy costs and efficiencies. There seems to be no mechanism for cross-bridges to recognize whether the mechanical work performed by cross-bridge cycling is conveyed to the outside of the fiber or stored in the series elasticity within it.

Suga developed the idea that the time-varying elastance model of the ventricle could help solve this intriguing problem of cardiac energetics [15]. He proposed this model as a result of his own ventricular pressure and volume measurements in canine hearts [16-18]. Although this model of the ventricle is conceptually the same as the time-varying capacitance simulating cardiac pumping in computer models of the cardiovascular system [16, 19], he gave a resolute physiological basis to the time-varying elastance model of the left ventricle (LV) [16, 19, 20]. In this model, the level of ventricular contractile state was assessed in terms of a new index, Emax $[21,22]$. Emax is the maximal or end-systolic value for the ratio $P(t) /[V(t)-$
$V_{0}$ ], where $P(t)$ and $V(t)$ are LV instantaneous pressure and volume and $V_{0}$ is the ventricular dead volume at which peak isovolumic pressure is zero [16, 23]. The dimensions of Emax are $\mathrm{mmHg} \cdot \mathrm{ml}^{-1}$. Normalized Emax with respect to $\mathrm{LV}$ weight can be expressed in terms of $\mathrm{mmHg} \cdot \mathrm{ml}^{-1} \cdot 100 \mathrm{~g}$. The advantages and limitations of the time-varying elastance model and the Emax concept have been well studied and fully reviewed [16, 24-27].

Emax is proposed as a slope of the linear ESPVR. However, in small animal LV the ESPVR is curvilinear, not linear. Therefore as an index for LV contractility, a new index should be proposed. Consequently, we proposed an equivalent Emax (a slope of a triangular area equivalent to pressure-volume area), described later [28].

\section{(2) Total mechanical energy and ventricular pressure-volume area (PVA)}

Based on the time-varying elastance model of the ventricle [21, 23-27], Suga [15] proposed a new measure of total mechanical energy of ventricular contraction. In this proposal, he used the simplest version of the time-varying elastance model that consisted of only an ideal elastance to increase and decrease as a function of time during each contraction [19-21, 29].

The energetic consequences of the time-varying elastance provide the theoretical basis for the definition and measurement of the total mechanical energy. This energy can be quantified as a specific area, the systolic pressure-volume area (PVA), in a pressurevolume diagram. Mechanical energy is generated with increases in the time-varying elastance and the counterclockwise rotation of the instantaneous pressure-volume relation curve $[15,23]$. The total area swept by the instantaneous pressure-volume curve on the origin side of the working pressure-volume point during a contraction represents the total mechanical energy generated by the contraction. The total area consists of smaller areas: One is the area for external work (EW), surrounded by the P-V loop, and the other is the area for mechanical or elastic potential energy (PE) between the end-systolic and end-diastolic P-V relation curves on the origin side of the P-V loop [15]. Thus PVA is a simple sum of EW and PE. The shape of the instantaneous end-systolic and end-diastolic pressure-volume curves do not affect the definition and determination of the total mechanical energy and PVA [15, 30].

Although the amount of EW is independent of the model used, the nature and amount of PE depend on the mechanical model of the heart. Although PE is a type of internal energy, it is not equal to the previously 
defined internal work [31, 32]. Therefore PE was adopted instead of internal work [15, 33].

Although PVA has been determined exclusively on the basis of the ideal time-varying elastance model, more-complex time-varying elastance models may be needed to simulate ventricular pressure-volume relations and mechanical energetics under various loading and contractile conditions [34, 35]. An output resistance may be required to simulate the flow dependence of the elastance [34, 36-38]. This series resistance, if it is a viscous one, consumes energy when ejection flow exists so that EW would be underestimated by the energy loss $[15,35]$. Because PVA is determined from measured LV pressure, such a series resistance may make the actually determined PVA slightly, but variably, underestimate (by less than $10 \%$ in ordinary ejecting contractions) the true total mechanical energy generated inherently in the time-varying elastance [15, 35]. However, this series resistance has been shown to be nonviscous and not to have an important role in ventricular energetics [39].

The total mechanical energy generated by contraction could eventually be quantified by the total number of cross-bridge cycles and the thermodynamic efficiency of each cross-bridge hydrolyzing ATP [40, 41]. Although the number of cross-bridge cycles per one ATP is generally considered to be 1 and thus the number of cross-bridge cycles to be proportional to the number of ATP moles hydrolyzed [42], there is evidence that the coupling ratio between cross-bridge cycling and ATP hydrolysis deviates from unity under certain loading conditions [43]. Moreover, the cycling rate of a cross-bridge is calculated to be 1-3 cycles per beat [44]. A recent study using Spring-8 succeeded for the first time in observing myocardial cross-bridge dynamics in the beating whole heart [45].

\section{(3) $\mathrm{VO}_{2}$-PVA relation}

Whether and how PVA would correlate with myocardial $\mathrm{O}_{2}$ consumption per beat $\left(\mathrm{VO}_{2}\right)$ of the $\mathrm{LV}$ has been studied, using the excised cross-circulated canine heart preparation [5]. The Emax and PVA of each contraction were determined online. LV PVA normalized for $100 \mathrm{~g} \mathrm{LV}$ was expressed in $\mathrm{mmHg} \cdot \mathrm{ml} \cdot$ beat $^{-1}$. $100 \mathrm{~g}^{-1}$.

$\mathrm{VO}_{2}$ was determined as the product of coronary flow and arteriovenous $\mathrm{O}_{2}$ content difference $\left(\mathrm{AVO}_{2} \mathrm{D}\right) /$ heart rate [46]. PVA and $\mathrm{VO}_{2}$ were both determined in a steady state under varied loading, heart rate, and inotropic conditions.

End-diastolic LV volume (preload) was changed to obtain a volume-loaded $\mathrm{VO}_{2}$-PVA relation. Isovolumic and ejecting contractions in a steady state were pro- duced at 4-5 different LV volumes including $V_{0}$. Volume-loaded $\mathrm{VO}_{2}$-PVA relations were obtained before and after inotropic interventions such as $\mathrm{Ca}^{2+}$ or dobutamine as described later [47]. During an inotropic intervention, a different type of $\mathrm{VO}_{2}$-PVA relation at a constant $\mathrm{LV}$ volume was obtained as a composite $\mathrm{VO}_{2}$-PVA relation.

Important findings obtained from these studies in normal canine hearts have been previously reviewed $[5,48]$. (1) $\mathrm{VO}_{2}$ correlates closely and linearly with PVA at different LV volumes in any stable contractile state whether control, enhanced by a positive inotropic agent such as $\mathrm{Ca}^{2+}$, or depressed by a negative inotropic agent such as pentobarbital sodium in any given heart. The $\mathrm{VO}_{2}$-axis intercept value of the $\mathrm{VO}_{2}$-PVA relation is the same as $\mathrm{VO}_{2}$ obtained in unloaded contraction at $V_{0}$. (2) The slope of the $\mathrm{VO}_{2}$-PVA relation is the same regardless of contraction mode, whether isovolumic or ejecting in a given heart. (3) The slope of the $\mathrm{VO}_{2}$-PVA relation is relatively constant in different normal hearts in a stable contractile state. (4) During a graded inotropic intervention, the slope of the composite $\mathrm{VO}_{2}-\mathrm{PVA}$ relation is usually steeper than the slope of the volume-loaded $\mathrm{VO}_{2}$-PVA relation. (5) The volume-loaded $\mathrm{VO}_{2}$-PVA relation shifts upward or downward usually in a parallel manner with an enhanced or depressed contractile state. (6) The magnitudes of the upward or downward shift of the $\mathrm{VO}_{2}$-PVA relation and thus the $\mathrm{VO}_{2}$ intercept (PVAindependent $\mathrm{VO}_{2}$ ) are usually comparable to increases or decreases in contractility assessed by Emax.

However, more recent studies exhibited a different type of mechanoenergetic results in rat hearts, mentioned later.

\section{(4) Load-independence of the $\mathrm{VO}_{2}$-PVA relation}

Isovolumic versus ejecting. In our previous studies, the $\mathrm{VO}_{2}$-PVA relation was compared between isovolumic and ejecting contractions in each canine ventricle [49]. In either mode of contraction, the relation was linear with a nearly unity correlation coefficient $(r=0.96$ on average). When both modes are pooled, the two relations were superimposable and the resultant $\mathrm{VO}_{2}$-PVA relation was also linear with a similar $r$ (0.96 on average).

The concept of PVA, which was originally developed for a ventricular chamber, was applied to a papillary muscle preparation [50]. The linear muscle version of PVA was called "force-length area" (FLA). The correlation coefficient, $r$ between $\mathrm{VO}_{2}$ and FLA, was 0.96 on average. Moreover, the $\mathrm{VO}_{2}$-FLA relation was common to both isometric and shortening con- 
tractions. These results indicate that the linear, loadindependent $\mathrm{VO}_{2}$ versus total mechanical energy relationship holds reasonably well in myocardium in the same manner as in the ventricle. That is, the loadindependent linear $\mathrm{VO}_{2}$-PVA relationship seems to be intrinsic to myocardium; it is not necessary to consider the complex shape of the ventricular chamber and myocardial fiber orientation within the ventricular wall in energetics. This feature of the $\mathrm{VO}_{2}$-PVA (or FLA) relationship seems to be closely related to the law of conservation of energy because energy is a scalar variable and the total is a simple sum of all the parts.

Energy equivalence of external work and potential energy. The load independence of the $\mathrm{VO}_{2}$-PVA relation was confirmed not only in the baseline contractile state without any intervention, but also in an enhanced contractile state as long as the contractile state was stable [23].

Within a constant PVA, almost all the PE can be converted effectively into EW without affecting $\mathrm{VO}_{2}$ by appropriately unloading LV pressure-volume load during the relaxation period [51]. This result evidently indicates that the mechanical energy represented by PVA can be either PE or EW without affecting myocardial energetics, i.e., PE and EW are energetically equivalent.

In an isovolumic contraction, PE stored in the ventricle at peak contraction is given by PVA. If no external work is done, PE is released as heat, and thus the heat released in relaxation should be identical to PVA. These results confirmed the energetic prediction of the time-varying elastance model developed for the whole LV; PE (= PVA in an isovolumic contraction) is released as heat when unused.

\section{(5) Contractility-dependence of the $\mathrm{VO}_{2}$-PVA relation}

Cytosolic $\mathrm{Ca}^{2+}$ is bound to troponin $\mathrm{C}$ and this binding elicits cross-bridge cycling [42]. An increased concentration of extracellular $\mathrm{Ca}^{2+}$ increases sarcolemmal $\mathrm{Ca}^{2+}$ influx through voltage-dependent $\mathrm{Ca}^{2+}$ channels during the membrane depolarization. The resultant increase in intracellular $\mathrm{Ca}^{2+}$ concentration augments total released $\mathrm{Ca}^{2+}$ from the $\mathrm{SR}$ and enhances contractility.

Dobutamine binds to $\beta_{1}$-adrenergic receptors ( $\beta$ ARs) and activate adenylate cyclase by coupling through the stimulatory G-protein, Gos. The resulting increase in intracellular cAMP activates cAMP-dependent protein kinase (PKA). PKA has several substrates in cardiomyocytes that influence contractility in response to activated $\beta A R$ signaling; these include the L-type
$\mathrm{Ca}^{2+}$ channel in the sarcolemma, the ryanodine receptor (RyR2), and phospholamban (PLB) in the sarcoplasmic reticulum (SR). The phosphorylation of PLB leads to the increase of $\mathrm{SR} \mathrm{Ca}^{2+}$ ATPase (SERCA) and consequent accelerated $\mathrm{Ca}^{2+}$ accumulation in SR. Consequently, dobutamine enhances contraction and relaxation [5].

When the intracoronary arterial administration of $\mathrm{CaCl}_{2}$ or dobutamine increased Emax by $50-100 \%$, it also elevated the volume-loaded $\mathrm{VO}_{2}$-PVA relation in a parallel manner to the baseline-volume-loaded $\mathrm{VO}_{2}-$ PVA relation with a 50-100\% increase in the PVAindependent $\mathrm{VO}_{2}[23,47]$. This is usually the standard basic protocol to examine the dependency of the $\mathrm{VO}_{2}-$ PVA relation on Emax.

\section{(6) $\mathrm{O}_{2}$ cost of PVA}

The slope of the $\mathrm{VO}_{2}$-PVA relation means the " $\mathrm{O}_{2}$ cost of PVA" or the $\mathrm{O}_{2}$ cost of mechanical energy. When the slope is a, PVA-dependent $\mathrm{VO}_{2}$ is expressed by aPVA. Then $\mathrm{VO}_{2}$ is given as $\mathrm{VO}_{2}=\mathbf{a P V A}+\mathrm{PVA}-$ independent $\mathrm{VO}_{2}$. From a large number of canine $\mathrm{LV}$ in our previous studies, an average value of 1.4-1.6 $\times$ $10^{-5} \mathrm{mlO}_{2} \cdot \mathrm{mmHg}^{-1} \cdot \mathrm{ml}^{-1}$ was obtained for the $\mathrm{O}_{2}$ cost of PVA [47, 52, 53]. This means that about 1.4-1.6 $\times$ $10^{-5} \mathrm{mlO}_{2}$ is needed to increase PVA by 1 $\mathrm{mmHg} \cdot \mathrm{ml} \cdot$ beat $^{-1}$. One $\mathrm{mlO}_{2}$ is biochemically equivalent to approximately $20 \mathrm{~J}$, or precisely $19.5-20.5 \mathrm{~J}$, depending on the metabolic substrate used [54]. One $\mathrm{mmHg} \cdot \mathrm{ml}$ of PVA is physically equivalent to $1.33 \times$ $10^{-4} \mathrm{~J}$. Therefore the a value of $1.5-1.8 \times 10^{-5} \mathrm{ml}$ $\mathrm{O}_{2} \cdot \mathrm{mmHg}^{-1} \cdot \mathrm{ml}^{-1}$ is convertible to about $2.3-2.7$ (dimensionless) [5]. Note that this value is independent of LV weight.

\section{(7) $\mathrm{O}_{2}$ cost of Emax}

The activation component of $\mathrm{VO}_{2}$ is considered to reflect the energy expenditure by both sarcolemmal $\mathrm{Na}^{+}-\mathrm{K}^{+}$-ATPase and SR Ca ${ }^{2+}$-ATPases. Since the total amount of released $\mathrm{Ca}^{2+}$ is considered to increase in an enhanced contractile state, it is easily conceivable that a greater amount of $\mathrm{Ca}^{2+}$ is removed mostly into the SR by the $\mathrm{Ca}^{2+}$-ATPase consuming more ATP with a stoichiometry of $2 \mathrm{Ca}^{2+}: 1 \mathrm{ATP}$ [55] and additionally to the outside by the sarcolemmal $\mathrm{Na}^{+}-\mathrm{Ca}^{2+}$ exchanger. More $\mathrm{Ca}^{2+}$ seems to flow into the myocardial cell through the voltage-dependent $\mathrm{Ca}^{2+}$ channel during membrane depolarization in an enhanced contractile state [55]. This amount of $\mathrm{Ca}^{2+}$ must be removed from the cell during repolarization [56]. The $\mathrm{Na}^{+}-\mathrm{Ca}^{2+}$ exchanger per se does not consume ATP to remove $\mathrm{Ca}^{2+}$ in exchange with influx $\mathrm{Na}^{+}$(stoichiometry $=3 \mathrm{Na}^{+}$: $1 \mathrm{Ca}^{2+}$ ) [55]. However, this influx $\mathrm{Na}^{+}$must be pumped 
out by the $\mathrm{Na}^{+}-\mathrm{K}^{+}$-ATPase with a stoichiometry of $3 \mathrm{Na}^{+}: 2 \mathrm{~K}^{+}: 1 \mathrm{ATP}$. Therefore the net stoichiometry is $1 \mathrm{Ca}^{2+}: 1 \mathrm{ATP}$, which is half that of the SR $\mathrm{Ca}^{2+}$-ATPase. As a whole, the enhancement of contractility is associated with increases in both the amount of $\mathrm{Ca}^{2+}$ handled in the excitation-contraction-relaxation cycle and its energy utilization.

Therefore our finding of a PVA-independent $\mathrm{VO}_{2}$ proportionally increased to an increase in Emax seems to be based on the stoichiometry between the amount of $\mathrm{Ca}^{2+}$ to be handled in the excitation-contractionrelaxation process and the amount of ATP consumed in the ion pumps [5].

We have introduced the $\mathrm{O}_{2}$ cost of Emax to quantify the requirement of PVA-independent $\mathrm{VO}_{2}$ per a unit increase in Emax. This cost is expressed by the slope of the relation between PVA-independent $\mathrm{VO}_{2}$ and Emax obtained while Emax is being changed by an inotropic intervention [5]. When $\mathrm{VO}_{2}$-PVA relations are obtained at different levels of Emax, they elevate differently, but their slopes are virtually the same. The elevation increases proportionally with increased Emax. We fix ventricular end-diastolic volume (EDV) and change Emax gradually because the $\mathrm{VO}_{2}$-PVA relations at different Emax are parallel to each other [5].

When Emax and thus PVA and $\mathrm{VO}_{2}$ are increased gradually at constant EDV, the $\mathrm{VO}_{2}$-PVA data points linearly moved right-upward, i.e., deviated upward from the baseline $\mathrm{VO}_{2}-\mathrm{PVA}$ relation line [57]. We called the regression line of these points a composite $\mathrm{VO}_{2}-\mathrm{PVA}$ relation.

From this relation, we determined the PVA-independent $\mathrm{VO}_{2}$ for each Emax by drawing a line through the data point parallel to the baseline $\mathrm{VO}_{2}$-PVA relation. PVA-independent $\mathrm{VO}_{2}$ values were plotted against the corresponding Emax values, and the relation was linear. This relation could be formulated by an empirical equation: PVA-independent $\mathrm{VO}_{2}=\mathbf{c E m a x}+\mathbf{d}$. Slope coefficient $\mathbf{c}$ indicates the $\mathrm{O}_{2}$ cost of Emax. Constant $\mathbf{d}$ indicates the PVA-independent $\mathrm{VO}_{2}$ intercept of the relation. From our studies [47, 52, 53], the $\mathrm{O}_{2}$ cost of Emax was approximately $0.0015-0.0030$ $\mathrm{mlO}_{2} \cdot \mathrm{mmHg}^{-1}$. beat $^{-1} \cdot 100 \mathrm{~g}^{-2}$. The reciprocal of $\mathbf{c}$ means the economy of the E-C coupling.

\section{(8) PVA-dependent and PVA-independent $\mathrm{VO}_{2}$}

$\mathrm{KCl}$-arrested $\mathrm{VO}_{2}$ was not significantly affected by various inotropic agents when $\mathrm{KCl}$ was infused directly into coronary circulation at a barely minimal level to cause cardiac arrest [5]. This result indicates that the fraction of $\mathrm{VO}_{2}$ that changed with Emax at $V_{0}$, i.e., of unloaded contraction with zero PVA, is related to myocardial activation or E-C coupling, which primarily handles intracellular $\mathrm{Ca}^{2+}$ transport $[2,56]$. Any contraction with a positive PVA requires an extra $\mathrm{VO}_{2}$ proportional to the PVA. Therefore the total $\mathrm{VO}_{2}$ is composed of the three major energy expenditures, i.e., mechanical contraction, myocardial activation, and basal metabolism.

The energy expenditure of $\mathrm{Ca}^{2+}$ handling in the activation is assumed to be PVA-independent $\mathrm{VO}_{2}$. In fact, we have found that unloaded $\mathrm{VO}_{2}$ is virtually independent of whether the unloaded contraction is either the isovolumic contraction at $V_{0}$ or completely systolic unloaded contractions from high EDVs [58].

The linear $\mathrm{VO}_{2}$-PVA relation indicates that $\mathrm{VO}_{2}$ for mechanical contraction is proportional to PVA. Therefore it is reasonable to call the $\mathrm{VO}_{2}$ above the unloaded $\mathrm{VO}_{2}$ "PVA-dependent $\mathrm{VO}_{2}$ " and the $\mathrm{VO}_{2}$ below the unloaded $\mathrm{VO}_{2}$ "PVA-independent $\mathrm{VO}_{2}$ ".

PVA-dependent $\mathrm{VO}_{2}$ is consumed for ATP production for myosin ATPase. PVA-independent $\mathrm{VO}_{2}$ is consumed for ATP production for SR $\mathrm{Ca}^{2+}$-ATPase [59], sarcolemmal $\mathrm{Na}^{+}-\mathrm{K}^{+}$-ATPase, and basal metabolism. It remains unknown whether the PVA-independent $\mathrm{VO}_{2}$ is always constant regardless of PVA, because this $\mathrm{VO}_{2}$ component cannot explicitly be separated from the PVA-dependent $\mathrm{VO}_{2}$ in contractions with positive PVA.

\section{(9) E-C coupling $\mathrm{Ca}^{2+}$ handling energy}

In cardiac myocytes, the transition from the resting relaxed state with a low intracellular concentration of $\mathrm{Ca}^{2+}$ to a contraction occurs because a small quantity of $\mathrm{Ca}^{2+}$ crosses the sarcolemma and induces a much larger release of $\mathrm{Ca}^{2+}$ from the SR. The initial events that couple excitation to contraction are initiated by a depolarization of the cell membrane, which causes an opening of the voltage-gated $\mathrm{Na}^{+}$and $\mathrm{Ca}^{2+}$ channels. The initial upstroke of the action potential in ventricular cardiac myocytes is caused by $\mathrm{Na}^{+}$influx via the $\mathrm{Na}^{+}$channel, whereas the subsequent slow inward current maintaining the plateau of the action potential is caused primarily by $\mathrm{Ca}^{2+}$ influx via the L-type $\mathrm{Ca}^{2+}$ channel. Although cumulative $\mathrm{Na}^{+}$influx via the $\mathrm{Na}^{+}$ channel can influence intracellular $\mathrm{Ca}^{2+}$ concentration via the $\mathrm{Na}^{+}-\mathrm{Ca}^{2+}$ exchanger $\left(\mathrm{Ca}^{+}\right.$influx- $\mathrm{Na}^{+}$efflux $)$, it is the $\mathrm{Ca}^{2+}$ influx via the $\mathrm{Ca}^{2+}$ channel that is considered to be of greatest importance in E-C coupling [6063].

The $\mathrm{Ca}^{2+}$ that enters the cell activates the $\mathrm{Ca}^{2+}$ release channel of the SR, releasing $\mathrm{Ca}^{2+}$ from internal stores within the SR: calcium-induced calcium release (CICR) [64]. The probability of opening the $\mathrm{Ca}^{2+}$ release channel in the SR is markedly increased by ex- 
posure to $\mu \mathrm{M}$ concentrations of $\mathrm{Ca}^{2+}$. The $\mathrm{SR} \mathrm{Ca}^{2+}$ channel has phosphorylation, ATP-binding, and calmodulin-binding sites. The $\mathrm{Ca}^{2+}$ released from the $\mathrm{SR}$ binds to the contractile proteins and initiates contraction. In the resting state, the interaction of actin and myosin is inhibited by the troponin-tropomyosin complex, which is bound to actin. When $\mathrm{Ca}^{2+}$ binds to troponin $\mathrm{C}$, a conformational change of the troponintropomyosin complex is induced, relieving this inhibition and resulting in a cross-bridge interaction and contractile element shortening [65]. Thus changes in the affinity of the contractile proteins to $\mathrm{Ca}^{2+}$ as well as the magnitude of the $\mathrm{Ca}^{2+}$ transient achieved during each beat can regulate force development by a myocyte [63].

The decay of the $\mathrm{Ca}^{2+}$ transient occurs primarily by a reuptake of $\mathrm{Ca}^{2+}$ into the $\mathrm{SR}$ mediated by the SR $\mathrm{Ca}^{2+}$ ATPase and secondarily extrusion of $\mathrm{Ca}^{2+}$ from the myocyte mostly by the $\mathrm{Na}^{+}-\mathrm{Ca}^{2+}$ exchanger: $\mathrm{Ca}^{2+}$ efflux- $\mathrm{Na}^{+}$influx "forward" mode of operation.

The contribution of the sarcolemmal $\mathrm{Ca}^{2+}$-ATPase is practically negligible [69] except in failing hearts. The Kca (a Km for $\mathrm{Ca}^{2+}$ ) for $\mathrm{Ca}^{2+}$ transport of the SR $\mathrm{Ca}^{2+}$ ATPase is 300-400 nM. Thus the SR Ca ${ }^{2+}-\mathrm{AT}-$ Pase is strongly activated in the range of physiological $\mathrm{Ca}^{2+}$ concentrations that occur during the normal contraction-relaxation cycle. The regulation of the SR $\mathrm{Ca}^{2+}$ ATPase occurs primarily by phosphorylation of PLB [59].

Competition between $\mathrm{Ca}^{2+}$ extrusion by the $\mathrm{Na}^{+}$$\mathrm{Ca}^{2+}$ exchanger and $\mathrm{Ca}^{2+}$ uptake by the $\mathrm{SR}$ is physiologically important because $\mathrm{Ca}^{2+}$ that is taken up by the SR is available to the $\mathrm{Ca}^{2+}$ transient during a subsequent beat and thus can contribute to force development. In a steady state, the amount of $\mathrm{Ca}^{2+}$ entering the cell equals that extruded from the cell, and the amount released by the SR equals that sequestered by the SR.

The $\mathrm{VO}_{2}$ for E-C coupling is used for removing SR $\mathrm{Ca}^{2+}$ from $1-10 \mu \mathrm{M}$ to $0.1 \mu \mathrm{M}$ by active transport, mainly by $\mathrm{SR} \mathrm{Ca}^{2+}$-ATPase, to relax contraction [6668]. Changes in contractility are accompanied by proportional changes in the amount of $\mathrm{Ca}^{2+}$ involved in the E-C coupling unless $\mathrm{Ca}^{2+}$ sensitivity (or responsiveness) of the contractile proteins is altered [47, 53, 6971]. Such $\mathrm{Ca}^{2+}$ changes would then change the energy required for $\mathrm{Ca}^{2+}$ sequestration by the following four $\mathrm{Ca}^{2+}$ transport systems: (1) SR $\mathrm{Ca}^{2+}$-ATPase; (2) sarcolemmal $\mathrm{Na}^{+}-\mathrm{Ca}^{2+}$ exchanger (these two mechanisms are predominant); (3) sarcolemmal $\mathrm{Ca}^{2+}$-ATPase; (4) mitochondrial $\mathrm{Ca}^{2+}$ uptake (the latter two mechanisms are about 50-fold slower than the former two mechanisms) [63, 72-74].
A tight coupling exists between two moles of $\mathrm{Ca}^{2+}$ transported and one mole of ATP hydrolyzed in myocardial SR unless the $\mathrm{SR}$ is leaky to $\mathrm{Ca}^{2+}[75,76]$. This tight $\mathrm{Ca}^{2+}$ : ATP stoichiometry suggests that $\mathrm{VO}_{2}$ for $\mathrm{Ca}^{2+}$ handling by the $\mathrm{SR}$ is proportional to the amount of $\mathrm{Ca}^{2+}$ handled by the SR in the E-C coupling regardless of the $\mathrm{Ca}^{2+}$ release and uptake speeds [21, 75]. Uncertainty of the amount of $\mathrm{Ca}^{2+}$ handling via the $\mathrm{Na}^{+}-\mathrm{Ca}^{2+}$ exchanger makes it difficult to exactly partition the $\mathrm{Ca}^{2+}$ handling $\mathrm{VO}_{2}$ into the $\mathrm{VO}_{2}$ components of the $\mathrm{SR} \mathrm{Ca}^{2+}$ pump and the $\mathrm{Na}^{+}-\mathrm{Ca}^{2+}$ exchanger.

Low concentrations of ryanodine open the $\mathrm{SR} \mathrm{Ca}^{2+}$ release channel and thus deplete the $\mathrm{SR} \mathrm{Ca}^{2+}$ stores. In the presence of a continued stimulation of myocardial cells, ryanodine does not completely deplete the SR. However, in the rested cells exposed to ryanodine, the SR becomes completely depleted [63]. Therefore in the resting myocardium, energy expenditure for sequestering leaked $\mathrm{Ca}^{2+}$ appears to be small [76].

The activation (or E-C coupling) energy of $0.4 \mathrm{~J} /$ $100 \mathrm{~g}$ observed experimentally in a control contractile state corresponds to about $100 \mathrm{nmol} \mathrm{Ca}{ }^{2+} / \mathrm{g}$ tissue to be released and sequestered per beat on the basis of a $\mathrm{Ca}^{2+}$ pump stoichiometry of $2 \mathrm{Ca}^{2+} / \mathrm{ATP}$ [77]. Then $\mathrm{VO}_{2}$ for E-C coupling of about $0.3-0.4 \mathrm{~J} \cdot$ beat $^{-1} \cdot 100$ $\mathrm{g}^{-1}$ in the excised cross-circulated canine heart [23] suggests the involvement of $60-100 \mathrm{nmol} \mathrm{Ca} \mathrm{Ca}^{2+} / \mathrm{g}$ tissue $[3,78]$. This amount of $\mathrm{Ca}^{2+}$ involved in E-C coupling varies among literatures; for example, the 20 and $70 \%$ maximum force developments require $\mathrm{Ca}^{2+}$ of 17 and $26 \mathrm{nmol} / \mathrm{g}$ wet muscle in canine heart [79].

The parallel shifts of the $\mathrm{VO}_{2}$-PVA relation under varied Emax [21] are consistent with the contemporary concept that the primary cellular change accompanying changes in contractility is the amount of $\mathrm{Ca}^{2+}$ released to the myofilaments per beat. The close relation between unloaded $\mathrm{VO}_{2}$ and Emax seems consistent with the linearity of the relation between $\mathrm{Ca}^{2+}$ transients and contractility [79]. This close relation also seems consistent with a fixed and linear stoichiometry between $\mathrm{Ca}^{2+}$ uptake and ATP consumption by $\mathrm{SR}$ independent of the contractile state $[68,75]$.

\section{(10) Basal metabolism}

The basal metabolism of myocardium is the energy utilization of myocardial activities other than the electrical activation and the mechanical contraction. Canine whole heart preparations can be relaxed under high $\mathrm{K}^{+}$(10-20 $\mathrm{mM}$ ) perfusion, and basal metabolic $\mathrm{VO}_{2}$ can be measured directly. The basal metabolic $\mathrm{VO}_{2}$ is $1.24 \pm 0.59 \mathrm{mlO}_{2}$ at $5 \mathrm{~min}$ under $\mathrm{KCl}$ arrest, decreases to $1.01 \pm 0.53 \mathrm{ml} \mathrm{O}_{2}$ within the next $5 \mathrm{~min}$, and does not significantly decrease thereafter until 
30 min under $\mathrm{KCl}$ arrest [80]. The $\mathrm{KCl}$-arrested basal metabolic $\mathrm{VO}_{2}$ significantly increases with neither increases in EDV from $V_{0}$ (about $7 \mathrm{ml}$ ) to $50 \mathrm{ml}$ [80] nor $50-100 \%$ increases in Emax by dobutamine.

The basal metabolic $\mathrm{VO}_{2}$ of myocardium seems to include ATP utilization for protein synthesis such as healing over, maintenance of cell membrane polarization by the $\mathrm{Na}^{+}-\mathrm{K}^{+}$-ATPase, and phosphorylation of various proteins. The $\mathrm{Na}^{+}-\mathrm{K}^{+}$-ATPase contributes to only $5-20 \%$ of the basal metabolism [81]. Much remains to be elucidated regarding the components of basal metabolic energy utilization.

\section{(11) Residual cross-bridge cycling $\mathrm{O}_{2}$ consumption}

Even the unloaded ventricle contracting with zero PVA changes its shape. The shape change suggests an existence of myocardial shortening by residual crossbridge cycling and some mechanical energy generation. However, the $\mathrm{VO}_{2}$ values of contractions that are mechanically unloaded throughout systole by quick release from large EDVs are close to the $\mathrm{VO}_{2}$ of unloaded contractions at $V_{0}$ [58]. These $\mathrm{VO}_{2}$ data may be called PVA-independent, because PVA is zero or almost zero in any of these contractions. Therefore the $\mathrm{VO}_{2}$ attributable to the length (preload)-dependent activation seems negligible at least in the canine $\mathrm{LV}$ [58]. Furthermore, $\mathrm{VO}_{2}$ did not significantly decrease even when ventricular volume was decreased from $V_{0}$ to complete collapse with a negative pressure in the ventricle [82]. The former condition greatly increased ventricular shape and size changes, and the latter condition minimized ventricular shape changes. Both these observations indicate that ventricular shape changes produced by residual cross-bridge cycling at zero PVA require no significant $\mathrm{VO}_{2}$.

In contrast to this contention, a group of investigators [83-85] claim that mechanical unloading cannot unequivocally distinguish mechanical from nonmechanical $\mathrm{VO}_{2}$ because the mechanically unloaded heart undergoes shape changes with each contraction and beat-to-beat pressure fluctuations in the negative range. Thus they suspected that when the ventricle is unloaded, there is an uncertain amount of energy consumption for residual cross-bridge cycling, and it has been incorrectly assigned to the nonmechanical $\mathrm{VO}_{2}$. Their contention is based on the method to partition heat output in rabbit papillary muscles into tensiondependent (cross-bridge cycling) and tension-independent (E-C coupling) components by using a negative inotropic drug, 2,3-butanedione monoxime (BDM) [83]. The principle of this approach is that at relatively low concentrations $(<5 \mathrm{mM})$ in isolated rabbit muscles, BDM inhibits cross-bridge cycling without affecting other energy consuming processes $[86,87]$. They considered that extrapolation of the $\mathrm{VO}_{2}$-force time integral (FTI) relation at $\mathrm{BDM}<5 \mathrm{mM}$ to the $\mathrm{VO}_{2}$ axis provides an estimate of nonmechanical $\mathrm{VO}_{2}$, which includes $\mathrm{VO}_{2}$ for both $\mathrm{E}-\mathrm{C}$ coupling and basal metabolism, but not $\mathrm{VO}_{2}$ for residual cross-bridge cycling. Nonmechanical $\mathrm{VO}_{2}$ was estimated to be 0.00132-0.0137 $\mathrm{mlO}_{2} \cdot$ beat $^{-1} \cdot 100 \mathrm{~g} \mathrm{LV}^{-1}$ [85]. In contrast, mechanically unloaded $\mathrm{VO}_{2}$ was estimated to be $0.0276 \mathrm{mlO}_{2} \cdot$ beat $^{-1} \cdot 100 \mathrm{~g} \mathrm{LV}^{-1}$, about twice the value of the $\mathrm{VO}_{2}$-axis intercept of the $\mathrm{VO}_{2}$-FTI relation [85]. These results suggested that during mechanically unloaded conditions, there is considerable energy utilization for "residual" cross-bridge cycling.

However, in the ferret papillary muscle, BDM at concentrations even as low as $1 \mathrm{mM}$ reduced $\mathrm{Ca}^{2+}$ current, reduced the peak $\mathrm{Ca}^{2+}$ transient, and decreased the sensitivity of the myofilaments [88]. In the excised cross-circulated canine hearts, BDM 0.5-7 mM principally reduces the energy related to $\mathrm{Ca}^{2+}$ handling for E-C coupling [89].

Therefore the partition of mechanically unloading $\mathrm{O}_{2}$ consumption, i.e., the ratio of $\mathrm{O}_{2}$ consumption for the residual cross-bridge cycling has been controversial until a new approach that uses LV myocardial slices is developed [see Ref. 109].

\section{(12) Free $\mathrm{Ca}^{2+}$ and total $\mathrm{Ca}^{2+}$ kinetics}

The energy utilization for $\mathrm{Ca}^{2+}$ handling tends to be markedly underestimated on the basis of the popular observation that the peak $\mathrm{Ca}^{2+}$ transient needed to activate mechanical contraction is $0.5-2 \mu \mathrm{M}$ [69]. However, the amount of $\mathrm{Ca}^{2+}$ to be related with energy utilization is the total $\mathrm{Ca}^{2+}$ removed by both $\mathrm{SR}$ $\mathrm{Ca}^{2+}$-ATPase and a combination of the $\mathrm{Na}^{+}-\mathrm{Ca}^{2+}$ exchanger and the $\mathrm{Na}^{+}-\mathrm{K}^{+}$-ATPase. Seventy-five to $95 \%$ of the total $\mathrm{Ca}^{2+}$ released to the contractile machinery is removed by the $\mathrm{SR} \mathrm{Ca}^{2+}$-ATPase (recirculation fraction). This amount is 25-400 times greater than the free $\mathrm{Ca}^{2+}$ measured as the $\mathrm{Ca}^{2+}$ transient [69]. On the basis of the proportionality between the amount of $\mathrm{Ca}^{2+}$ handled in the E-C coupling and the $\mathrm{Ca}^{2+}$ handling energy in the SR, the $\mathrm{O}_{2}$ cost of Emax indirectly indicates the total amount of $\mathrm{Ca}^{2+}$ handled in the E-C coupling needed to cause a unit change in Emax. The $\mathrm{Ca}^{2+}$ loading run (increasing extracellular $\mathrm{Ca}^{2+}$ concentration) is the standard protocol to obtain the $\mathrm{O}_{2}$ cost of Emax.

It is important to recognize the difference between the $\mathrm{Ca}^{2+}$ transient and the total released $\mathrm{Ca}^{2+}$ for a better understanding of cardiac energetics. The naive 
estimation of a change in the total released $\mathrm{Ca}^{2+}$ from an observed change in the $\mathrm{Ca}^{2+}$ transient may easily lead to a wrong conclusion.

\section{Definition and analyses of left ventricular function in rat and mouse hearts}

\section{(1) In situ rat hearts}

An eight-electrode conductance catheter (No. 7F, $10 \mathrm{~cm}$ ) previously developed by Baan et al. [90] has been applied to big animals such as dogs and humans to measure instantaneous absolute LV volume quantitatively. For calibration they developed the formula $V(t)=(1 / a) \times L^{2} \times r \times G(t)-V_{\mathrm{c}}$, where $V(t)$ is timevarying $L V$ volume, $a$ is a dimensionless constant, $L$ is the electrode separation, $r$ is the conductivity of blood obtained by a sampling cuvette, and $G(t)$ is the measured conductance within the LV cavity. $V_{\mathrm{c}}$ is a correction term caused by the parallel conductance of structures surrounding the cavity and is measured by transiently changing the resistivity of the blood in the LV by an injection of a small bolus of hypertonic saline $(10 \% \mathrm{NaCl}$ solution). This conductance catheter only when appropriately installed provides a reliable and simple method to measure instantaneous LV volume [90-92]. When the pressure is simultaneously recorded, we could assess the LV pump performance by displaying pressure-volume loops.

A more miniaturized conductance catheter (No. 3F, $1.2 \mathrm{~cm}$ ) for rats was instituted by Ito et al. [93]. It is equipped with six equidistant $(3 \mathrm{~mm})$ ring electrodes. The current is delivered by a signal conditioner-processor. With this conductance catheter system and a micromanometer-tipped transducer, we obtained dynamic pressure-volume loops by changing afterload with a temporary aortic clamp. This enables us to obtain curved ESPVR and PVA at an appropriate LV volume (midrange $\mathrm{LV}$ volume) $\left(\mathrm{PVA}_{\mathrm{mLVV}}\right)$ to assess contractile states and mechanical work, respectively, in situ in small experimental animals such as rats. Furthermore, this conductance catheter system is developed for mice smaller than rats. When the conductance catheter system for these small animals has been instituted, it will be easy to obtain dynamic pressure-volume loops and to estimate cardiac pump function more appropriately. For example, various types of transgenic mice such as $\mathrm{Na}^{+}-\mathrm{H}^{+}$antiporter overexpression or endothelin-1 deficiency can be used for analyzing the function of a specific gene at the whole body level. Pathological model animals such as hypertrophy can also be used for analyzing pathological features at the whole body level [94]

\section{(2) Cross-circulation with blood vs. Langendorff perfusion with crystalloid in rat in vitro hearts}

Although canine LV mechanoenergetics has been studied mostly in the blood-perfused heart [5, 48], rat LV mechanoenergetics has not been studied in a bloodperfused whole heart preparation. Although rat LV mechanoenergetics has been well used in the crystalloid-perfused heart preparation [95], the crystalloid perfusate has only a tenth of the $\mathrm{O}_{2}$-carrying capacity of the normal blood. The blood-perfused rat heart preparation is more physiological than the crystalloidperfused rat whole heart preparation and less expensive and more compliant to animal welfare than the canine preparation. Furthermore, the rat is frequently used to create genetically engineered models and pathological models of human disease such as transgenic and hypertensive rats $[9,11,94]$.

\section{(3) LV mechanoenergetics in cross- circulated rat heart preparations}

The objectives for the first study in the excised cross-circulated rat whole heart preparation are to investigate ESPVR and the relation of $\mathrm{VO}_{2}$ and PVA and to establish a new evaluation of rat LV mechanoenergetics. Although we could reasonably expect a curved ESPVR as in in situ rat LV [96, 97], we hypothesize that the $\mathrm{VO}_{2}$-PVA relation would still be linear as in the puppy LV [98]. We obtain the results to indicate linear $\mathrm{VO}_{2}$-PVA relations of the rat $\mathrm{LV}$ despite its curvilinear ESPVRs within physiological ranges of contractile and loading conditions. From these results, we propose PVA at an appropriate LV end-diastolic (= end-systolic) volume (midrange LVV) $\left(\mathrm{PVA}_{\mathrm{mLVV}}\right)$ and the slope and $\mathrm{VO}_{2}$ intercept of the $\mathrm{VO}_{2}$-PVA relation as good LV mechanoenergetic indexes [99].

Experimental procedure. A thin latex balloon (volume, $0.08 \mathrm{ml}$ ) is fitted into the $\mathrm{LV}$ and connected via a polyethylene tube to a pressure transducer and a 0.5 $\mathrm{ml}$ precision glass syringe with fine scales (minimum scale: $0.005 \mathrm{ml}$ ). LV pressure (LVP) is measured with this transducer. The balloon does not develop any pressure and thus is unstretched as long as its volume is below approximately $0.4 \mathrm{ml}$. LVV is therefore changed and measured by adjusting intraballoon water volume with the syringe in $0.05 \mathrm{ml}$ steps and fixed constant by a three-way stopcock. Systolic unstressed volume $\left(V_{0}\right)$ should be determined as the volume at which peak isovolumic pressure and thus PVA are zero. $V_{0}$ is determined as the volume-axis intercept of the pressurevolume relation by curve fitting with an equation (see below). 
$\mathrm{LV}$ epicardial electrocardiogram (ECG) is recorded with a pair of electrodes. Heart rate is maintained constant $20 \%$ higher than the sinus rhythm by the electrical pacing of the right atrium at $300 \pm 50$ beats $/ \mathrm{min}$ (mean $\pm \mathrm{SD}$ ) throughout each experiment. The temperature of the heart is maintained at $37^{\circ} \mathrm{C}$ by a heater throughout the experiment. Systemic arterial blood pressure of the support rat is served as coronary perfusion pressure and is maintained between 90 and $130 \mathrm{mmHg}$ throughout the experiment by transfusion. Arterial $\mathrm{pH}, P_{\mathrm{O}_{2}}$, and $P_{\mathrm{CO}_{2}}$ of the support rat are maintained within their physiological ranges by using supplemental oxygen and changing respiratory rate as needed. We use only isovolumic contractions throughout this study.

$\mathrm{O}_{2}$ consumption. Total coronary blood flow is continuously measured with an electromagnetic flowmeter placed in the middle of the coronary venous drainage tubing from the RV. LV thebesian flow is negligible. Coronary arteriovenous $\mathrm{O}_{2}$ content difference $\left(\mathrm{AVO}_{2} \mathrm{D}\right)$ is continuously measured by passing all the arterial and venous cross-circulation blood through the two cuvettes of a custom-made arteriovenous $\mathrm{O}_{2}$ content difference analyzer.

Cardiac $\mathrm{O}_{2}$ consumption is obtained as the product of coronary flow and $\mathrm{AVO}_{2} \mathrm{D}$. It is divided by heart rate (beats/min) to obtain $\mathrm{O}_{2}$ consumption per beat $\left(\mathrm{VO}_{2}\right)$ in a steady state. As in canine hearts, the $\mathrm{VO}_{2^{-}}$ PVA relation is linear in the rat $\mathrm{LV} . \mathrm{VO}_{2}$ is known to be composed of PVA-dependent and PVA-independent $\mathrm{VO}_{2}$ at each PVA. $\mathrm{VO}_{2}$ intercept represents PVAindependent $\mathrm{VO}_{2}$. The $\mathrm{RV}$ is kept collapsed by con- tinuous hydrostatic drainage of the coronary venous return; thus the RV PVA and therefore PVA-dependent $\mathrm{VO}_{2}$ are assumed to be negligible. The RV component of PVA-independent $\mathrm{VO}_{2}$ is calculated by multiplying biventricular PVA-independent $\mathrm{VO}_{2}$ in each contractile state with the ratio of RV weight divided by the sum of the RV and LV weights. The RV PVA-independent $\mathrm{VO}_{2}$ is subtracted from the total $\mathrm{VO}_{2}$ to yield $\mathrm{LV} \mathrm{VO}_{2}$. At the end of each experiment, the LV including the septum (approximately $1 \mathrm{~g}$ ), and the RV free wall (approximately $0.2 \mathrm{~g}$ ) are separately weighed.

Experimental protocol for volume-loading run (volume run). LV pressure, $\mathrm{VO}_{2}$, and PVA data are obtained at six varied volumes (mean volume range: 0.28 $\mathrm{ml}$ ) in each heart (volume run). LV volume is increased in steps up to an end-diastolic pressure of $10 \mathrm{mmHg}$. The $\mathrm{VO}_{2}$ of the minimally volume-loaded beating hearts at a pacing rate of $250-300$ beats $/ \mathrm{min}$ is measured by minimizing intraballoon water volume as close to zero as possible (minimally loaded $\mathrm{VO}_{2}$ ). "Control volume run" is performed with no inotropic interventions. After the control volume run, "calcium volume run" at the same LV volumes used in the control volume run is performed during $\mathrm{CaCl}_{2}(1 \%)$ infusion into the coronary artery. In each steady state, pressure-volume, $\mathrm{AVO}_{2} \mathrm{D}$, and coronary flow signals are sampled at $500 \mathrm{~Hz}$ for $2 \mathrm{sec}$ simultaneously, and the sampling is usually repeated 2-3 times at intervals of $0.5-1 \mathrm{~min}$.

Data analysis. We computed PVA by the method described below because the ESPVR of the rat LV is an upward convex curve unlike the linear ESPVR of

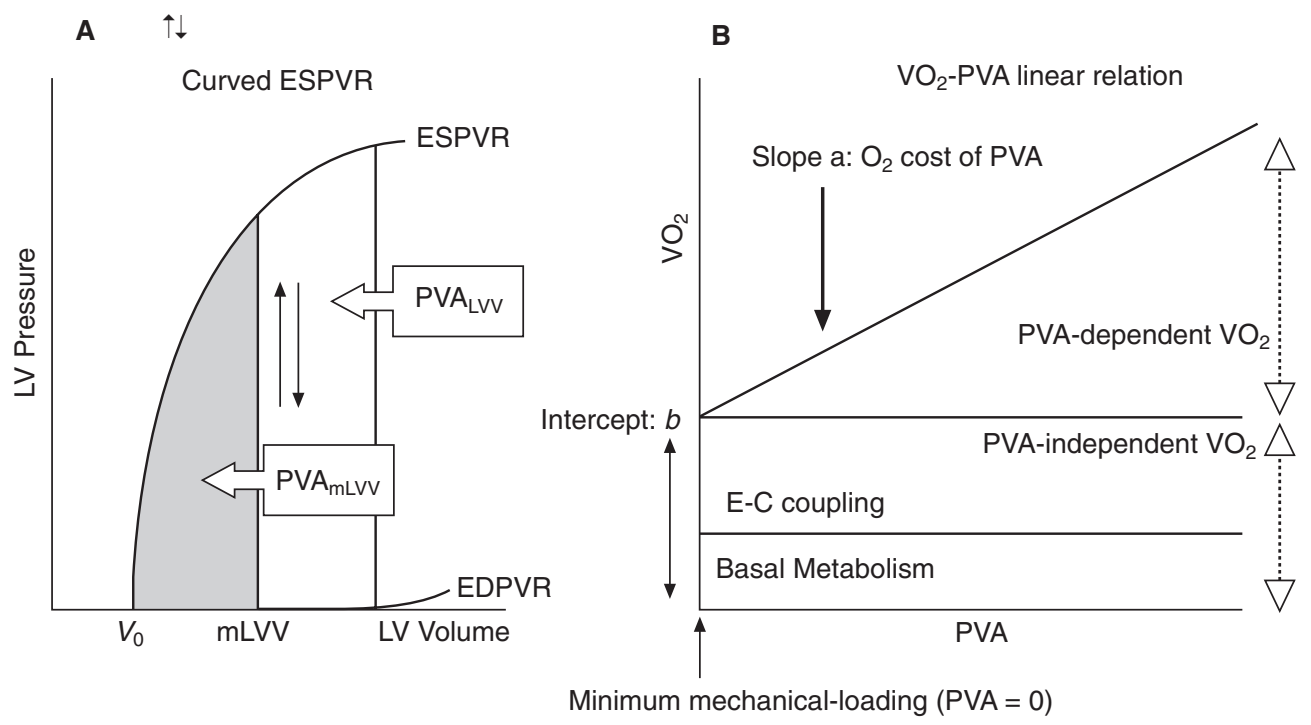

Fig. 1. Key framework of ESPVR-VO $\mathrm{O}_{2}-\mathrm{PVA}$ for assessment of left ventricular mechanoenergetics. $\uparrow \downarrow$ : isovolumic contraction and relaxation at $\mathrm{mLVV}$. ESPVR: end-systolic pressure-volume relation. EDPVR: end-diastolic pressure-volume relation. $\mathrm{mLVV}$ : midrange left ventricular volume. $\mathrm{VO}_{2}$ : myocardial oxygen consumption per beat. PVA: systolic pressurevolume area. E-C: excitation-contraction. $V_{0}$ : volume intercept of ESPVR. Detailed explanations are described in the text. 
the adult canine LV [28, 99]. Figure 1A shows a representative ESPVR obtained from experimentally obtained rat $\mathrm{LV} P-V$ data. We attempted to fit the endsystolic $P-V$ points by the following equation:

$$
\text { Pes }=A\left\{1-\exp \left[-B\left(V-V_{0}\right)\right]\right\}
$$

where Pes is the end-systolic peak isovolumic pressure, $V$ the isovolumic volume, $V_{0}$ the volume intercept of the nonlinear curve best fitted to the end-systolic $P-V$ points, and $A$ and $B$ the fitting parameters. Equation 1 is the same as that used in the previous study on puppy LV mechanics [100]. PVA is defined as the pressure-volume area circumscribed by the curvilinear ESPVR, EDPVR, and the systolic portion of the ventricular pressure-volume trajectory (thick vertical line in Fig. 1A: an isovolumic contraction). The area under the EDPVR was reasonably assumed to be zero within the same volume range. PVA was then normalized by $L V$ mass to $1 \mathrm{~g}$. A representative PVA at midrange LVV (mLVV) is shown by the shaded area in Fig. 1A. In a representative study, mLVV was 0.15 $\mathrm{ml} / \mathrm{g}\left[\mathrm{PVA}_{0.15}\right]$ in the range of changed LVV (0.08$0.33 \mathrm{ml}$ ) for data sampling [99].

\section{(4) Curved ESPVR and linear $\mathrm{VO}_{2}-\mathrm{PVA}$ relation}

Although the changes in coronary flow and $\mathrm{AVO}_{2} \mathrm{D}$ were slightly different among individual hearts, $\mathrm{VO}_{2}$ always increased with increased PVA in all hearts. A representative control ESPVR obtained from $P-V$ data at several varied LVV is shown in Fig. 1A. The ESPVR that is the best-fit curve by Eq. 1, is an upward convex curve. On average, the best-fit parameters $A(=\mathrm{mmHg})$ and $B\left(=\mathrm{ml}^{-1}\right)$ were approximately 160 and 16 . We consider that all rat hearts physiologically have curved LV ESPVRs because there is supporting evidence. The first evidence is that in in situ ejecting rat LVs, we obtained similar curved ESPVRs [94, 96, 97, 101]. The second evidence is indicated by the previous literature showing that rat papillary muscles had similar convex-upward end-systolic tension-sarcomere length relations at higher $\mathrm{Ca}^{2+}$ concentrations $[102,103]$. However, the blood $\mathrm{Ca}^{2+}$ concentration in rats was approximately $1 \mathrm{mmol} / \mathrm{L}$. Therefore the upward convexity of the rat LV ESPVR may not be due to its high contractility, as in the rat papillary muscle.

Despite the curved ESPVR, there is a reasonably linear relation between $\mathrm{VO}_{2}$ and PVA (Fig. 1B); $\mathrm{VO}_{2}$ increases proportionally with increased PVA. For example, the slope of this $\mathrm{VO}_{2}$-PVA relation is 0.015 $\mu \mathrm{O}_{2} \cdot \mathrm{mmHg}^{-1} \cdot \mathrm{ml}^{-1}$, and its $\mathrm{VO}_{2}$ intercept is 0.38 $\mu 1 \mathrm{O}_{2} \cdot$ beat $^{-1} \cdot \mathrm{g}^{-1}$.

\section{(5) The framework for assessment of LV mechanoenergetics in rat hearts}

The nonlinearity of rat LV ESPVR means that we cannot simply quantify rat LV contractility by a wellknown contractility index, Emax [5]. Initially, we calculated $A B$, which had been previously used in puppies [100], but as mentioned later we propose a new contractility index, equivalent Emax (eEmax) and $\mathrm{PVA}_{\mathrm{mLVV}}$ as an index to assess LV mechanoenergetics $[28,99]$. If we drew a vertical (i.e., isovolumic) $P-V$ line at midrange $\mathrm{LVV}$, such as $0.15 \mathrm{ml} / \mathrm{g}$, both $\mathrm{AB}$ and $\mathrm{PVA}_{0.15}$ increase with the enhanced contractile state. However, AB represents only the initial slope of the ESPVR curve at $V_{0}$, and $\mathrm{PVA}_{0.15}$ represents the total mechanical energy of an isovolumic contraction at the volume of $0.15 \mathrm{ml} / \mathrm{g}$ based on the linear $\mathrm{VO}_{2}-\mathrm{PVA}$ relation. Thus we propose $\mathrm{PVA}_{\mathrm{mLVV}}$ to quantify and compare LV mechanoenergetics.

Despite the curvilinear ESPVR, $\mathrm{VO}_{2}$ linearly correlates with PVA in either the control or the enhanced contractile state. The parallel upward shift of the $\mathrm{VO}_{2}$ PVA relation under the enhanced contractility by $\mathrm{Ca}^{2+}$ in rat hearts is comparable to that in dog hearts [48]. These results suggest that at least the $\mathrm{VO}_{2}$-PVA relations are similar between the rat and dog hearts despite the marked differences in the shape of LV ESPVR, heart size, heart rate, and the pattern of myosin isozyme. We consider that the linear $\mathrm{VO}_{2}$-PVA relations in both dog and rat may manifest the proportionality between actually measured energy use and our measure of total mechanical energy in different species.

\section{(6) Mean slope and intercept of the $\mathrm{VO}_{2}$-PVA relation}

The mean slope of the $\mathrm{VO}_{2}$-PVA relation for rats is almost the same as reported for dogs (0.013-0.021 $\left.\mu \mathrm{lO}_{2} \cdot \mathrm{mmHg}^{-1} \cdot \mathrm{ml}^{-1}\right)[10,11,28,48,99,104]$ and for rabbits $\left(0.011-0.025 \mu \mathrm{O} \mathrm{O}_{2} \cdot \mathrm{mmHg}^{-1} \cdot \mathrm{ml}^{-1}\right)[105,106]$. The mean slope of this relation is also consistent with the values reported for rats under crystalloid perfusion $\left(0.014 \pm 0.005 \mu \mathrm{O} \mathrm{O}_{2} \cdot \mathrm{mmHg}^{-1} \cdot \mathrm{ml}^{-1}\right)$ at unphysiologically lower heart rates $\left(150-215\right.$ beats $\left.\cdot \mathrm{min}^{-1}\right)$ than ours $\left(300\right.$ beats $\left.\cdot \mathrm{min}^{-1}\right)[95,107]$. The slope of the $\mathrm{VO}_{2}-$ PVA relation for rat hearts seems to be maintained highly constant under various mechanoenergetic conditions [7-13], indicating metabolic adaptation in the whole heart level.

On the other hand, the mean $\mathrm{VO}_{2}$ intercept of this relation for rats $\left(0.35-0.37 \mu \mathrm{O}_{2} \cdot\right.$ beat $\left.^{-1} \cdot \mathrm{g}^{-1}\right)$ is slightly higher than the intercept values for dogs $(0.25-0.35$ $\mu \mathrm{O}_{2} \cdot$ beat $\left.^{-1} \cdot \mathrm{g}^{-1}\right)[6,8,11,28,48,99]$, but it corresponds to those for rabbits $\left(0.36-0.40 \mu \mathrm{l} \mathrm{O}_{2} \cdot\right.$ beat $\left.^{-1} \cdot \mathrm{g}^{-1}\right)$ [105, 106]. 


\section{(7) PVA-independent $\mathrm{VO}_{2}$}

The $\mathrm{VO}_{2}$ intercept represents PVA-independent $\mathrm{VO}_{2}$. The PVA-independent $\mathrm{VO}_{2}$ seems to correspond primarily to the $\mathrm{VO}_{2}$ for $\mathrm{Ca}^{2+}$ handling in the $\mathrm{E}-\mathrm{C}$ coupling, basal metabolism, and possibly the $\mathrm{VO}_{2}$ for residual cross-bridge cycling $[58,82,85,108] . \mathrm{Ca}^{2+}$ intracoronary infusion increased the PVA-independent $\mathrm{VO}_{2}$, but did not increase basal metabolism [7, 10]. Increasing extracellular $\mathrm{Ca}^{2+}$ concentrations did not increase the corresponding value to this basal metabolism in rat myocardial slices [109]. The increase in PVA-independent $\mathrm{VO}_{2}$ is considered to be due to the increased $\mathrm{VO}_{2}$ for $\mathrm{Ca}^{2+}$ handling in the E-C coupling, though the $\mathrm{VO}_{2}$ for residual cross-bridge cycling may exist as the minor component of PVA-independent $\mathrm{VO}_{2}[82,108,109]$. Taken together, the $\mathrm{VO}_{2}$ for $\mathrm{Ca}^{2+}$ handling in the E-C coupling is the major component of the PVA-independent $\mathrm{VO}_{2}$ except for basal metabolism in the blood-perfused rat heart preparations (Fig. 1B).

To conclude, the LV curved ESPVR and the linear $\mathrm{VO}_{2}$-PVA relation that coexisted in the excised crosscirculated rat whole heart preparation seem promising for mechanoenergetic assessment not only in normal rats, but also in pathological and genetically engineered model rats.

\section{(8) Effects of thapsigargin and $\mathrm{KCl}$ on LV mechanoenergetics}

$\mathrm{PVA}_{\mathrm{mLVV}}$ and the $\mathrm{VO}_{2}$ intercept of the $\mathrm{VO}_{2}$-PVA relation can be good indexes for assessing rat $\mathrm{LV}$ mechanoenergetics. The $\mathrm{VO}_{2}$ intercept would mainly consist of $\mathrm{VO}_{2}$ for $\mathrm{Ca}^{2+}$ handling in E-C coupling and basal metabolism. However, the fraction of the $\mathrm{VO}_{2}$ by the SR $\mathrm{Ca}^{2+}$-ATPase in the total $\mathrm{Ca}^{2+}$ handling $\mathrm{VO}_{2}$ has not yet been examined. The energetic cost of SR $\mathrm{Ca}^{2+}$-ATPase (involved in E-C coupling) has not been determined in rat-excised cross-circulated whole heart preparation. To evaluate this, the effects of thapsigargin, a well-known specific SR $\mathrm{Ca}^{2+}$-ATPase inhibitor [110$112]$, and $\mathrm{KCl}$ on the ESPVR and $\mathrm{VO}_{2}$-PVA relation were examined in the rat blood-perfused whole heart preparation.

Effects of thapsigargin. The ESP at the corresponding LVVs to the control volume run decreased, and the ESPVR curve became blunter and reached a lower pressure level than control during thapsigargin infusion. These responses are opposite to those of $\mathrm{Ca}^{2+}$ [99]. Thapsigargin $(2.5 \mu \mathrm{mol} / \mathrm{L})$ significantly decreased $\mathrm{PVA}_{0.15}$ by $65 \%(p<0.01)$.

$\mathrm{VO}_{2}$ correlated linearly with PVA in either contractile state. The linear $\mathrm{VO}_{2}$-PVA relation shifted downward with the decreased contractile state during thapsigargin infusion. $\mathrm{VO}_{2}$-PVA data points deviated left-downward from the baseline $\mathrm{VO}_{2}$-PVA data points at each LVV. The slope of each $\mathrm{VO}_{2}$-PVA relation in the thapsigargin volume run was not significantly different from the control, but the $\mathrm{VO}_{2}$ intercept value of each relation significantly decreased during thapsigargin infusion $\left(P<0.01\right.$ by ANCOVA). The mean $\mathrm{VO}_{2}$ intercept of the $\mathrm{VO}_{2}$-PVA relations significantly decreased by $40 \%$ of control $(P<0.01$ by paired t-test $)$ with no changes in the mean slope.

$\mathrm{KCl}$ arrest. On average, the $\mathrm{VO}_{2}$ intercept value is $92.4 \mu \mathrm{O}_{2} \cdot \mathrm{min}^{-1} \cdot \mathrm{g}^{-1}\left(30.9 \mathrm{~mW} \cdot \mathrm{g}^{-1}\right)$. The basal metabolism of the heart was measured by arresting it with $\mathrm{KCl}(0.03 \mathrm{mM})$ (basal metabolic $\left.\mathrm{VO}_{2}\right)$. The coronary flow did not significantly decrease, but $\mathrm{AVO}_{2} \mathrm{D}$ significantly did. The $\mathrm{VO}_{2}$ intercept was decreased by $75 \%$ with $\mathrm{KCl}$, and basal metabolic $\mathrm{VO}_{2}$ was found to be $25 \%$ of the $\mathrm{VO}_{2}$ intercept. Thus the mean $\mathrm{VO}_{2}$ intercept significantly decreased to $24.3 \mu \mathrm{l} \mathrm{O} \cdot \mathrm{min}^{-1} \cdot \mathrm{g}^{-1}$ by $75 \%$ (resting $\mathrm{VO}_{2} ; 8.1 \mathrm{~mW} \cdot \mathrm{g}^{-1}$ or $2.43 \mu \mathrm{l} \mathrm{O} \cdot \mathrm{min}^{-1}$ $\cdot 100 \mathrm{~g}^{-1}$ ), and the energy rate associated with activation processes is $22.8 \mathrm{~mW} \cdot \mathrm{g}^{-1}$. These data are in good agreement with results from the Alpert and Gibbs laboratories in regard to the activation or tension-independent heat [113].

To conclude, the $\mathrm{VO}_{2}$ intercept mainly consists of $\mathrm{VO}_{2}$ for $\mathrm{Ca}^{2+}$ handling in the E-C coupling (at least $40 \%$ is consumed by the SR $\mathrm{Ca}^{2+}$-ATPase) and basal metabolism $(25 \%)$.

Basal metabolic $\mathrm{VO}_{2}$ measured after $\mathrm{KCl}$ arrest presumably includes $\mathrm{VO}_{2}$ for $\mathrm{Na}^{+}-\mathrm{K}^{+}$-ATPase to maintain membrane polarization [80]. The higher basal metabolic $\mathrm{VO}_{2}$ of the rat heart than those of dogs and rabbits is consistent with previous reports $[109,114$, 115]. The higher basal metabolic $\mathrm{VO}_{2}$ in the rat is thought to be due to the rat SR having a poor $\mathrm{Ca}^{2+}$ retaining capacity [109]. Consequently, $\mathrm{Ca}^{2+}$ continues to cycle between the SR and the sarcoplasm even in the absence of E-C coupling activation [114]; thus the energy used at the SR is wasted. However, there is no suppression of basal metabolism by either $\mathrm{SR} \mathrm{Ca}^{2+}$ ATPase inhibitor [115] in contrast to the results by Ebus and Stienen [116], suggesting no energy waste in SR.

\section{Advanced framework of ESPVR-PVA- eEmax for LV mechanoenergetics in rat hearts}

\section{(1) New index for $\mathrm{O}_{2}$ cost of contractility (eEmax) from curved ESPVR}

The $\mathrm{O}_{2}$ cost of LV contractility indicates $\mathrm{VO}_{2}$ for 
$\mathrm{Ca}^{2+}$ handling in E-C coupling per unit of $\mathrm{LV}$ contractility change in the rat heart. This cost is obtainable as a slope of a linear relation between PVAindependent $\mathrm{VO}_{2}$ and $\mathrm{LV}$ contractility.

\section{(2) PVA-independent $\mathrm{VO}_{2}$}

The control curved ESPVR from the observed ESP$\mathrm{V}$ data at four or five different LVVs is first obtained. During a $\mathrm{Ca}^{2+}$ inotropism run at $\mathrm{mLVV}$ in the range of changed volume, ESP-V and $\mathrm{VO}_{2}$ data are sampled. Each best-fit ESPVR from the observed ESP-V data at the $\mathrm{mLVV}$ during a $\mathrm{Ca}^{2+}$ inotropism run, and those at $V_{0}$ are drawn. PVA is calculated by integrating each ESPVR from $V_{0}$ up to the mLVV (Fig. 2A). PVA proportionally increased to ESP under an isovolumic contraction.

Then the composite $\mathrm{VO}_{2}$-PVA relation at the mLVV during stepwise increased $\mathrm{Ca}^{2+}$ infusion is obtained. The $\mathrm{VO}_{2}$-PVA relation of an $\mathrm{LVV}$ loading run during $\mathrm{Ca}^{2+}$ infusion at a maximal rate shifted upward in parallel to the control $\mathrm{VO}_{2}$-PVA relation, as previously reported [99]. Thus the dotted lines, including every $\mathrm{VO}_{2}$-PVA data during the $\mathrm{Ca}^{2+}$ infusion in steps at the $\mathrm{mLVV}$, are drawn in parallel to the control $\mathrm{VO}_{2}$-PVA relation line (Fig. 2B). The gradually increased $\mathrm{VO}_{2}-$ intercept values (PVA-independent $\mathrm{VO}_{2}$ values) (See b1-bn in Fig. 2B) of the dotted lines proportionally to the enhanced $\mathrm{LV}$ contractility by $\mathrm{Ca}^{2+}$ are obtained by this procedure.

\section{(3) LV contractility (eEmax mLvv)}

eEmax $_{\mathrm{mLVV}}$ is obtained by calculating the ESP-V ratio of the specific virtual triangular $\mathrm{PVA}_{\mathrm{mLVV}}$ $\left(1 / 2 \cdot \mathrm{ESV} \cdot \mathrm{eESP}_{\mathrm{mLVV}}\right)$ that is energetically equivalent to the real $\mathrm{PVA}_{\mathrm{mLVv}}$ experimentally obtained (Fig. 2A$a$ and $b$ ). The equation for calculation is

$$
\begin{aligned}
\operatorname{eEmax}_{\mathrm{mLVV}} & =(\mathrm{eESP} / \mathrm{ESV})_{\mathrm{mLVV}} \\
& =2 \mathrm{PVA}_{\mathrm{mLVV}} / \mathrm{ESV}^{2},
\end{aligned}
$$

where eESP is the equivalent end-systolic pressure, ESV is the end-systolic volume $\left(\mathrm{mLVV}-V_{0}\right)$, and $\mathrm{PVA}_{\mathrm{mLVV}}$ is the systolic pressure-volume area at an mLVV. The values of mLVV and $V_{0}$ are normalized by $\mathrm{LV}$ mass to $1 \mathrm{~g}$.

Our new index for quantifying LV contractility is based on $\mathrm{PVA}_{\mathrm{mLVV}}$ (a total mechanical energy per beat at an $\mathrm{mLVV}$ ) that has been proposed to be a good index for a mechanoenergetic evaluation of rat $\mathrm{LV}$ contractility $[99,117,96,97]$. Therefore the value of eEmax $_{\mathrm{mLVV}}$ is mechanoenergetically reasonable. Since this contractility index is an ESP value normalized by ESV at an mLVV, it is usable to compare LV contractility
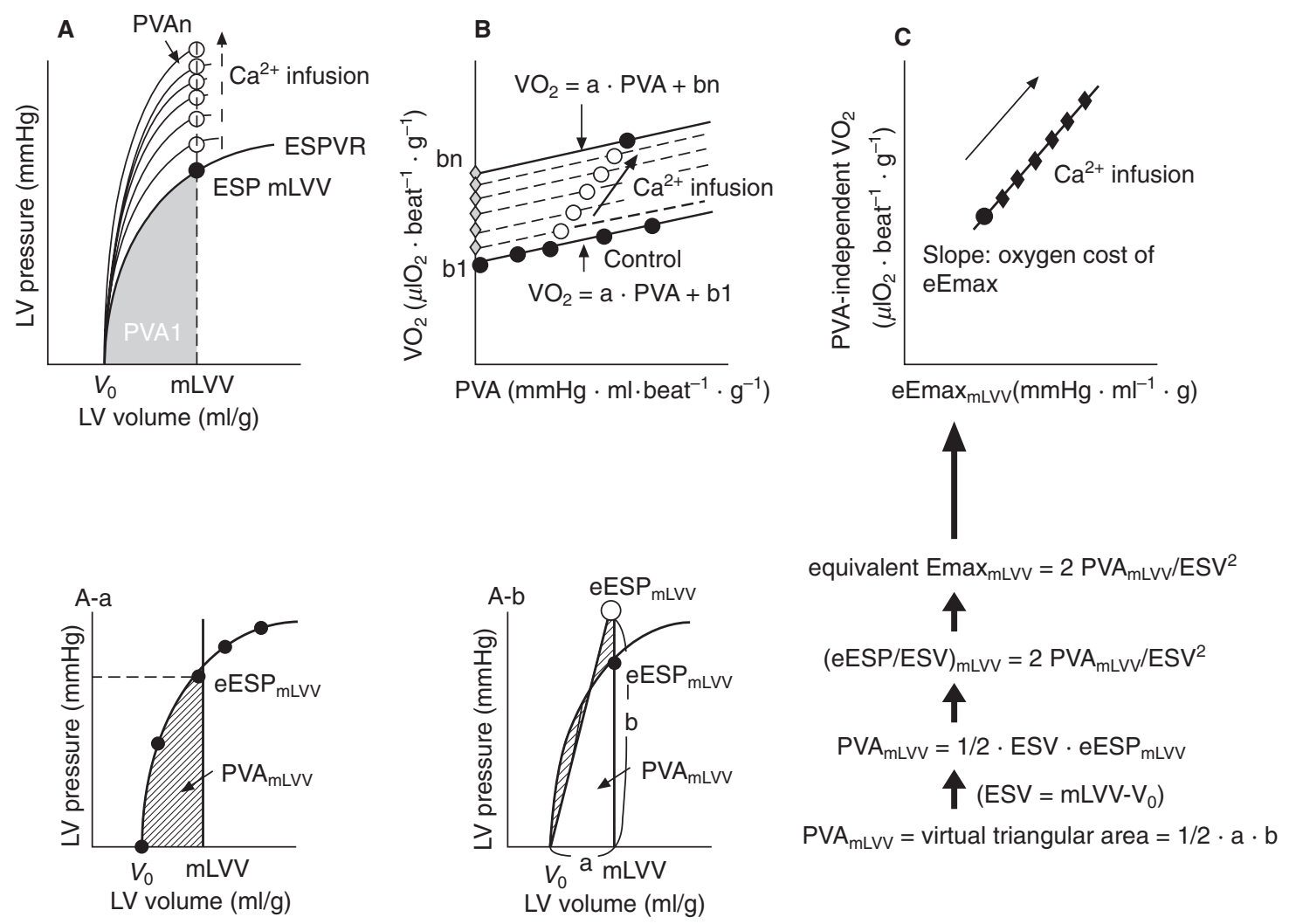

Fig. 2. How to obtain oxygen cost of left ventricular contractility (eEmax) from the experimental data. Abbreviations are the same as in Fig. 1. Detailed explanations are described in the text. 
in the hearts with different volumes. Moreover, if an

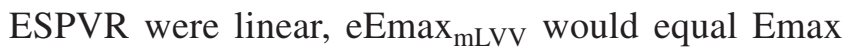
because eESP equals ESP, and ESP/ESV is constant at all LVVs. The dimensions of this new contractility index $\left(\mathrm{mmHg} \cdot \mathrm{ml}^{-1} \cdot \mathrm{g}\right.$ or $\left.\mathrm{mmHg} \cdot \mathrm{ml}^{-1} \cdot 100 \mathrm{~g}\right)$ are substantially the same as those of Emax [5, 48]. Thus this new index is usable to compare LV contractility among hearts of different animals, such as dogs and rabbits $[5,48]$, regardless of the curivilinearity of ESPVR.

\section{(4) $\mathrm{O}_{2}$ cost of LV contractility}

By plotting PVA-independent $\mathrm{VO}_{2}$ and eEmax $\mathrm{mLVV}$ data, we are able to obtain a relation between them. This relation became linear (Fig. 2C), and thus the oxygen cost of LV contractility is obtained as the slope of the relation. This slope is an index quantifying oxygen consumption for $\mathrm{Ca}^{2+}$ handling in the E-C coupling per unit LV contractility change. Moreover, as mentioned above, if an ESPVR is linear, eEmax $\operatorname{mLVV}_{\mathrm{m}}$ would equal Emax. The dimensions of oxygen cost of $\mathrm{LV}$ contractility $\left(\mu \mathrm{l} \mathrm{O}_{2} \cdot \mathrm{ml} \cdot \mathrm{mmHg}^{-1} \cdot\right.$ beat $^{-1} \cdot \mathrm{g}^{-2}$ or $\mathrm{ml} \mathrm{O}_{2} \cdot \mathrm{ml} \cdot \mathrm{mmHg}^{-1} \cdot$ beat $^{-1} \cdot 100 \mathrm{~g}^{-2}$ ) are substantially the same as those of the oxygen cost of Emax in canine hearts $[47,53,118,119]$. Thus our proposed mechanoenergetic index for rat hearts, i.e., the oxygen cost of LV contractility has the generality for other animal hearts.

\section{(5) $\mathrm{O}_{2}$ cost of LV contractility for $\mathrm{Ca}^{2+}$}

The $\mathrm{O}_{2}$ cost of $\mathrm{LV}$ contractility for $\mathrm{Ca}^{2+}$ indicates the $\mathrm{VO}_{2}$ needed for $\mathrm{Ca}^{2+}$ handling in the E-C coupling per unit change in LV contractility. We would consider that this value is changed by myofilament $\mathrm{Ca}^{2+}$ responsiveness (the $\mathrm{LV}$ contractility/ $\mathrm{Ca}^{2+}$ handling relation) and/or the $\mathrm{Ca}^{2+}$ handling/ATP ratio in the sarcoplasmic reticulum [5, 48, 120]. The heart showing high cost is energetically less economical (energy wasting), and that showing low cost is energetically more economical (energy saving).

Although other inotropic agents such as a $\beta$-stimulant are also available tools to assess the oxygen cost of LV contractility, we adopted $\mathrm{Ca}^{2+}$ as the first tool. $\mathrm{Ca}^{2+}$ directly increases $\mathrm{Ca}^{2+}$ handling in the E-C coupling mediated neither via receptors nor via intracellular signal transduction systems. Therefore $\mathrm{Ca}^{2+}$ is a golden standard substance to assess the oxygen cost of LV contractility.

Limitations. Our proposed LV contractility index eEmax $_{m L V v}$ is devised from the curved ESPVR and $\mathrm{PVA}_{\mathrm{mLVV}}$. In the curved ESPVR, ESP does not proportionally increase to ESV. Therefore this index somewhat depends on LVV in contrast to Emax, which is independent of LVV. However, a midrange LVV where
ESP was $77 \%$ of the maximum ESP is constantly adopted. This yielded a reasonably constant oxygen cost of LV contractility despite small deviations in mLVV values in individual hearts. In conclusion, this index is appropriate for assessing cardiac mechanoenergetics, especially the economy of total $\mathrm{Ca}^{2+}$ handling in E-C coupling, regardless of the curvilinearity of ESPVR. It would be meaningful to investigate how total $\mathrm{Ca}^{2+}$ handling changes induced by various interventions affect the oxygen cost of LV contractility.

\section{(6) $\mathrm{O}_{2}$ cost of LV contractility for dobutamine in normal and acute failing rat hearts}

The $\mathrm{O}_{2}$ cost of $\mathrm{LV}$ eEmax for dobutamine should be assessed instead of a golden standard substance, $\mathrm{Ca}^{2+}$ [28]. Dobutamine is often used clinically as a cardiotonic agent. It is known to activate the $\beta$-adrenergic receptor-adenylate cyclase-cAMP-protein kinase $\mathrm{A}$ (PKA) signaling pathway [121], resulting in the phosphorylation of L-type $\mathrm{Ca}^{2+}$ channels, ryanodine receptors, and the $\mathrm{SR} \mathrm{Ca}^{2+}$-ATPase regulator, PLB. This signal pathway increases the intracellular $\mathrm{Ca}^{2+}$ and LV contraction amplitude and accelerates the kinetics of the target proteins of PKA. On the other hand, $\mathrm{Ca}^{2+}$ directly increases the intracellular $\mathrm{Ca}^{2+}$ and LV contraction amplitude by increasing the $\mathrm{Ca}^{2+}$ influx through L-type $\mathrm{Ca}^{2+}$ channels. Because the mechanisms for enhancing the total $\mathrm{Ca}^{2+}$ handling are different, the $\mathrm{O}_{2}$ costs of $\mathrm{LV}$ eEmax for $\mathrm{Ca}^{2+}$ and for dobutamine are considered to be different.

The $\mathrm{O}_{2}$ cost of LV eEmax for dobutamine (a $\beta$ receptor stimulant) is assessed and compared with that for $\mathrm{Ca}^{2+}$ in normal rat hearts and then is assessed and compared in $\mathrm{Ca}^{2+}$ overload-induced failing rat hearts [10]. The mean $\mathrm{O}_{2}$ cost of $\mathrm{LV}$ eEmax $\left(\times 10^{-4} \mu \mathrm{O} \mathrm{O}_{2} \cdot\right.$ beat $^{-1}$ $\cdot \mathrm{mmHg}^{-1} \cdot \mathrm{ml} \cdot \mathrm{g}^{-2}$ ) for $\mathrm{Ca}^{2+}$ is $1.30 \pm 0.37$, and that for dobutamine is $1.26 \pm 0.30$ in normal hearts. The mean $\mathrm{O}_{2}$ cost of $\mathrm{LV}$ eEmax for dobutamine is $1.15 \pm 0.27$, and that for $\mathrm{Ca}^{2+}$ is $0.81 \pm 0.36$ in the same normal hearts (paired analysis). These mean values show no significant differences between $\mathrm{Ca}^{2+}$ and dobutamine.

In $\mathrm{Ca}^{2+}$ overload-induced failing hearts, though the mean $\mathrm{O}_{2}$ cost of $\mathrm{LV}$ eEmax for $\mathrm{Ca}^{2+}$ could not be assessed as mentioned later [7], the mean $\mathrm{O}_{2}$ cost of $\mathrm{LV}$ eEmax for dobutamine is $1.04 \pm 0.40$. This mean value for dobutamine does not differ significantly from those (see above $1.26 \pm 0.30$ or $1.15 \pm 0.27$ ) in the normal hearts. These results indicate, in terms of the coupling of mechanical work and energetics of the heart, that the total $\mathrm{Ca}^{2+}$ handling $\mathrm{VO}_{2}$ in $\mathrm{E}-\mathrm{C}$ coupling against unit LV contractility change for dobutamine in the contractile failing hearts does not 
differ from that in the normal hearts. This suggests that in the $\mathrm{Ca}^{2+}$ overload-induced contractile failing hearts, there are no changes in the sensitivity of the contractile machinery for $\mathrm{Ca}^{2+}$, the $\mathrm{Ca}^{2+} / \mathrm{ATP}$ in the total $\mathrm{Ca}^{2+}$ handling, and $\mathrm{ATP} / \mathrm{VO}_{2}$ in the mitochondria.

In normal rat hearts, $80-87 \%$ of $\mathrm{Ca}^{2+}$ recirculates intracellulary $[122,123]$, i.e., the $\mathrm{SR} \mathrm{Ca}{ }^{2+}$-ATPase originally has a main role in the $\mathrm{Ca}^{2+}$ handling in E-C coupling. A previous study reveals that the $\mathrm{O}_{2}$ cost of $\mathrm{LV}$ eEmax is increased when SR $\mathrm{Ca}^{2+}$-ATPase is suppressed, and consequently the sarcolemmal $\mathrm{Na}^{+}-\mathrm{Ca}^{2+}$ exchanger and $\mathrm{Na}^{+}-\mathrm{K}^{+}$-ATPase are activated in rat hearts [95]. Although the basal activity of the L-type $\mathrm{Ca}^{2+}$ channel is considered to be impaired in the high $\mathrm{Ca}^{2+}$ induced $\mathrm{Ca}^{2+}$ overload failing hearts [7], dobutamine could enhance the activity of L-type $\mathrm{Ca}^{2+}$ channels via the activation of phosphorylation. The $\mathrm{O}_{2}$ cost of eEmax for dobutamine remained unchanged in this $\mathrm{Ca}^{2+}$ overload-induced failing hearts. Therefore it is possible that dobutamine could sufficiently activate L-type $\mathrm{Ca}^{2+}$ channels and thus activate intracellular $\mathrm{Ca}^{2+}$ handling without activation of sarcolemmal $\mathrm{Na}^{+}-\mathrm{Ca}^{2+}$ exchanger and $\mathrm{Na}^{+}-\mathrm{K}^{+}$-ATPase.

The high $\mathrm{Ca}^{2+}$-induced $\mathrm{Ca}^{2+}$ overload contractile failing rat hearts with unchanged $\mathrm{O}_{2}$ cost of PVA, decreased $\mathrm{VO}_{2}$ intercept, and unchanged $\mathrm{O}_{2}$ cost of eEmax for dobutamine are similar to $\mathrm{Ca}^{2+}$ overloadinduced stunned myocardium in dog hearts with unchanged $\mathrm{O}_{2}$ cost of PVA, decreased $\mathrm{VO}_{2}$ intercept, and unchanged $\mathrm{O}_{2}$ cost of Emax for $\mathrm{Ca}^{2+}$ [48].

On the other hand, in postischemic, hypercapnic acidotic, and postacidotic stunned myocardium in dog hearts, the $\mathrm{O}_{2}$ costs of Emax for $\mathrm{Ca}^{2+}$ increase [48]. In the $\mathrm{Ca}^{2+}$ overload contractile failing rat hearts, a transient energy-wasting process is observed during high $\mathrm{Ca}^{2+}$ infusion, as previously reported [7]. This transient process may last longer in the postischemic, hypercapnic acidotic, and postacidotic stunned canine myocardium showing the high $\mathrm{O}_{2}$ cost of Emax [48]. Furthermore, the $\mathrm{Ca}^{2+}$ overload contractile failing rat heart seems to induce less cellular breakdown than ischemic-reperfusion injury [7]. Therefore the increases in $\mathrm{O}_{2}$ costs of Emax for $\mathrm{Ca}^{2+}$ in postischemic, hypercapnic acidotic, and postacidotic stunned myocardium in dog hearts may relate to more cellular breakdown.

No significant differences in the $\mathrm{O}_{2}$ cost of $\mathrm{LV}$ contractility are found between dobutamine and $\mathrm{Ca}^{2+}$ in normal and high- $\mathrm{Ca}^{2+}$-induced $\mathrm{Ca}^{2+}$ overload failing hearts. On the other hand, the $\mathrm{O}_{2}$ cost of $\mathrm{LV}$ contractility for nitroprusside is found to be much higher (fivefold) than those for dobutamine and $\mathrm{Ca}^{2+}$ [124].
Therefore this cost could be a sensitive index to evaluate any changes in the total $\mathrm{Ca}^{2+}$ handling in the $\mathrm{E}-\mathrm{C}$ coupling in rat hearts in terms of the coupling of cardiac mechanical work and energetics.

\section{Mechanically unloaded LV myocardial slice $\mathrm{MVO}_{2}$ and motility in rat and mouse hearts}

\section{(1) Measurements and definition}

A new measuring method of the myocardial $\mathrm{O}_{2}$ consumption of mechanically unloaded rat LV slices is established by Takaki et al. [109, 115]. Our recent finding is that freely shortening myocardial slices under mechanically unloaded conditions do not require a significant additional $\mathrm{VO}_{2}$ for cross-bridge cycling [109, $125,126]$. This finding is further supported by the result showing that a specific cross-bridge cycling inhibitor, $5 \mathrm{mM}$ BDM, does not affect the slice $\mathrm{VO}_{2}$, though $5 \mathrm{mM}$ BDM markedly reduced the slice motility [109]. On the other hand, we observed the increase in $\mathrm{VO}_{2}$ by barium as a result of the enhanced crossbridge cycling [127]. Therefore the measured increment in $\mathrm{VO}_{2}$ by electrical activation under the mechanically unloaded condition corresponds to the $\mathrm{VO}_{2}$ for the nonmechanical activities of myocardium.

LV myocardial slice preparation. The heart and its slices are prepared as described before [109]. Briefly, the whole heart is excised after the Tyrode perfusion for $5-10 \mathrm{~min}$. Tyrode solution at $18^{\circ} \mathrm{C}$ oxygenated with $100 \% \mathrm{O}_{2}$ is the perfusate. Its composition in $\mathrm{mM}$ is $\mathrm{NaCl}, 136.0 ; \mathrm{KCl}, 5.4 ; \mathrm{MgCl}_{2} \cdot 6 \mathrm{H}_{2} \mathrm{O}, 1.0$; $\mathrm{NaH}_{2} \mathrm{PO}_{4} \cdot 2 \mathrm{H}_{2} \mathrm{O}, 0.33 ; \mathrm{CaCl}_{2} \cdot 2 \mathrm{H}_{2} \mathrm{O}, 0.9$; glucose, 10.0 ; HEPES, 5.0; pH, corrected to 7.4 with $\mathrm{NaOH}$ at $30^{\circ} \mathrm{C}$. The LV is longitudinally cut into three pieces. Each piece is cut into $300 \mu \mathrm{m}$ thick slices in parallel with the epicardium with a microslicer. This cut is chosen so that most fibers are parallel-sectioned to fiber orientation according to the known fiber architecture of the heart wall. Consequently, 16-20 slices (average single-side surface area is approximately $30 \mathrm{~mm}^{2}$ ) are obtained from each heart. The slices are stored 1-2 hours in $18^{\circ} \mathrm{C}$ Tyrode and oxygenated with $100 \% \mathrm{O}_{2}$.

Experimental procedure. Five to $10(8 \pm 1)$ slices are placed between a pair of platinum field-stimulating electrodes in the airtight chamber filled with the prepared $2.24 \pm 0.12 \mathrm{ml}$ Tyrode solution oxygenated with $100 \% \mathrm{O}_{2}$. After the slices are incubated for 10 min, oxygenation is stopped and the chamber is closed tightly to prevent any leaks of water and $\mathrm{O}_{2} \cdot \mathrm{MVO}_{2}$ (myocardial $\mathrm{O}_{2}$ consumption per minute) of the quiescent slices without stimulation is obtained during the 
first minute, and $\mathrm{mVO}_{2}$ of the activated and free-shortening slices with electrical stimulation is obtained during the next $2 \mathrm{~min}$ at $30^{\circ} \mathrm{C}$.

Image analysis of myocardial slices. For image analysis, myocardial slices of comparable thickness and surface area to those for oximetry are used in each experiment. A slice showing as much unidirectional motility as possible is selected for image analysis. The slice motility is analyzed as the relative changes (motility index, \%) in the total number of pixels of the discriminated video signal of slice image in contraction and relaxation cycle, as previously proposed by Takaki et al. [115]. The motility index of intermittent seven contraction-relaxation cycles is averaged at 20sec intervals throughout the latter 2 min of the electrical stimulation period ( $3 \mathrm{~min}$ ).

The slices with thickness $(300 \mu \mathrm{m})$ seem to be sufficiently oxygenated by diffusion, according to the published data and calculation $[2,109,128,129,130]$. These myocardial slices would be virtually free from mechanical constraints (preload, afterload, tethering, and shear stress) that they had in situ, though some internal viscoelastic loading may still be present. The $\mathrm{O}_{2}$ consumption of unstimulated myocardium corresponds to the basal metabolism. The $\mathrm{O}_{2}$ consumption of electrically stimulated $(1 \mathrm{~Hz})$ myocardium includes basal metabolism and $\mathrm{O}_{2}$ consumption primarily for $\mathrm{Ca}^{2+}$ handling in the E-C coupling, but it does not include $\mathrm{O}_{2}$ consumption for cross-bridge cycling. Thus $\mathrm{O}_{2}$ consumption for the E-C coupling is obtained by subtracting basal metabolism from $\mathrm{O}_{2}$ consumption of the stimulated myocardium. Basal metabolic $\mathrm{mVO}_{2}$ is about $2 \times 10^{-2} \mathrm{mlO}_{2} \cdot \mathrm{min}^{-1} \cdot \mathrm{g} \mathrm{LV}^{-1}$. E-C coupling $\mathrm{mVO}_{2}$ is about $0.9 \times 10^{-2} \mathrm{mlO}_{2} \cdot \mathrm{min}^{-1} \cdot \mathrm{g} \mathrm{LV}^{-1}(0.15$ $\mathrm{mlO}_{2} \cdot$ beat $^{-1} \cdot \mathrm{g} \mathrm{LV}^{-1}$ ), corresponding to about $45 \%$ of basal metabolic $\mathrm{mVO}_{2}$. No arrhythmia occurred in slices shortened with $1: 1$ synchrony with stimulation throughout the experiment.

Basal metabolism. Myocardial $\mathrm{mVO}_{2}$ measured in the absence of stimulation in normal Tyrode solution corresponds to basal metabolism, which is considered to include $\mathrm{VO}_{2}$ for $\mathrm{Na}^{+}-\mathrm{K}^{+}$-ATPase to maintain membrane polarization. However, the $\mathrm{VO}_{2}$ for $\mathrm{Na}^{+}-\mathrm{K}^{+}-$ ATPase for electrical activation is negligibly small relative to the basal metabolic $\mathrm{VO}_{2}$ [109]. This result is consistent with findings obtained by other methods $[3,15,116,131]$.

Basal metabolic $\mathrm{mVO}_{2}$ is comparable to previous rat heart data in literature $[119,130]$ and before our study [109], but it is greater than those in dogs and rabbits $\left(1.74,1.25\right.$ or $\left.1.02 \mathrm{mlO}_{2} \cdot \mathrm{min}^{-1} \cdot 100 \mathrm{~g} \mathrm{LV}^{-1}\right)$ $[80,85,108]$. This species difference is consistent with the report that the basal metabolism of the rat myocar- dium is greater than those of other species [114].

E-C coupling The increases in $\mathrm{mVO}_{2}$ by stimulation represents E-C coupling $\mathrm{VO}_{2}$ mainly for $\mathrm{Ca}^{2+}$ handling, since the residual cross-bridge cycling for free shortening is trivial in the mechanically unloaded slice contractions. The E-C coupling $\mathrm{VO}_{2}$ in normal Tyrode solution corresponds to about $45 \%$ of the basal metabolism. This percent value seems to be smaller than the E-C coupling $\mathrm{VO}_{2}$ value in canine heart preparations corresponding to $100-240 \%$ of the basal metabolism [47, 132]. However, the E-C coupling $\mathrm{VO}_{2}$ was increased to $130 \%$ of basal metabolism by $2-\mathrm{Hz}$ stimulation (our unpublished observation). Thus the present smaller percent value of the E-C coupling $\mathrm{VO}_{2}$ is due to a lower stimulation frequency than in dogs.

\section{(2) SR Ca ${ }^{2+}$-ATPase blockade decreases $\mathrm{O}_{2}$ use for $\mathrm{E}-\mathrm{C}$ coupling of mechanically unloaded contracting rat heart slices}

The composition of E-C coupling $\mathrm{VO}_{2}$ is analyzed by using $\mathrm{SR} \mathrm{Ca}^{2+}$-ATPase inhibitors, thapsigargin (TG) and cyclopiazonic acid (CPA), and to evaluate the role of the SR $\mathrm{Ca}^{2+}$ handling in the myocardial E-C coupling. TG and CPA are well known to inhibit the SR $\mathrm{Ca}^{2+}$ ATPase in cardiac muscles and myocytes [112, 133-137]. The $\mathrm{Ca}^{2+}$ released from the SR by $\mathrm{Ca}^{2+}$ entry across the sarcolemma increases the intracellular $\mathrm{Ca}^{2+}$ in the E-C coupling, activating myocardial cells. Relaxation results as the $\mathrm{Ca}^{2+}$ is removed mainly back into the SR (by the $\mathrm{Ca}^{2+}$-ATPase) and partly out of the cell (primarily by $\mathrm{Na}^{+}-\mathrm{Ca}^{2+}$ exchange) [138]. The $\mathrm{Na}^{+}-\mathrm{Ca}^{2+}$ exchange requires no ATP and thus no $\mathrm{VO}_{2}$, but it is dependent on the activity of the $\mathrm{Na}^{+}-\mathrm{K}^{+}-$ ATPase, which maintains the $\mathrm{Na}^{+}$and $\mathrm{K}^{+}$inonic gradients and thus the membrane potential in a steady state. Therefore it is reasonable to hypothesize that E-C coupling $\mathrm{VO}_{2}$ primarily includes $\mathrm{VO}_{2}$ for the $\mathrm{SR} \mathrm{Ca}{ }^{2+}$ pump.

A blockade of the SR $\mathrm{Ca}^{2+}$-ATPase by TG $0.1-1$ $\mu \mathrm{M}$ or by CPA $10 \mu \mathrm{M}$ significantly reduces $\mathrm{O}_{2}$ consumption for the E-C coupling by $40 \%$ or $70 \%$ of the respective controls. Neither TG nor CPA reduces basal metabolic $\mathrm{O}_{2}$ consumption. The magnitude of free shortening of the unloaded myocardial slices quantified by slice surface area reduction is small (about $1.5 \%$ ) because of no external preload. TG $1 \mu \mathrm{M}$ and CPA $10 \mu \mathrm{M}$ markedly attenuated the already reduced free shortening. All these results reveal that the $\mathrm{O}_{2}$ consumption of myocardial slices for the $\mathrm{Ca}^{2+}$ handling in the E-C coupling is mainly used for the SR $\mathrm{Ca}^{2+}$-ATPase. This validation is possible by taking the advantage of mechanically unloaded myocardial slice preparation. 
The inhibitory effect of TG was not dose-dependent from 0.1 to $1 \mu \mathrm{M}$. This may be explained by an incomplete blockade by TG of the SR $\mathrm{Ca}^{2+}$ ATPase because of its restricted permeability to intracellular action sites of the myocardial slice [139, 140]. The validity of this speculation is supported by the results showing that the slice's free shortening is much less attenuated by TG $1 \mu \mathrm{M}$ than by CPA $10 \mu \mathrm{M}$. The inhibitory effect of CPA is dose-dependent from 1 to $10 \mu \mathrm{M}$; at $10 \mu \mathrm{M}, \mathrm{CPA}$ reduced the E-C coupling $\mathrm{VO}_{2}$ by $70 \%$. Therefore CPA $10 \mu \mathrm{M}$ seems to exert an almost complete blockade on the SR $\mathrm{Ca}^{2+}$-ATPase. When the TG and CPA data are taken together, the SR $\mathrm{Ca}^{2+}$-ATPase consumes at least $70 \%$ of E-C coupling $\mathrm{VO}_{2}$.

In normal rat hearts, $80-87 \% \mathrm{Ca}^{2+}$ recirculates intracellulary $[122,123]$, i.e., the $\mathrm{SR} \mathrm{Ca}^{2+}$-ATPase has a main role in $\mathrm{Ca}^{2+}$ handling. However, the $\mathrm{Na}^{+}-\mathrm{Ca}^{2+}$ exchange will become more important after an inhibition of the SR $\mathrm{Ca}^{2+}$-ATPase [141]. Other energy consuming processes such as sarcolemmal $\mathrm{Na}^{+}-\mathrm{K}^{+}-\mathrm{AT}-$ Pase, therefore, may contribute to the cost of E-C coupling. However, this possibility may be excluded because TG or CPA has greatly reduced the slice motility, and thus sarcolemmal $\mathrm{Na}^{+}-\mathrm{K}^{+}$-ATPase may not have been stimulated.

Myocardial E-C coupling $\mathrm{VO}_{2}$ in mechanically unloaded contractions mainly includes the $\mathrm{VO}_{2}$ needed for the SR $\mathrm{Ca}^{2+}$-ATPase, but basal metabolism does not include $\mathrm{VO}_{2}$ for the $\mathrm{SR} \mathrm{Ca}{ }^{2+}$ pump in the rat $\mathrm{LV}$ slices. In conclusion, the $\mathrm{SR} \mathrm{Ca}^{2+}$-ATPase has a major role in $\mathrm{Ca}^{2+}$ handling in E-C coupling in the rat myocardium.

\section{(3) $\mathrm{mVO}_{2}$ and motility of mechanically unloaded LV slices in mouse hearts}

The genetic manipulation of cardiac specific genes by transgenic mouse models holds promise for studies focused on exploring the specific role of contractile elements and $\mathrm{Ca}^{2+}$-handling constituents in E-C coupling [142-144]. To interpret findings in such a genetically manipulated mouse, the evaluation of cardiac function in normal mouse should be accomplished in terms of the coupling of cardiac mechanical work and energetics because there are many differences between rat and mouse hearts [145]. Nevertheless, there are only a small number of reports on mouse cardiac mechanical work [146-149] and energetics [150].

An analysis of cardiac mechanical work and energetics in mice was recently performed $[150,151]$. In the analysis, the feasibility of an isolated, balloon- in-ventricle, isovolumically contracting, crystalloidperfused mouse heart preparation for the studies of cardiac mechanoenergetics using the framework of ESPVR-PVA-VO $\mathrm{VO}_{2}$ employed in larger species was tested $[6,48,151]$. The $\mathrm{VO}_{2}$-PVA relation is well fitted by a straight line, and the $\mathrm{VO}_{2}$-intercept value corresponding to mechanically minimally unloaded $\mathrm{VO}_{2}$ in mouse $\mathrm{LV}$ has been reported $[150,151]$. The $\mathrm{VO}_{2}-$ intercept value includes $\mathrm{VO}_{2}$ for total $\mathrm{Ca}^{2+}$ handling in E-C coupling and for basal metabolism, as in dogs and rats $[5,48,108,113,152]$. The $\mathrm{VO}_{2}$-intercept value, however, is threefold that in rat LV [7-11, 117]; thus residual mechanical-loading-derived $\mathrm{VO}_{2}$ may be included.

To test the feasibility for studies of cardiac energetics by use of a mouse LV myocardial slice $300 \mu \mathrm{m}$ thick, we performed the measurements of basal $\mathrm{mVO}_{2}$ and $\mathrm{mVO}_{2}$ for total $\mathrm{Ca}^{2+}$ handling in E-C coupling by using the same oximetry as that employed for rat LV 300- $\mu \mathrm{m}$-thick slices. LV mouse myocardial slices of $300 \mu \mathrm{m}$ thickness freely shorten by $1 \mathrm{~Hz}$ electrical field stimulation without external load.

Mouse LV myocardial slice preparations. The whole heart was excised under the perfusion with Tyrode solution oxygenated with $100 \% \mathrm{O}_{2}$ at 12 for $5 \mathrm{~min}$. The composition of Tyrode solution (in $\mathrm{mM}$ ) was 136.0 $\mathrm{NaCl}, 5.4 \mathrm{KCl}, 1.0 \mathrm{MgCl}_{2} \cdot 6 \mathrm{H}_{2} \mathrm{O}, 0.33 \mathrm{NaH}_{2} \mathrm{PO}_{4} \cdot 2 \mathrm{H}_{2} \mathrm{O}$, $1.8 \mathrm{CaCl}_{2} \cdot 2 \mathrm{H}_{2} \mathrm{O}, 10.0$ glucose, and 5.0 HEPES, with $\mathrm{pH}$ adjusted to 7.4 with $\mathrm{NaOH}$ at $30^{\circ} \mathrm{C}$. Each whole $\mathrm{LV}$ was cut into slices $300 \mu \mathrm{m}$ thick along the LV long axis in parallel with the septum. Twelve to 16 slices (single-side surface area $23.0 \pm 7.5 \mathrm{~mm}^{2}$; length and width $\sim 4.8 \pm 1.8$ and $\sim 5.2 \pm 1.9 \mathrm{~mm}$, respectively) were taken from two mice. The slices were stored in oxygenated Tyrode solution at 18 for $30 \mathrm{~min}$, subsequently at 25 for at least $30 \mathrm{~min}$. The $\mathrm{mVO}_{2}$ of slices were measured $2.5 \mathrm{~h}$ after the heart's excision.

Mechanically unloaded $\mathrm{mVO}_{2}$. In normal Tyrode solution, mean $\mathrm{mVO}_{2}$ without electrical stimulation is $0.97 \pm 0.14 \mathrm{ml} \mathrm{O}_{2} \cdot \mathrm{min}^{-1} \cdot 100 \mathrm{~g} \mathrm{LV}^{-1}$, and mean $\mathrm{mVO}_{2}$ with electrical stimulation increases to $1.80 \pm 0.17 \mathrm{ml}$ $\mathrm{O}_{2} \cdot \mathrm{min}^{-1} \cdot 100 \mathrm{~g} \mathrm{LV}^{-1}$. Mean delta $\mathrm{mVO}_{2}\left(=\right.$ the $\mathrm{mVO}_{2}$ with stimulation - the $\mathrm{mVO}_{2}$ without stimulation) is $0.83 \pm 0.12 \mathrm{ml} \mathrm{O}_{2} \cdot \mathrm{min}^{-1} \cdot 100 \mathrm{~g} \mathrm{LV}^{-1}$. There are no differences between mean $\mathrm{mVO}_{2}$ with and without stimulation under $\mathrm{Ca}^{2+}$ free. The increases in extracellular $\mathrm{Ca}^{2+}$ concentrations up to $14.4 \mathrm{mM}$ do not increase the $\mathrm{mVO}_{2}$ without stimulation, but significantly increases the $\mathrm{mVO}_{2}$ with stimulation up to $140 \%$ of control. The delta $\mathrm{mVO}_{2}$ significantly increases up to $190 \%$ of the control in a dose-dependent manner. 
(4) SR $\mathrm{Ca}^{2+}$-ATPase blockade decreases the delta $\mathrm{mVO}_{2}$ of contracting mouse heart slices

CPA $30 \mu \mathrm{M}$ significantly reduces the delta $\mathrm{mVO}_{2}$ to $0.27 \pm 0.06 \mathrm{ml} \mathrm{O}_{2} \cdot \mathrm{min}^{-1} \cdot 100 \mathrm{~g} \mathrm{LV}^{-1}$ (35\% of control). The combination of $5 \mathrm{mM}$ BDM and $30 \mu \mathrm{M}$ CPA does not further decrease delta $\mathrm{mVO}_{2}$, although BDM (3-5 $\mathrm{mM}$ ) decreases it by $28-30 \%$ of control not in a dosedependent manner (Ref. 3-5 mM BDM dose-dependently decreases the slice-free shortening). The delta $\mathrm{mVO}_{2}$ of mouse LV slices during free shortening consists of energy expenditure for total $\mathrm{Ca}^{2+}$ handling in the E-C coupling and basal metabolism and probably no residual cross-bridge cycling.

The main part of delta $\mathrm{mVO}_{2}$ is energy expenditure utilized for total $\mathrm{Ca}^{2+}$ handling in E-C coupling in mouse LV slices as in rat LV slices $[109,115]$. This finding is evidenced by (1) an increase of delta $\mathrm{mVO}_{2}$ in a $\mathrm{Ca}^{2+}$ concentration-dependent manner, and by (2) a decrease of delta $\mathrm{mVO}_{2}$ by CPA in a dose-dependent manner.

However, in mouse LV slices, unlike in rat LV slices $[109,115]$, BDM 3-5 mM significantly decreases delta $\mathrm{mVO}_{2}$ by $28-30 \%$. Furthermore, after CPA $30 \mu \mathrm{M}$ treatment, $35 \%$ of $\mathrm{mVO}_{2}$ remained. Therefore it is possible that delta $\mathrm{mVO}_{2}$ includes energy expenditure partly utilized for residual cross-bridge cycling. If $5 \mathrm{mM}$ BDM directly inhibits cross-bridge cycling, the combination of $30 \mu \mathrm{M} \mathrm{CPA}$ and $5 \mathrm{mM}$ BDM would further decrease delta $\mathrm{mVO}_{2}$. However, the combination does not further decrease delta $\mathrm{mVO}_{2}$, suggesting the possibility that BDM decreases delta $\mathrm{mVO}_{2}$ not mediated by directly inhibiting cross-bridge cycling. The inhibitory effect of CPA on delta $\mathrm{mVO}_{2}$ for $\mathrm{Ca}^{2+}$ handling in E-C coupling is maximal at $30 \mu \mathrm{M}$, since CPA does not further decrease delta $\mathrm{mVO}_{2}$ at $100 \mu \mathrm{M}$. For this reason, the inhibitory effect of $5 \mathrm{mM} \mathrm{BDM}$ on delta $\mathrm{mVO}_{2}$ for $\mathrm{Ca}^{2+}$ handling must be masked.

Consequently, in mouse slices, as in rat myocardial slices, the possibilities that delta $\mathrm{mVO}_{2}$ for the residual cross-bridge cycling is negligibly small and that the BDM-induced definite decrease in delta $\mathrm{mVO}_{2}$ is due to the inhibition of $\mathrm{Ca}^{2+}$ handling in $\mathrm{E}-\mathrm{C}$ coupling are highly supportable. In fact, many reports show that BDM decreases energy expenditure utilized for total $\mathrm{Ca}^{2+}$ handling in E-C coupling [153-156].

The motility index indicates only residual crossbridge cycling at a mechanically unloaded state, and thus motility is originally small. Therefore even at a lower $\mathrm{Ca}^{2+}$ concentration $(3.6 \mathrm{mM})$, the motility index reached maximum value.

Basal $\mathrm{mVO}_{2}$ in mice LV slices are unexpectedly smaller than those in rat LV myocardial slices $(0.97$ vs. $2.09 \mathrm{ml} \mathrm{O}_{2} \cdot \mathrm{min}^{-1} \cdot 100 \mathrm{~g}^{-1}$ ), but delta $\mathrm{mVO}_{2}$ in mice
LV slices $\left(0.83 \mathrm{mlO}_{2} \cdot \mathrm{min}^{-1} \cdot 100 \mathrm{~g}^{-1}\right)$ does not differ from that in rat LV slices $\left(0.91 \mathrm{ml} \mathrm{O}{ }_{2} \cdot \mathrm{min}^{-1} \cdot 100 \mathrm{~g}^{-1}\right)$ [see Ref. 115]. Basal $\mathrm{mVO}_{2}$ is believed to correlate reversely with body weight [114]. The reasons why basal $\mathrm{mVO}_{2}$ is smaller in mouse $\mathrm{LV}$ slices than in rat $\mathrm{LV}$ slices remain to be clarified.

The $\mathrm{VO}_{2}$-PVA relation is well fitted by a straight line, and the value of $\mathrm{VO}_{2}$ at zero PVA $\left(\mathrm{VO}_{2}\right.$-intercept value) [150] theoretically corresponds to mechanically minimally unloaded $\mathrm{VO}_{2}$ in mouse $\mathrm{LV}$ of whole heart preparations; the $\mathrm{VO}_{2}$-intercept value corresponds to $\mathrm{mVO}_{2}$ with stimulation in mouse $\mathrm{LV}$ myocardial slices. The $\mathrm{VO}_{2}$-intercept value $\left(=0.92 \mu 1 \mathrm{O}_{2} \cdot\right.$ beat $\left.^{-1} \cdot \mathrm{g} \mathrm{LV}^{-1}\right)$, however, is practically threefold of $\mathrm{mVO}_{2}$ with stimulation $\left(0.30 \mu \mathrm{O} \mathrm{O}_{2} \cdot\right.$ beat $\left.^{-1} \cdot \mathrm{g} \mathrm{LV}^{-1}\right)$ in mice LV myocardial slices. The measurements made in whole heart preparations [150] may be an overestimate resulting from the loss of oxygen across the epicardial surface of the perfused heart. Another overestimate may be due to energy expenditure for residual cross-bridge cycling, as described above. This might be possible, because it is difficult to make completely mechanically unloading conditions in the mouse whole heart preparation.

The motility index for mice LV slices is approximately $2.2 \%$, whereas free shortening of mouse cardiac cells is $5-10 \%$ [157]. The relatively small motility index seems to be partly due to the heterogeneity of muscle fiber orientations of mouse LV slices, as in rat LV slices [115]. Nevertheless, the relative changes of the motility index could be beneficial to evaluate the effects of agents acting on residual cross-bridge cycling.

In conclusion, the $\mathrm{mVO}_{2}$ of slices $300 \mu \mathrm{m}$ thick from mouse $\mathrm{LV}$ under a quiescent condition represents basal $\mathrm{mVO}_{2}$ used for cardiac basal metabolism and the increase in $\mathrm{mVO}_{2}$ of the slices with $1 \mathrm{~Hz}$ field stimulation mainly represents energy expenditure used for total $\mathrm{Ca}^{2+}$ handling in E-C coupling in the heart.

\section{Acute failing heart models}

\section{(1) High $\mathrm{Ca}^{2+}$-induced $\mathrm{Ca}$ overload failing rat hearts}

Acute failing canine heart models have been produced by different procedures, such as hypercapnic acidosis [132], postacidotic stunning [158], postischemic stunning [159], and transient $\mathrm{Ca}^{2+}$ overloading [53]. These interventions have been associated with different abnormalities in cardiac mechanoenergetics, suggesting that acidosis, ischemia, and free radicals contribute to the observed contractile failure. In clinical settings, perfusion with blood cardioplegia after car- 
diac arrest often results in stunned myocardium, even though no evidence of ischemia or acidosis is found. $\mathrm{Ca}^{2+}$ overload may contribute to the stunning of these hearts during cardioplegia. The mechanisms leading to contractile dysfunction after $\mathrm{Ca}^{2+}$ overload are well understood from various points of view, but $\mathrm{Ca}^{2+}$ overload heart following exposure to high $\mathrm{Ca}^{2+}$ in the absence of ischemia and acidosis is still poorly understood in terms of the coupling of mechanical work and energetics.

High $\mathrm{Ca}^{2+}$ infusion into the coronary circulation makes $\mathrm{Ca}^{2+}$ overload-induced contractile dysfunction in rat hearts independent of ischemia and acidosis. The blood $\mathrm{Ca}^{2+}$ concentration reached 9-15 mM. After the clearance of blood with high $\mathrm{Ca}^{2+}$ concentration for $20 \mathrm{~min}$, the levels of $\mathrm{Ca}^{2+}$ decrease to 1.1-2.5 $\mathrm{mM}$, and venous $\mathrm{P}_{\mathrm{O}_{2}}$ values are from 39 to $45 \mathrm{mmHg}$. The values of arterial-venous differences in lactate throughout the experiment are from 0.19 to $0.25 \mathrm{mM}$, indicating no lactate production. $\mathrm{pH}$ is maintained at about 7.45 .

In cross-circulated rat heart preparations following exposure to high $\mathrm{Ca}^{2+}$, there is a contractile failure associated with a parallel downward-shift of the ESPVR and the linear LV PVA- $\mathrm{VO}_{2}$ relation. The basal metabolic $\mathrm{VO}_{2}$ is unchanged. This result suggests a decrease in oxygen consumption for total $\mathrm{Ca}^{2+}$ handling in E-C coupling.

After postischemic reperfusion, the proteolysis of a cytoskeletal protein, $\alpha$-fodrin, a linker protein, ankyrin, or a regulatory element of the myofilament, troponin I, in rat hearts have been reported previously [160163]. The proteolysis of fodrin or ankyrin is caused by the activation of a neutral protease, calpain, resulting from $\mathrm{Ca}^{2+}$ overload [160-162]. The proteolysis of fodrin in the homogenate of the heart with interventions under various $\mathrm{Ca}^{2+}$ loading conditions, including high $\mathrm{Ca}^{2+}$ infusion, was examined because fodrin is localized to the sarcolemma, the intercalated disks, and $\mathrm{Z}$ bands [161].

Although no proteolysis of $\operatorname{ankyrin}_{\mathrm{R}}$, troponin I, or a gap junction protein, connexin 43 , is detected in the membrane fractions of LV myocardium from the high$\mathrm{Ca}^{2+}$-infused contractile failing hearts, a large amount of the $150 \mathrm{kD}$ fragment of $\alpha$-fodrin is detected in the heart after the clearance of blood with high $\mathrm{Ca}^{2+}$ concentration. This result seems to indicate that $\mathrm{Ca}^{2+}$ overload protocol induces less cellular breakdown than ischemia-reperfusion injury does [159-162].

Relation between fodrin proteolysis and $\mathrm{VO}_{2}$ intercept. The rat hearts subjected to the $\mathrm{Ca}^{2+}$ overloading protocol exhibit markedly decreased $\mathrm{VO}_{2}$ intercepts of the $\mathrm{LV} \mathrm{VO}_{2}$-PVA relations, but the exceptional hearts rarely exhibit unchanged $\mathrm{VO}_{2}$ intercepts. $\alpha$-fodrin proteolysis in membrane fractions of LV myocardium is investigated in the hearts with the decreased $\mathrm{VO}_{2}$ intercepts and other hearts with unchanged $\mathrm{VO}_{2}$ intercepts. The amount of the proteolytic products in hearts with the decreased $\mathrm{VO}_{2}$ intercepts is significantly increased, but in hearts with the unchanged $\mathrm{VO}_{2}$ intercepts, it is not significantly increased. It seems quite likely that there are significant correlations between the decrease of $\mathrm{VO}_{2}$ intercepts and membrane $\alpha$-fodrin degradation

A synthetic calpain inhibitor, calpain inhibitor-1 (Nacetyl-Leucine-Leucine-Norleucinal; ALLNoL; CI-1) (final concentration, 2.5-25 $\mu \mathrm{M}$ at coronary flow of $4 \mathrm{ml} / \mathrm{min}$ ) [161, 164], perfused at $6 \mathrm{ml} / \mathrm{h}$ for $5 \mathrm{~min}$ before, for 40-45 min during, and for $5 \mathrm{~min}$ after the high $\mathrm{Ca}^{2+}$ infusion suppressed the contractile failure by high $\mathrm{Ca}^{2+}$, the decrease in oxygen consumption for the total $\mathrm{Ca}^{2+}$ handling and membrane $\alpha$-fodrin degradation. In conclusion, we found that the exposure to high $\mathrm{Ca}^{2+}$ induces contractile dysfunction by suppressing total $\mathrm{Ca}^{2+}$ handling in E-C coupling and degradation of membrane $\alpha$-fodrin via activation of the calpain.

$\mathrm{O}_{2}$ costs of PVA and LV contractility. The unchanged oxygen cost of PVA indicates an unchanged chemomechanical energy transduction rate after the $\mathrm{Ca}^{2+}$ overloading protocol. This suggests that there are no changes in the product of the PVA/ATP coupling ratio in the contractile machinery and in the ATP/ $\mathrm{VO}_{2}$ coupling ratio in the mitochondria between normal and high $\mathrm{Ca}^{2+}$-induced $\mathrm{Ca}^{2+}$ overloaded acute failing rat hearts [7].

The unchanged oxygen cost of LV contractility indicates the unchanged $\mathrm{Ca}^{2+}$ handling $\mathrm{VO}_{2}$ in $\mathrm{E}-\mathrm{C}$ coupling per unit change in $\mathrm{LV}$ contractility after the $\mathrm{Ca}^{2+}$ overloading protocol. This suggests that there are no changes in the sensitivity of the contractile machinery for $\mathrm{Ca}^{2+}$, the $\mathrm{Ca}^{2+} /$ ATP in the total $\mathrm{Ca}^{2+}$ handling, and the ATP/ $/ \mathrm{VO}_{2}$ in the mitochondria $[5,7,48]$. This suggests that the amount of $\mathrm{Ca}^{2+}$ handled in E-C coupling remains proportional to $\mathrm{LV}$ contractility.

Possible mechanisms for contractile dysfunction. The transient $\mathrm{Ca}^{2+}$ overload seems to have caused proteolysis of $\alpha$-fodrin at the sarcolemma and a decrease in $\mathrm{Ca}^{2+}$ handling $\mathrm{VO}_{2}$ by the activation of a $\mathrm{Ca}^{2+}$ dependent protease, calpain. It has been proposed that $\alpha$-fodrin maintains the integrity of the plasma membranes as a constituent of the membrane skeleton [165, 166]. Therefore it seems quite likely that the degradation of $\alpha$-fodrin in membrane fractions would alter the properties of ion channels [161]. The decreased $\mathrm{Ca}^{2+}$ handling $\mathrm{VO}_{2}$ in $\mathrm{E}-\mathrm{C}$ coupling with unchanged oxygen costs of PVA and LV contractility reflected the 
decreased total amount of $\mathrm{Ca}^{2+}$ handled, which may have been due to a suppression of the transsarcolemmal $\mathrm{Ca}^{2+}$ influx.

The possibility that a disruption of cytoskeletal proteins inactivates L-type $\mathrm{Ca}^{2+}$ channels has been reported $[167,168]$. We speculate that the linkage of the L-type $\mathrm{Ca}^{2+}$ channel to the membrane $\alpha$-fodrin acts to tether the channel in place, which somehow modulates the basal activity of the channel, and a loss of the linkage may impair its regulation.

\section{(2) Ischemic-reperfused acute failing hearts}

After ischemic-reperfusion (I-R), similar contractile failure would occur. All hearts underwent 15-minute global ischemia and 60-minute reperfusion. Mean $\mathrm{ESP}_{\mathrm{mLVV}}$ and $\mathrm{PVA}_{\mathrm{mLVV}}$ were significantly decreased, and mean $\mathrm{VO}_{2}$ intercept of $\mathrm{VO}_{2}$-PVA relation was significantly decreased without change in its slope. To explore the mechanism for this, the effects of KB$\mathrm{R} 7943$, a reverse mode $\mathrm{Na}^{+}-\mathrm{Ca}^{2+}$ exchanger inhibitor, were investigated. After KB-R7943 $(10 \mu \mathrm{M})$ infusion for $1 \mathrm{~min}$ before ischemia and $5 \mathrm{~min}$ after reperfusion, the downwardshift of ESPVR and thus the decreases in mean $\mathrm{ESP}_{\mathrm{mLVV}}$ and $\mathrm{PVA}_{\mathrm{mLVV}}$ were reversed to the control level, though not completely. Mean $\mathrm{VO}_{2}$ intercept and the slope of $\mathrm{VO}_{2}$-PVA relation were unchanged. The results suggest the contribution of reverse-mode $\mathrm{Na}^{+}-\mathrm{Ca}^{2+}$ exchanger to the $\mathrm{Ca}^{2+}$ handling failure in E$\mathrm{C}$ coupling after I-R [see Ref. 223].

Role of the $\mathrm{Na}^{+}-\mathrm{H}^{+}$and $\mathrm{Na}^{+}-\mathrm{Ca}^{2+}$ exchange systems. The role of the $\mathrm{Na}^{+}-\mathrm{Ca}^{2+}$ and $\mathrm{Na}^{+}-\mathrm{H}^{+}$exchangers in failing hearts are vitally important at both processes of their generation and recovery [53, 73, 132, $158,159]$. The $\mathrm{Na}^{+}-\mathrm{Ca}^{2+}$ exchanger is electrogenic and sensitive to membrane potential. The time-course with which $\mathrm{Ca}^{2+}$ is extruded, is influenced by the time course of membrane potential. All the $\mathrm{Ca}^{2+}$ entering the cell during the initial depolarization seems to be extruded by the $\mathrm{Na}^{+}-\mathrm{Ca}^{2+}$ exchange [63]. It appears that $\mathrm{Ca}^{2+}$ influx via the $\mathrm{Na}^{+}-\mathrm{Ca}^{2+}$ exchanger (reverse mode) can also occur during the initial depolarization of cardiac cells. This process may be further stimulated by subsarcolemmal rises in $\mathrm{Na}^{+}$concentration caused by the $\mathrm{Na}^{+}$influx via the cardiac $\mathrm{Na}^{+}$channel. However, whether this occurs during normal E-C coupling remains controversial [63].

As the intracellular $\mathrm{Ca}^{2+}$ concentration subsequently begins to rise as a result of $\mathrm{Ca}^{2+}$ release from the SR, the reversal potential for the $\mathrm{Na}^{+}-\mathrm{Ca}^{2+}$ exchanger becomes greater than the plateau of the membrane potential. The $\mathrm{Na}^{+}-\mathrm{Ca}^{2+}$ exchanger then operates in a $\mathrm{Ca}^{2+}$ efflux $-\mathrm{Na}^{+}$influx "forward" mode. However, the weight of this exchanger in extrusion of cytosolic $\mathrm{Ca}^{2+}$, especially in failing hearts, is still controversial [63, 73].

Mechanoenergetic disorders after a rapid correction of acidosis [158] is considered to result from transient $\mathrm{Ca}^{2+}$ overload via an accelerated $\mathrm{Na}^{+}-\mathrm{Ca}^{2+}$ exchanger (reverse mode) because of the heavily operating $\mathrm{Na}^{+}-\mathrm{H}^{+}$exchanger carrying $\mathrm{H}^{+}$out of myocytes at the time of rapid $\mathrm{pH}$ recovery. The same mechanisms may occur in the postischemic stunned myocardium [159] and the transient $\mathrm{Ca}^{2+}$ overload myocardium evoked by $\mathrm{Ca}^{2+}$-free and high $\mathrm{Ca}^{2+}$ Tyrode perfusion [53] in canine hearts. At least in part, the $\mathrm{Na}^{+}-\mathrm{Ca}^{2+}$ exchanger (reverse mode) and/or the $\mathrm{Na}^{+}-\mathrm{H}^{+}$exchanger contribute to the above I-R acute failing rat hearts.

Cardioprotective effects of calpain inhibitor I. We investigated the cardioprotective effects of calpain inhibitor-1 (CI-1) for I-R acute failing hearts by using the framework of LV ESPVR-PVA-VO $\mathrm{VO}_{2}$ relation and the $\mathrm{O}_{2}$ costs of LV PVA and eEmax with $\mathrm{Ca}^{2+}$. All hearts underwent 15 -minute global ischemia $\left(37^{\circ} \mathrm{C}\right)$. After a 60-minute blood reperfusion with an infusion of CI-1, LV ESPVR and $\mathrm{VO}_{2}$-PVA relation, and the $\mathrm{O}_{2}$ costs of LV PVA and eEmax were obtained. Mean $\mathrm{ESP}_{\mathrm{mLVV}}$ and $\mathrm{PVA}_{\mathrm{mLVV}}$ are significantly decreased, and the mean $\mathrm{VO}_{2}$ intercept of $\mathrm{VO}_{2}$-PVA relation is significantly decreased without a change in its slope after I-R, whereas mean $\mathrm{ESP}_{\mathrm{mLVV}}$ and $\mathrm{PVA}_{\mathrm{mLVV}}$ after I-R with CI-1 are hardly changed. The slopes of $\mathrm{VO}_{2^{-}}$ PVA relationships are unchanged after I-R with CI-1. Mean $\mathrm{VO}_{2}$ intercepts of $\mathrm{VO}_{2}$-PVA relationships significantly $(P<0.01)$ decrease after I-R, but they are unchanged after I-R with CI-1. The relation between PVA-independent $\mathrm{VO}_{2}$ and eEmax during the $\mathrm{Ca}^{2+}$ infusion is linear, and its slope indicates the $\mathrm{O}_{2}$ cost of eEmax. There is no significant difference in the $\mathrm{O}_{2}$ cost of eEmax after I-R with CI-1. A Western blotting of $\alpha$-fodrin indicates that the proteolysis of $\alpha$-fodrin is protected with CI- 1 . The immunostainings of $\alpha$ fodrin, and the $145-$ and $150-\mathrm{kD}$ proteolytic products of $\alpha$-fodrin also confirm that CI-1 protects proteolysis of $\alpha$-fodrin at membrane. The results indicate that the total $\mathrm{Ca}^{2+}$ handling is impaired after I-R injury, whereas calpain inhibitor-1 prevents the heart from I-R injury mediated via inhibiting the $\mathrm{Ca}^{2+}$ handling failure (see Ref. [233]).

\section{Chronic failing heart models}

\section{(1) Spontaneously diabetic mellitus rats}

Left ventricular diastolic dysfunction in type II diabetes mellitus model rats. Although the principal pathophysiological feature of diabetes mellitus (DM) 
is called diabetic microangiopathy, the presence of myocardial dysfunction "diabetic cardiomyopathy" independent of coronary artery disease has been well documented in streptozotocin-induced DM $[169,170]$. The Otsuka Long-Evans Tokushima Fatty (OLETF) rat model of DM [171] manifests stable clinical and pathological features that resemble human type II DM. The causal link between microangiopathy and the pathogenesis of diabetic cardiomyopathy in OLETF rats has been investigated [172]. Early diastolic transmitral inflow exhibited prolonged deceleration time and low peak-velocity in the prediabetic stage [172]. Abnormal relaxation is usually among the earliest manifestations of cardiac dysfunction, and diastolic impairment is seen before systolic impairment [173], but the pathogenesis of diabetic cardiomyopathy is not well understood. Specifically, the coupling of mechanical work and energetics of the heart in diabetic cardiomyopathy is not well understood.

To gain insight into the pathogenesis of diabetic cardiomyopathy in terms of the coupling of LV mechanical work and energetics, LV mechanoenergetic studies on OLETF rat hearts were performed. It is hypothesized that diastolic dysfunction may manifest itself in early diabetic cardiomyopathy as a result of the dysfunction of SERCA2. If so, it is predicted that $\mathrm{VO}_{2}$ for total $\mathrm{Ca}^{2+}$ handling in the E-C coupling may decrease, and the $\mathrm{O}_{2}$ cost of LV contractility may increase because of a resultant activation of the $\mathrm{Na}^{+}-$ $\mathrm{Ca}^{2+}$ exchanger and $\mathrm{Na}^{+}-\mathrm{K}^{+}$-ATPase $[95,141]$. To prove this hypothesis, LV systolic and diastolic functions linked with intracellular $\mathrm{Ca}^{2+}$ handling were investigated in spontaneously DM, OLETF rats.

There were no significant differences between L-I OLETF (40-46 wk of age; early DM) and L-I control (40-52 wk) rats in body weights, whereas body weights in L-II OLETF (62-66 wk of age; late DM) rats were significantly $(P<0.001$ unpaired t-test $)$ lighter than those in L-II control rats (60-72 wk). The body weights of L-II OLETF rats were significantly $(P<0.05$ unpaired t-test) lower than those of L-I OLETF rats, indicating severe DM in L-II OLETF rats. The fasted blood glucose levels in L-I and L-II OLETF rats were $390 \pm 89 \mathrm{mg} / \mathrm{dl}$ and $484 \pm 97 \mathrm{mg} / \mathrm{dl}$.

Neither LV systolic function and mean coronary flow nor coronary flow reserve differed even in late DM rats. The amount of oxygen required for mechanical work and contraction was unaltered, though myosin isozyme was finally transformed from $V_{1}$ to $V_{3}$. The maximum pacing rate decreased from 300 to 240 beats/ min. To evaluate the LV relaxation rate or lusitropism, by using previously proposed "logistic" time constant $\left(T_{\mathrm{L}}\right)$ derived from a logistic model [174] and the con- ventional "exponential" time constant $\left(T_{\mathrm{E}}\right)$, we analyzed $\mathrm{LV}$ isovolumic relaxation pressure-time curves at mLVV. The time constants of the hearts paced at approximately 300 beats/min in early DM versus the control rats were compared, along with those of the hearts paced at 240 beats/min in late DM. The LV relaxation rate was significantly $(P<0.05)$ slower only in late DM rats.

The $\mathrm{O}_{2}$ consumption per min for total $\mathrm{Ca}^{2+}$ handling in E-C coupling, mainly consumed by $\mathrm{SR} \mathrm{Ca}^{2+}$ ATPase (SERCA2), was decreased, without significant changes in basal metabolism or in mitochondrial oxidative phosphorylation. The protein level of SERCA2 in membranes was significantly $(P<0.001)$ lower in severe DM rats. Both the ADP/O ratio and the State III $\mathrm{O}_{2}$ in late DM rat hearts showed a tendency to decrease but not to differ significantly from those in the control rats, though RCI in late DM rat hearts was significantly $(P<0.05)$ smaller than in the control rat hearts. In late DM rats, diabetic cardiomyopathy with lusitropic dysfunction and with unchanged coronary flow and coronary flow reserve were found, but up to 66 wks no systolic dysfunction was observed at $240 \mathrm{bpm}$ pacing. From these results it seems very likely that mitochondrial respiratory function was not impaired even in late DM rat hearts. In conclusion, we found that the only lusitropic dysfunction resulting from the decreased amount of SERCA2 expression was related to generating diabetic cardiomyopathy in the spontaneously diabetic rats.

On the other hand, the possibility that the LV diastolic dysfunction is associated with an increase in cardiac collagen content at the prediabetic stage has been suggested [172]. Late DM rats showed a significant slowing of the LV relaxation rate compared with that in the control rats without significant differences in collagen contents. Therefore it seems very likely that LV diastolic dysfunction in the L-II OLETF rats was not simply related to the increased collagen content, but also was related to the decreased protein level of SERCA2.

Curved ESPVR, linear $\mathrm{VO}_{2}-\mathrm{PVA}$ relationship, and oxygen cost of $P V A$. No significant differences were found between late DM and the control rats in either $\mathrm{ESP}_{\mathrm{mLVV}}$ or $\mathrm{PVA}_{\mathrm{mLVV}}$. Each mean slope of the $\mathrm{VO}_{2^{-}}$ PVA relationship $\left(\mathrm{O}_{2}\right.$ cost of PVA) in late DM and the control rats was almost the same as that previously reported [7, 8, 28, 99, 117]. Therefore the $\mathrm{O}_{2}$ cost of PVA and thus the efficiency of chemomechanical energy transduction rate was unchanged, despite the different myosin isozymes in late DM rats, as in hypothyroid rats.

PVA-independent $\mathrm{VO}_{2}$. The significantly decreased PVA-independent $\mathrm{VO}_{2}$ per minute with unchanged basal 
metabolism in late DM rat hearts suggested a decrease in $\mathrm{VO}_{2}$ for total $\mathrm{Ca}^{2+}$ handling in the E-C coupling per minute. The $\mathrm{VO}_{2}$ for $\mathrm{Ca}^{2+}$ handling in the $\mathrm{E}-\mathrm{C}$ coupling was primarily consumed by SERCA2 [115, 117]. Therefore the decrease in $\mathrm{VO}_{2}$ for $\mathrm{Ca}^{2+}$ handling per minute indicated a decrease in $\mathrm{O}_{2}$ consumption by SERCA2. This was causally related to the decreased pacing rate to prevent an incomplete LV relaxation. This decrease in the pacing rate was due to a dysfunction of SERCA2 resulting from the decreased amount of SERCA2.

$\mathrm{O}_{2}$ cost of LV contractility, eEmax. In non-insulindependent diabetic hearts, no changes in the myocardial $\beta$-receptor population could be found, but the reduced responsiveness to a $\beta$-adrenergic agonist was reported [175]. The $\mathrm{O}_{2}$ cost of $\mathrm{LV}$ contractility for dobutamine in late DM rat hearts, however, was unchanged. Furthermore, the $\mathrm{O}_{2}$ cost of LV contractility for $\mathrm{Ca}^{2+}$ was also unchanged. All these results indicate that changes in the total $\mathrm{Ca}^{2+}$ handling $\mathrm{VO}_{2}$ in the E-C coupling against unit change in LV contractility induced by $\mathrm{Ca}^{2+}$ or dobutamine were not altered on a beat-to-beat basis in the late DM rat hearts. When we decreased the pacing rate to 240 beats/min, from 300 beats/min, it was possible to maintain the unchanged systolic function and the unchanged $\mathrm{O}_{2}$ cost of LV contractility in the late and severe DM rats.

$L V$ diastolic dysfunction. In the late DM rat heart, the LV myosin isozyme is transformed to $V_{3}$ from $V_{1}$. This transformation might be causally related to a significant slowing of the LV relaxation rate. However, in hypothyroid rat hearts where myosin isozyme is $V_{3}$, both LV systolic and diastolic dysfunctions were found under the decreased pacing rate and the decreased $\mathrm{VO}_{2}$ intercept without any change in the $\mathrm{O}_{2}$ cost of PVA [11]. The decreased $\mathrm{VO}_{2}$ intercept was due to the decreased $\mathrm{VO}_{2}$ for $\mathrm{Ca}^{2+}$ handling in E-C coupling and the decreased basal metabolism [11]. These findings indicate that the LV mechanical work and energetic characterization very much differ between the hypothyroid and the late DM rats, in both of which myosin isozymes were the same $V_{3}$. Therefore it seems unlikely that the transformation of myosin isozyme into $V_{3}$ is causally related to the $\mathrm{LV}$ diastolic dysfunction in the late DM rats, though the possibility for its partial contribution could not be excluded.

Although the LV systolic function was not impaired and the $\mathrm{O}_{2}$ cost of LV contractility did not increase, we proved that diastolic dysfunction manifested itself because of the depressed expression of SERCA2 and that the decrease in $\mathrm{VO}_{2}$ for $\mathrm{Ca}^{2+}$ handling in $\mathrm{E}-\mathrm{C}$ coupling per minute manifested itself because of a decreased pacing rate in the late DM rat. In conclu- sion, the LV lusitropic function in the late DM rat hearts was impaired by a depressed expression of SERCA2, and the impaired $\mathrm{Ca}^{2+}$ uptake function by SERCA2 was found to have an important role in the pathogenesis of diabetic cardiomyopathy in a type II DM rat model.

\section{(2) Hypothyroid rats}

Cardiac dysfunction. In canine and human hearts, LV myocardial myosin isozyme is $V_{3}$ in contrast to $V_{1}$ in normal adult rat hearts [176, 177]. It is well known that ATPase activity of $V_{1}$ myosin isozyme is higher than that of $V_{3}$ myosin isozyme and that the shortening velocity of $V_{1}$-dominant myocardium is faster than that of $V_{3}$-dominant myocardium $[178,179]$. In the hypothyroid rat ( $V_{3}$-dominant myocardium), the isometric tension of native trabecular preparations substantially decreased [180] and peak developed tension of LV papillary muscle preparations significantly decreased [178], although the isometric tension of glycerinated trabecular preparations hardly changed. A decrease in LV contractility in in situ ejecting hearts of hypothyroid rats has been reported previously [97]. Nevertheless, it is still unknown whether the depressed contractility in in situ ejecting hearts of hypothyroid rats derives from the $V_{3}$-dominant myocardium, the $\mathrm{Ca}^{2+}$ handling failure, or the abnormal pre- and/or afterload conditions resulting from hypothyroidism.

It is hypothesized that cardiac dysfunction in hypothyroidism is mainly caused by the $\mathrm{Ca}^{2+}$ handling failure. To prove this hypothesis, cardiac function was investigated in terms of the coupling of rat LV mechanical work and energetics without interference of preload and afterload in the excised, cross-circulated whole heart preparations from the hypothyroid rats.

Animal preparations. Drinking the water including 8-propylthiouracil (PTU, $0.8 \mathrm{mg} / \mathrm{ml}$ ) for $4-5 \mathrm{wks}$ made the rat hypothyroidism [178]. Decreased T3 and T4 levels in plasma, which were decreased to $34.2 \pm$ $7.1 \%$ and $2.6 \pm 0 \%$ of normal, respectively, confirmed hypothyroidism. Myosin isozyme in LV myocardium was $V_{3}(95.1 \pm 2.0 \%$ of total myosin isozyme) in the hypothyroid rats, whereas it was $V_{1}(89.5 \pm 9 \%$ of the total) in the normal rats. The LV, including the septum and the right ventricle, were $1.07 \pm 0.08$ and $0.29 \pm$ $0.06 \mathrm{~g}$ in normal rats and $0.85 \pm 0.10$ and $0.21 \pm 0.03$ $\mathrm{g}$ in hypothyroid rats. The left and right ventricular weights were significantly different between the two groups.

LV inotropism and lusitropism were significantly depressed, and these mechanical dysfunctions are causally related to a marked decrease of myocardial $\mathrm{VO}_{2}$ for the $\mathrm{Ca}^{2+}$ handling and for basal metabolism. The 
former total $\mathrm{Ca}^{2+}$ handling $\mathrm{VO}_{2}$ in $\mathrm{E}-\mathrm{C}$ coupling was primarily consumed by SERCA2 [115, 117]. It is well known that thyroid hormone affects SERCA2 activity through the expression of both SERCA2 and PLB [181188]. In fact, the higher protein levels of PLB and the lower protein levels of SERCA2 were found, although the oxygen costs of $\mathrm{LV}$ contractility for $\mathrm{Ca}^{2+}$ and for dobutamine in the hypothyroid rats did not differ from those in age-matched normal rats.

The results reveal that $\mathrm{LV}$ energetic changes associated with the decreased mechanical work in hypothyroid rats were mainly caused by the impairment of $\mathrm{Ca}^{2+}$ uptake via SERCA2. In conclusion, we find that the impairment of $\mathrm{Ca}^{2+}$ uptake plays an important role in the pathogenesis of cardiac dysfunction in hypothyroidism.

Curved ESPVR, linear $\mathrm{VO}_{2}-P V A$ relationship, and oxygen cost of PVA. Marked differences in $\mathrm{ESP}_{\mathrm{mLVV}}$ or PVA $\mathrm{mLVV}_{\mathrm{m}}$ were found between normal and hypothyroid rats, whereas each mean slope of the $\mathrm{VO}_{2}$-PVA relation $\left(\mathrm{O}_{2}\right.$ cost of PVA $)$ in the two groups was found to be almost the same as that previously reported [7, 8 , 28, 99, 117]. In hyperthyroid rabbits, where myosin isozyme is $V_{1}$, the increased $\mathrm{O}_{2}$ cost of PVA was observed [106], though in hyperthyroid dogs, where myosin isozyme remains $V_{3}$, the unchanged $\mathrm{O}_{2}$ cost of PVA was observed [189]. From these findings, it has been predicted that the $\mathrm{O}_{2}$ cost of PVA is related to types of myosin isozyme. The results, however, indicate that no correlation exists between the $\mathrm{O}_{2}$ cost of PVA and the types of myosin isozyme in the normal and the hypothyroid rats. The unchanged $\mathrm{O}_{2}$ cost of PVA in the hypothyroid rats indicates that the efficiency of chemomechanical energy transduction (the inverse of $\mathrm{O}_{2}$ cost of PVA) remained unchanged despite the different types of myosin isozyme.

$P V A$-independent $\mathrm{VO}_{2}$. The mean $\mathrm{VO}_{2}$ intercept of the $\mathrm{VO}_{2}$-PVA relation (PVA-independent $\mathrm{VO}_{2}$ ) in the hypothyroid rats was significantly smaller than in the normal rats. The $\mathrm{VO}_{2}$ for total $\mathrm{Ca}^{2+}$ handling in the E-C coupling and for basal metabolism were both significantly smaller in the hypothyroid rats. The decrease in $\mathrm{VO}_{2}$ for total $\mathrm{Ca}^{2+}$ handling reflects a decrease in the uptake activity of SERCA2 on a beat-to-beat basis, as mentioned above.

Thyroid hormone changes the expression of mitochondrially encoded respiratory genes [190]. In the hypothyroid state, the mitochondrial respiratory function may be depressed by the depressed gene expression, and further mitochondrial cytochrome oxidase activity is depressed [191]. Therefore it seems quite likely that hypothyroidism leads to a depressed mitochondrial respiration. This speculation is supported by the present result showing the noticeably smaller basal metabolism in the left ventricle of the hypothyroid rats.

$\mathrm{O}_{2}$ cost of LV contractility, eEmax. In the hypothyroid rats, the pacing of the heart at 300 beats/min failed, but the pacing at 262 beats/min succeeded. Although this reflects the dysfunction of SERCA2, the decreased pacing rate may lead to unchanged $\mathrm{O}_{2}$ costs of $\mathrm{LV}$ contractility for $\mathrm{Ca}^{2+}$ and for dobutamine on a beat-tobeat basis in the hypothyroid rats.

In developing rat hearts, hypothyroidism decreased the function of SERCA2 and increased the function of $\mathrm{Na}^{+}-\mathrm{Ca}^{2+}$ exchanger $[192,193,187]$. In normal adult rats, $81 \%$ of the $\mathrm{Ca}^{2+}$ released from the $\mathrm{SR}$ was recirculated by SERCA2; $\mathrm{Ca}^{2+}$ handling relied largely on SR [122]. If this hypothyroidism decreased the uptake function of LV SERCA2 and increased the extrude function of $\mathrm{LV} \mathrm{Na}{ }^{+}-\mathrm{Ca}^{2+}$ exchanger, the $\mathrm{O}_{2}$ cost of $\mathrm{LV}$ contractility might have increased [95]. But the unchanged $\mathrm{O}_{2}$ cost of LV contractility in this hypothyroid rat indicates no change in the relative functions of SERCA2 and $\mathrm{Na}^{+}-\mathrm{Ca}^{2+}$ exchanger. This speculation is supported by a recent study showing no increase in $\mathrm{LV} \mathrm{Na}{ }^{+}-\mathrm{Ca}^{2+}$ exchanger protein in hypothyroid rats compared to that in normal rats [194]. The decreased total $\mathrm{Ca}^{2+}$ handling $\mathrm{VO}_{2}$ in the E-C coupling in the hypothyroid rats suggests a decrease in the total amount of $\mathrm{Ca}^{2+}$ handled in the E-C coupling with no change in the recirculation fraction of $\mathrm{Ca}^{2+}$ uptaken by SR.

$L V$ systolic and diastolic dysfunctions. In the excised hearts of the hypothyroid rats, at a pacing rate lower than normal, a significant slowing of the LV contraction and relaxation rates was found. In in situ hearts, the preload and afterload and the hormonal and neuronal influences could interfere with LV function. In contrast, in the cross-circulated (blood-perfused) excised hearts, LV function can be characterized by the myocardium per se. Therefore LV systolic and diastolic dysfunctions in myocardium seem to be actually caused in the hypothyroid rats.

In the hypothyroid rats, LV myosin isozyme $V_{1}$ was transformed to $V_{3}$ [177]. This transformation might be causally related to a significant slowing of the LV contraction and relaxation rates $[178,180]$. But in the same-type heart preparations of the type II DM rats, where myosin isozyme is $V_{3}$ just as in hypothyroid rats, only diastolic dysfunction was found under the decreased pacing rate without any change in the $\mathrm{VO}_{2}$ intercept of the $\mathrm{VO}_{2}$-PVA relation and the $\mathrm{O}_{2}$ cost of PVA [9]. These findings indicate that the hypothyroid and the type II DM rats differ in the LV mechanical work and energetic characterization, though their 
myosin isozymes are the same $V_{3}$. Therefore it seems very unlikely that the only transformation of myosin isozyme into $V_{3}$ is causally related to the LV systolic and diastolic dysfunctions in the hypothyroid rats.

Not only systolic and diastolic dysfunctions and a decrease in $\mathrm{VO}_{2}$ for $\mathrm{Ca}^{2+}$ handling in E-C coupling in physiological functional studies, but also a depressed expression of SERCA2 and an enhanced expression of PLB were found in the hypothyroid rats, as previously reported [183-187]. Furthermore, it has been reported that in hypothyroid mice, decreases in SERCA2a gene expression are accompanied by prolonged contraction and relaxation of papillary muscles [182]. It seems quite likely that the dysfunction of SERCA2 leads to a primary diastolic dysfunction and that the decreased $\mathrm{Ca}^{2+}$-release resulting from the decrease in $\mathrm{Ca}^{2+}$ stored in SR leads to a secondary systolic dysfunction. On the other hand, the possibility of the final impairment of ryanodine receptor function cannot be excluded, because a lower level of expression of ryanodine receptor mRNA has been reported in 16wk hypothyroid rabbits [195].

It is reported that in the failing rat heart model made by aortic banding, the ratio of SERCA2a to PLB decreased associated with worsening metabolism, i.e., a decreased ratio of phosphocreatine to ATP [196]. Similar to this failing heart model, in the hypothyroid rat heart the ratio of SERCA2a to PLB decreased, but this is not associated with worsening metabolism, i.e., unchanged $\mathrm{O}_{2}$ costs of PVA and eEmax. In terms of the coupling of LV mechanical work and energetics, LV systolic and diastolic functions in the hypothyroid rats were impaired by the depressed $\mathrm{Ca}^{2+}$ uptake function by SERCA2. In conclusion, it was found that the impaired $\mathrm{Ca}^{2+}$ uptake function by SERCA2 plays an important role in the pathogenesis of heart failure in the hypothyroidism.

An overexpression of SERCA2a in the failing rat heart made by aortic banding improved cardiac function associated with an improvement of phosphocreatine to ATP ratio or the energy potential [196]. Furthermore, in the hypothyroid mice, an overexpression of SERCA2a also improves both the contraction and the relaxation of the papillary muscle [182]. Therefore, an overexpression of SERCA2a would be a promising strategy to rescue various cardiac dysfunctions, including the hearts in hypothyroidism.

\section{Gene targeting for these failing-heart models}

Our understanding of cardiac E-C coupling has improved significantly over the past 10 years, not only by cardiac mechanoenergetic studies, but also by other studies. Furthermore, defects in the various steps of E-C coupling that characterize cardiac dysfunction have been identified in human and experimental models of heart failure, as mentioned above. The various abnormalities in ionic channels, transporters, kinases, and various signaling pathways could contribute to the failing phenotype. An important tool in dissecting the importance of the various changes in heart failure has been the use of cardiac gene transfer. To achieve effective cardiac gene transfer a number of obstacles remain, including appropriate vectors for gene delivery, appropriate delivery systems, and a better understanding of "the biology of the disease." Gene transfer provides not only a potential therapeutic modality, but also an approach to identifying and validating molecular targets [197].

Cardiac myocytes from failing hearts are characterized by several cellular abnormalities in the E-C coupling processes $[7,9,11,198-201]$. These include changes at the levels of the sarcolemma, SR, myofilaments, and mitochondria, all of which contribute to depressed mechanical functions and reserves. Identifying how the underlying mechanisms for these changes contribute to the observed pathology is frequently confused by simultaneous alterations in multiple signaling pathways in the complex environment of the failing or myopathic heart [202, 203]. For this reason, gene transfer has the distinct advantage of editing single genes at a time and allowing investigators to probe various mechanisms [204]. However, before this smooth transition, several various obstacles must be overcome, including choice of vectors, delivery methods, and most important a better understanding of the biology and mechanisms of heart failure [204], as described above in this review.

The major disadvantages to recombinant adenoviral gene transfer have been its transience and the intense inflammation and robust immune response it evokes. In animal models, adenoviral gene transfer to adult myocardium in vivo has generally been found to mediate high-level expression for approximately 1 week [204-206].

E-C coupling and the role of SERCA2a and PLB. E-C coupling in cardiac myocytes occurs as a coordinated sequence between intracellular $\mathrm{Ca}^{2+}$ handling proteins. As described above in this review, the understanding of E-C coupling in cardiac myocytes continues to develop [207]. To confirm all of a series of coordinated steps in E-C coupling, we offer the following descriptions. Electrical excitation across the sarcolemma leads to the opening of voltage-gated $\mathrm{Ca}^{2+}$ channels, allowing the entry of a small amount of $\mathrm{Ca}^{2+}$, 
which triggers the release of a larger amount of $\mathrm{Ca}^{2+}$ from the SR through the ryanodine receptors (RYR2) [207, 208]. This increase in $\mathrm{Ca}^{2+}$ activates the myofilaments leading to contraction. Relaxation occurs when $\mathrm{Ca}^{2+}$ is dissociated from the myofilaments and is taken up by the SR $\mathrm{Ca}^{2+}$-ATPase pump into the $\mathrm{SR}$. The intracellular $\mathrm{Ca}^{2+}$ sparks arises from a cluster of RYR2 in close proximity to a voltage-dependent $\mathrm{Ca}^{2+}$ channel [207]. When a great many $\mathrm{Ca}^{2+}$ channels are activated, multiple $\mathrm{Ca}^{2+}$ sparks combine to increase cytosolic $\mathrm{Ca}^{2+}$, which leads to myofilament activation [207, 208].

The $\mathrm{Ca}^{2+}$ pumping activity of SERCA2a is influenced by PLB, which inhibits SERCA2a in the unphosphorylated state [209, 210]. Phosphorylation by cAMP and $\mathrm{Ca}^{2+}$-calmodulin-dependent protein kinases, however, reverses this inhibition.

The cardiac SR is composed of two main components: the junctional SR and the longitudinal tubules, which are not organized in relation to $\mathrm{T}$ tubules. For this reason, E-C coupling occurs mainly through diffusible signals: $\mathrm{Ca}^{2+}$-induced $\mathrm{Ca}^{2+}$ release accounts for the opening of the $\mathrm{SR} \mathrm{Ca}^{2+}$ release channels (RYR2), located on the junctional SR [211]. The RYR2 has a tetrameric structure composed of four monomers with a weight of $\sim 564 \mathrm{kDa}$.

The SR $\mathrm{Ca}^{2+}$-ATPase is localized in the longitudinal SR. Although five distinct $\mathrm{Ca}^{2+}$-ATPase isoforms are found in skeletal, smooth, and cardiac muscles [212, 213], an alternative splicing of the SERCA2 gene gives rise to two distinct isoforms: SERCA2a and SERCA2b. Cardiac muscle expresses mainly the SERCA2a isoform, which is modulated by the phosphoprotein PLB.

The amount of $\mathrm{Ca}^{2+}$ in the SR is a very important determinant of the open probability of the RYR2 and directly affects the fraction of $\mathrm{SR} \mathrm{Ca}^{2+}$ released for a given "spark." The maintenance of the $\mathrm{SR} \mathrm{Ca}^{2+}$ is essential for E-C coupling. There is a strong positive correlation between SR Ca ${ }^{2+}$-ATPase and contractility, based on experiments using SERCA2a inhibitors such as CPA and TG [115, 117, 214] as mentioned above in this review. SERCA2a is under the control of PLB, a small molecule and essential SR membrane phosphoprotein from a view of physiological function. This small protein has a hydrophilic domain that constitutes the cytosolic sector and a hydrophobic transmembrane domain. The latter domain inhibits the apparent affinity of SERCA2a for $\mathrm{Ca}^{2+}$. PLB can be phosphorylated at distinct sites by different protein kinases: serine 10 by protein kinase $C$, serine 16 by cAMP-dependent protein kinase, and threonine 17 by $\mathrm{Ca}^{2+}$-calmodulin-dependent kinase. The phosphory- lation of each of these sites is associated with enhanced SR $\mathrm{Ca}^{2+}$-ATPase activity [210, 215, 216]. Therefore PLB is a key regulator of cardiac mechanical function mediated by its effect on SERCA2a function.

$E-C$ coupling and the role of $\mathrm{Na}^{+}-\mathrm{Ca}^{2+}$ exchanger. $\mathrm{Ca}^{2+}$ is removed outside the cytosol by the sarcolemmal $\mathrm{Na}^{+}-\mathrm{Ca}^{2+}$ exchanger, which has a high capacity but low affinity, and is the major $\mathrm{Ca}^{2+}$ extrusion mechanism of the cardiac myocyte [217], though its contribution varies among individual species [95, 115, 117]. This system returns $\mathrm{Ca}^{2+}$ concentrations to diastolic levels and may therefore contribute significantly to cardiac relaxation. The consequence of an increased activity of the $\mathrm{Na}^{+}-\mathrm{Ca}^{2+}$ exchanger in failing hearts may compensate for the reduction in $\mathrm{SR} \mathrm{Ca}{ }^{2+}$-ATPase activity [207]. An increased activity of the $\mathrm{Na}^{+}-\mathrm{Ca}^{2+}$ exchanger should assist in cardiac relaxation, although $\mathrm{Ca}^{2+}$ release from the SR during systole might be reduced. This would be especially evident at higher rates of stimulation and thus lead to a blunted frequency response, as seen in myopathic human myocardium [218].

The $\mathrm{Na}^{+}-\mathrm{Ca}^{2+}$ exchanger can operate to bring $\mathrm{Ca}^{2+}$ into the cell or to extrude $\mathrm{Ca}^{2+}$ from the cell [207, 217, 219-223]. It has been suggested that the relaxation abnormalities produced by the loss of SERCA2a activity could be, at least partially, compensated for by an increase in the activity of the $\mathrm{Na}^{+}-\mathrm{Ca}^{2+}$ exchanger, as mentioned above [8,95] and by others [207, 217, 219-222].

\section{Gene transfer of $\mathrm{Ca}^{2+}$ handling proteins}

Gene transfer provides a unique opportunity to manipulate the expression of essential proteins and alter the expression of specific downstream signaling pathways implicated in the pathogenesis of heart failure. Cardiac mechanical dysfunction results from abnormalities in many subcellular mechanisms. Specifically, a single area of $\mathrm{Ca}^{2+}$ handling will be targeted: the $\mathrm{Ca}^{2+}$ handling proteins involved in E-C coupling (Fig. 3).

Recombinant adenoviral gene transfer has been instrumental in elucidating the molecular basis of the abnormalities in chronic failing hearts such as DM and hypothyroid failing heart models, and acute failing hearts such as $\mathrm{Ca}^{2+}$ overload and ischemicreperfused acute failing heart models, as mentioned above. Many of these mechanoenergetic changes seen in E-C coupling can be halted and even reversed in these failing hearts (Fig. 3). The transfer of SERCA2a, for example, has been shown to lead to an increase in $\mathrm{SR} \mathrm{Ca}^{2+}$-ATPase activity, an increase in the amount of 


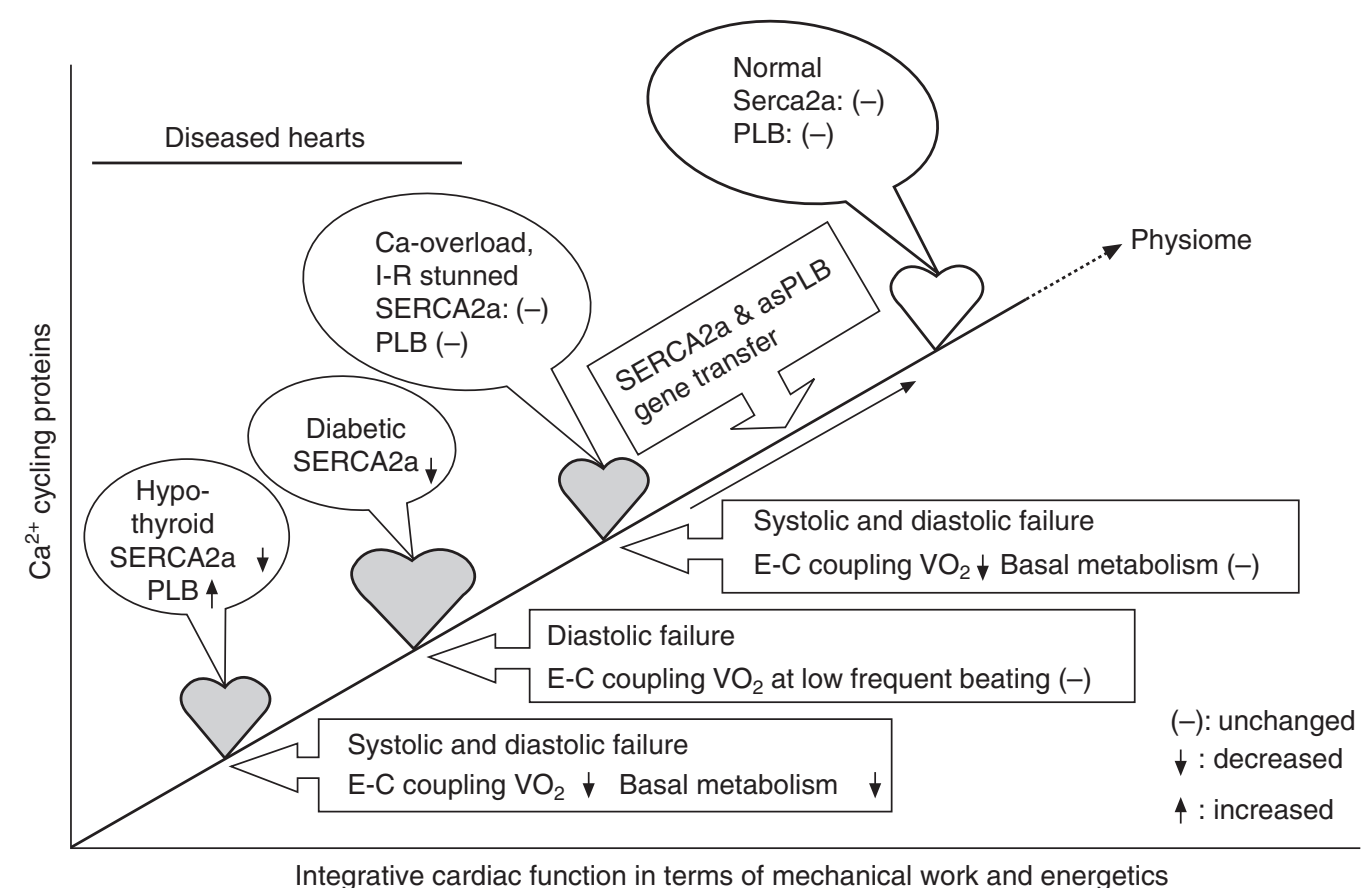

Fig. 3. The relation between $\mathrm{Ca}^{2+}$ cycling proteins and integrative cardiac function in terms of mechanical work and energetics. E-C: excitation-contraction. $\mathrm{VO}_{2}$ : myocardial oxygen consumption per beat. SERCA2a: sarcoplasmic reticulum $\mathrm{Ca}^{2+}$-ATPase. PLB: phospholamban. AsPLB: antisense phospholamban. I-R: ischemic-reperfused.

$\mathrm{Ca}^{2+}$ released, a faster relaxation phase, and a decrease in diastolic $\mathrm{Ca}^{2+}[204,206,224-229]$.

In contrast, it has been shown that increasing PLB relative to SERCA2a in isolated myocytes simulates the abnormalities of $\mathrm{Ca}^{2+}$ handling seen in failing ventricular myocardium [204, 206, 224-229]. These include prolongation of the relaxation phase of the $\mathrm{Ca}^{2+}$ transient, a decrease in $\mathrm{Ca}^{2+}$ release, and an increase in the resting cytosolic $\mathrm{Ca}^{2+}$ concentration.

Furthermore, overexpressing SERCA2a can largely rescue the phenotype created by increasing the ratio of PLB/SERCA2a [204, 206, 224-229]. More recently, the restoration of SERCA2a in failing human cardiomyocytes has been shown to restore the free shortening function of these failing human cells to normal level [204, 206, 224-229]. This study validated the premise that targeting SERCA2a by gene transfer using Ad.SERCA2a (E1-deleted recombinant adenovirus vector carrying cDNA for SERCA2a) may offer a new therapeutic modality in small animals with heart failure.

Furthermore, cardiac metabolism measured by the ratio of creatine phosphate to ATP was also restored to normal in these studies. The restoration of the energetics is surprising (!), because enhanced contractility is usually associated with increased energy demand. The fact that gene transfer of SERCA2a is not associated with a compromise in cardiac energetics means that a beneficial remodeling occurred within the cardiac cell restoring the metabolic machinery [197].

Ablation of PLB. The gene transfer of a dominant form of PLB has been shown to enhance contractile function both in vitro and in an animal model of heart failure [230-232]. Furthermore, antisense strategies showing the ablation of PLB (AsPLB) restored the free shortening function in human failing cardiac cells back to normal [206].

In conclusion, in terms of cardiac mechanical work and energetics in small animals, when the $\mathrm{O}_{2}$ costs of PVA and LV contractility (eEmax) are evaluated by use of the framework of $\mathrm{VO}_{2}$-PVA-eEmax, it could be determined whether a beneficial remodeling occurs within the heart, restoring the metabolic machinery. The result suggests that low $\mathrm{O}_{2}$ costs holding hearts are energy-saving hearts, and that high $\mathrm{O}_{2}$ costs holding hearts are energy-wasting hearts.

\section{Perspectives}

As shown in Fig. 3, AsPLB and SERCA2a gene transfer in vivo would rescue various types of failing hearts. Preliminary studies have been published recently [233]. The in vivo transfer of AsPLB prevented the formation of $\mathrm{Ca}^{2+}$ overload acute failing hearts induced by coronary infusion with high $\mathrm{Ca}^{2+}$. The downward shift of ESPVR and the upward shift of EDPVR and thus the decrease in $\mathrm{PVA}_{\mathrm{mLVV}}$ were restored back to normal by AsPLB transfer. Simultaneously, the decreased 


\section{TAKAKI}

$\mathrm{VO}_{2}$ intercept composed of $\mathrm{O}_{2}$ consumption for $\mathrm{Ca}^{2+}$ handling in E-C coupling and basal metabolism were restored back to normal without changes in the $\mathrm{O}_{2}$ costs of PVA and eEmax.

Gene transfer provides a unique opportunity to manipulate the expression of essential proteins and to alter the expression of specific downstream signaling pathways implicated in the pathogenesis of heart failure.

This author (MT) greatly thanks all researchers in the Departments of Physiology II, Surgery III, and Anesthesiology at the Nara Medical University for their research and contributions to this review. All studies included in this review were supported in part by Grants-in-Aid for Scientific Research (04454267, 04557041, 06213226, 07508003, 08670052, 09670053, 09307029, 11470277, and 14770016) from the Ministry of Education, Science, Sports and Culture, Japan. This author would also like to thank Dr. Hiroyuki Suga (Director General of NCVC Research Institute) for his encouragement to perform studies included in this review.

\section{REFERENCES}

1. Drake-Holland AJ and Noble MIM: Cardiac metabolism. Wiley, New York, 1983

2. Gibbs CL: Cardiac energetics. Physiol Rev 58: 174254, 1978

3. Gibbs CL and Chapman JB: Cardiac energetics. In: Bern RM, Sperelakis N, and Geiger SR (eds) Handbook of Physiology: The Cardiovascular System I. American Physiol Soc, Bethesda, pp 775-804, 1979

4. Chapman JB: Heat production. In: Drake-Holland AJ, Noble MIM (eds) Cardiac metabolism. Wiley, New York, pp 239-256, 1983

5. Suga H: Ventricular energetics. Physiol Rev 70: 247277, 1990

6. Takaki M, Namba T, Araki J, Ishioka K, Ito H, Akashi T, Zhao L-Y, Zhao D-D, Liu M, Fujii W, and Suga H: How to measure cardiac energy expenditure. In: Preusse CJ, and Piper HM (eds) Ischemia-reperfusion in cardiac surgery. Kluwer Academic, Dordrecht, pp. 403419, 1993

7. Tsuji T, Ohga Y, Yoshikawa Y, Sakata S, Abe T, Tabayashi N, Kobayashi S, Kohzuki H, Yoshida K, Suga H, Kitamura S, Taniguchi S, and Takaki M: Rat cardiac contractile dysfunction induced by $\mathrm{Ca}^{2+}$ overload: Possible link to the proteolysis of fodrin. Am J Physiol Heart Circ Physiol 281: H1286-H1294, 2001

8. Sakata S, Ohga Y, Abe T, Tabayashi N, Kobayashi S, Tsuji T, Kohzuki H, Misawa H, Taniguchi S, and Takaki M: No dependency of a new index for oxygen cost of left ventricular contractility on heart rates in the bloodperfused excised rat heart. Jpn J Physiol 51: 177185, 2001

9. Abe T, Ohga Y, Tabayashi N, Kobayashi S, Sakata S, Misawa H, Tsuji T, Kohzuki H, Suga H, Taniguchi S, and Takaki M: Left ventricular diastolic dysfunction in type II diabetes mellitus model rats. Am J Physiol Heart Circ Physiol 282: H138-H148, 2002
10. Tabayashi N, Abe T, Kobayashi S, Yoshikawa Y, Sakata S, Takenaka C, Misawa H, Taniguchi S, and Takaki M: Oxygen cost of left ventricular contractility for dobutamine and $\mathrm{Ca}^{2+}$ in normal hearts and the cost for dobutamine in $\mathrm{Ca}^{2+}$ overload-induced failing hearts. Jpn J Physiol 52: 163-171, 2002

11. Ohga Y, Sakata S, Takenaka C, Abe T, Tsuji T, Taniguchi $\mathrm{S}$, and Takaki M: Cardiac dysfunction in terms of left ventricular mechanical work and energetics in hypothyroid rats. Am J Physiol Heart Circ Physiol 283: H631H641, 2002

12. Sakata S, Ohga Y, Kohzuki H, Misawa H, Mochizuki S, Kajiya F, and Takaki M: Effects of sodium nitroprusside on left ventricular mechanoenergetics. Jpn J Physiol 50 (Suppl): S57-111, 2000

13. Takaki M, Kohzuki H, Sakata S, Ohga $Y$, Misawa $H$, Morimoto $\mathrm{T}$, and Ito $\mathrm{H}$ : Rat and mouse left ventricular mechanoenergetics. In Cardiac function in Osaka 2001: Topics in Genomics, Proteomics, and Physiomics, 2001 (Abstract)

14. Coleman HN, Sonnenblick EH, and Braunwald E: Myocardial oxygen consumption associated with external work: the Fenn effect. Am J Physiol 217: $291-$ 296, 1969

15. Suga $\mathrm{H}$ : Total mechanical energy of a ventricular model and cardiac oxygen consumption. Am J Physiol Heart Circ Physiol 236: H498-H505, 1979

16. Suga $\mathrm{H}$ : Cardiac mechanics and energetics - from Emax to PVA. Front Med Biol Eng 2: 3-22, 1990

17. Suga H: Time course of left ventricular pressure-volume relationship under various end-diastolic volumes. Jpn Heart J 10: 509-515, 1969

18. Suga $\mathrm{H}$ : Theoretical analysis of a left ventricular pumping model based on the systolic time-varying pressure/volume ratio. IEEE Trans Biomed Eng BME 18: 47-55, 1971

19. Sunagawa K, and Sagawa K: Models of ventricular contraction based on time-varying elastance. CRC Critical Rev Biomed Eng 7: 193-228, 1982

20. Sagawa K, Maughan L, Suga $H$, and Sunagawa K: Cardiac contraction and the pressure-volume relationship. Oxford University Press, New York, 1988

21. Suga H, Sagawa K, and Shoukas AA: Load independence of the instantaneous pressure-volume ratio of the canine left ventricle and effects of epinephrine and heart rate on the ratio. Circ Res 32: 314-322, 1973

22. Suga $H$, and Sagawa K: Instantaneous pressure-volume relationships and their ratio in the excised, supported canine left ventricle. Circ Res 35: 117-126, 1974

23. Suga H, Hisano R, Goto Y, Yamada O, and Igarashi Y: Effect of positive inotropic agents on the relation between oxygen consumption and systolic pressurevolume are in canine left ventricle. Circ Res 53: 306318, 1983

24. Sagawa K: The ventricular pressure-volume diagram revised. Circ Res 43: 677-687, 1978

25. Sagawa K: The end-systolic pressure-volume relation of the ventricle: definition, modification and clinical use. Circulation 63: 1223-1227, 1978

26. Sagawa K, Sunagawa K, and Maughan WL: Ventricular end-systolic pressure-volume relations. In: Levin 
HJ, Gaasch WH (eds) The Ventricle. Basic and Clinical Aspects. Nijhoff, Boston, pp 79-103, 1985

27. Suga $H$, and Sagawa K: Mathematical interrelationship between instantaneous ventricular pressure-volume ration and myocardial force-velocity relation. Ann Biomed Eng 1: 160-181, 1972

28. Tsuji T, Onga Y, Yoshikawa Y, Sakata S, Kohzuki S, Misawa H, Abe T, Tabayashi N, Kobayashi S, Kitamura S, Taniguchi S, Suga H, and Takaki M: New index for oxygen cost of contractility from curved end-systolic pressure-volume relations in cross-circulated rat hearts. Jpn J Physiol 49: 513-520, 1999

29. Shroff SG, Janicki JS, and Weber KT: Left ventricular systolic dynamics in terms of its chamber mechanical properties. Am J Physiol Heart Circ Physiol 245: H110H124, 1983

30. Suga H, Yamada O, and Goto Y: Comments on "pressure-volume relationship in isolated cat trabecular which appeared in Circ Res. 49: 388-394, 1981". Circ Res 54: 208-209, 1984

31. Suga H: External mechanical work from relaxing ventricle. Am J Physiol Heart Circ Physiol 236: H494H497, 1979

32. Suga $\mathrm{H}$ : Relaxing ventricle performs more external work than quickly released elastic energy. Eur Heart $\mathrm{J}$ 1, Suppl A: 131-137, 1979

33. Suga H: Total internal mechanical work of ventricle assessed from quick release pressure-volume curve. Jpn J Physiol 29: 227-237, 1979

34. Suga H, Sagawa K, and Demer L: Determinants of instantaneous pressure in canine left ventricle. Time and volume specification. Circ Res 46: 256-263, 1980

35. Yasumura Y, Nozawa T, Futaki S, Tanaka N, and Suga $\mathrm{H}$ : Time-invariant oxygen cost of mechanical energy in dog left ventricle: consistency and inconsistency of time-varying elastance model with myocardial energetics. Circ Res 64: 763-778, 1989

36. Hunter WC, Janicki JS, Weber KT, and Noodergraaf A: Systolic mechanical properties of the left ventricle. Effects of volume and contractile state. Circ Res 52: 319-327, 1983

37. Little WC, and Freeman GL: Description of LV pressure-volume relations by time-varying elastance and source resistance. Am J Physiol Heart Circ Physiol 253: H83-H90, 1987

38. Vaartjes SR, Boom HBK, and Boom BK: Left ventricular internal resistance and unloaded ejection flow assessed from pressure-flow relations: a flow-clamp study on isolated rabbit hearts. Circ Res 60: 727-737, 1987

39. Kawaguchi O, Goto Y, Futaki S, Ohgoshi Y, Yaku H, Hata K, Takasago T, Saeki A, and Suga H: Ejecting deactivation does not affect $\mathrm{O}_{2}$ consumption-pressure-volume area relation in dog hearts. Am J Physiol Heart Circ Physiol 265: H934-H942, 1993

40. Yasumura $Y$, and Suga H: Cross-bridge model compatible with the linear relation between left ventricular oxygen consumption and pressure-volume area. Jpn Heart J 29: 335-347, 1988

41. Taylor TW, Goto.Y, and Suga H: Variable cross-bridge cycling-ATP coupling accounts for cardiac mechanoenergetics. Am J Physiol Heart Circ Physiol 264: H994-H1004, 1993
42. Woledge RC, Curtin NA, and Homsher E: Energetic aspects of muscle contraction. Academic, London, 1985

43. Yanagida T, Arata T, and Oosawa F: Sliding distance of actin filament induced by a myosin cross-bridge during one ATP hydrolysis cycle. Nature 316: 366369, 1985

44. Suga H, Goto Y, Kawaguchi O, Hata K, Takasago T, Saeki A, and Taylor TW: Ventricular perspective on efficiency. Basic Res Cardiol 88 (suppl 2): 43-65, 1993

45. Yagi N, Shimizu J, Mohri S, Araki J, Nakamura K, Okuyama H, Toyota H, Morimoto T, Morizane Y, Kurusu M, Miura T, Hashimoto K, Tsujioka K, Suga $H$, and Kajiya F: X-ray diffraction from a left ventricular wall of the heart. Biophys J, 2004 (in press)

46. Suga $H$, Futaki S, Ohgoshi $Y$, Yaku $H$, and Goto $Y$ : Arteriovenous oximeter for $\mathrm{O}_{2}$ content difference, $\mathrm{O}_{2}$ saturations, and hemoglobin content. Am J Physiol Heart Circ Physiol 257: H1712-H1716, 1989

47. Namba T, Takaki M, Araki J, Ishioka K, and Suga H: Energetics of the negative and positive inotropism of pentobarbitone sodium in the canine left ventricle. Cardiovasc Res 28: 557-564, 1994

48. Takaki M, Matsubara H, Araki J, Zhao LY, Ito H, Yasuhara $\mathrm{S}$, Fujii W, and Suga H: Mechanoenergetics of acute failing hearts characterized by oxygen costs of mechanical energy and contractility. In: Sasayama S (ed). New Horizons for Failing Heart Syndrome. Tokyo, Japan: Springer-Verlag, pp 133-164, 1996.

49. Suga H, Hayashi T, and Shirahata M: Ventricular systolic pressure-volume area as predictor of cardiac oxygen consumption. Am J Physiol Heart Circ Physiol 240, H39-H44, 1981

50. Hisano R, and Cooper G IV: Correlation of force-length area with oxygen consumption in ferret papillary muscle. Circ Res 61: 318-328, 1987

51. Hata K, Goto Y, and Suga H: External mechanical work during relaxation period does not affect myocardial oxygen consumption. Am J Physiol Heart Circ Physiol 261: H1778-H1784, 1991

52. Takaki M, Akashi T, Ishioka K, Kikuta A, Matsubara H, Yasuhara S, Fujii W, and Suga H: Effects of capsaicin on mechanoenergetics of excised cross-circulated canine left ventricle and coronary artery. J Mol Cell Cardiol 26: 1227-1239, 1994

53. Araki J, Takaki M, Namba T, Mori M, and Suga $H$ : Short-term $\mathrm{Ca}^{2+}$ free-high $\mathrm{Ca}^{2+}$ coronary perfusion suppresses contractility and excitation-contraction coupling energy in canine hearts. Am J Physiol Heart Circ Physiol 268: H1061-H1070, 1995

54. Elzinga G: Cardiac oxygen consumption and the production of heat and work. In: Drake-Holland AJ, Noble MIM (eds) Cardiac Metabolism, Wiley, New York, pp 173-194, 1983

55. Ruegg JC: Calcium in muscle activation. Springer Verlag, Berlin, 1988

56. Suga H, Goto Y, Futaki S, Kawaguchi O, Yaku H, Hata $\mathrm{K}$, and Takasago T: Calcium kinetics and energetics in myocardium. Simulation study. Jpn Heart J 32: $57-$ 67, 1991

57. Ohgoshi Y, Goto Y., Futaki S, Yaku H, Kawaguchi O, and Suga $\mathrm{H}$ : New method to determine oxygen cost for contractility. Jpn J Physiol 40: 127-138, 1990 


\section{TAKAKI}

58. Yasumura Y, Nozawa T, Futaki S, Tanaka N, and Suga $\mathrm{H}$ : Minor preload dependence of $\mathrm{O}_{2}$ consumption of unload contraction in dog heart. Am J Physiol Heart Circ Physiol 256: H1289-H1294, 1989

59. Tada M, Shigekawa M, Kadoma M, and Nimura Y: Uptake of calcium by sarcoplasmic reticulum and its regulation and functional consequences. In: Sperelakis $\mathrm{N}$ (ed). Physiology and pathophysiology of the heart, 3rd edn. Kluwer Academic, Boston, pp 267-290, 1989

60. duBell WH, and Houser SR: Voltage and beat dependence of the $\mathrm{Ca}^{2+}$ transient in feline ventricular myocytes. Am J Physiol Heart Circ Physiol 257: H746H759, 1989

61. Beukelmann DJ, and Wier WG: Mechanism of release of $\mathrm{Ca}^{2+}$ from sarcoplasmic reticulum of guinea-pig cardiac cells. J Physiol 405: 233-255, 1988

62. Niggli E, and Lederer WJ: Voltage-independent calcium release in heart muscle. Science 250: 565-568, 1990

63. Barry WH, and Bridge JHB: Intracellular calcium homeostasis in cardiac myocytes. Circulation 87: 18061815, 1993

64. Fabiato A: Calcium induced release of calcium from the cardiac sarcoplasmic reticulum. Am J Physiol Cell Physiol 245: C1-C14, 1983

65. Moss $\mathrm{RL}: \mathrm{Ca}^{2+}$ regulation of mechanical properties of striated muscle. Circ Res 70: 865-884, 1992

66. Fabiato A: Time and calcium dependence of activation and inactivation of calcium-induced release of calcium from sarcoplasmic reticulum of a skinned canine cardiac Purkinje cell. J Gen Physiol 85: 247289, 1985

67. Tada M, and Katz AM: Phosphorylation of the sarcoplasmic reticulum and sarcolemma. Ann Rev Physiol 44: 401-423, 1982

68. Tada M, Yamamoto T, and Tonomura Y: Molecular mechanism of active calcium transport by sarcoplasmic reticulum. Physiol Rev 58: 1-79, 1978

69. Allen DG, and Kurihara S: Calcium transients in mammalian ventricular muscle. Eur Heart J 1 (Suppl A): 515, 1980

70. Endoh M, and Blinks JR: Actions of sympathomimetic amines on the $\mathrm{Ca}^{2+}$ transients and contractions of rabbit myocardium: reciprocal changes in myofibrillar responsiveness to $\mathrm{Ca}^{2+}$ mediated through $\alpha$ - and $\beta$ adrenoceptors. Circ Res 62: 247-265, 1988

71. Yue DT, Burkhoff D, Franz MR, Hunter WC, and Sagawa $\mathrm{K}$ : Postextrasystolic potentiation of the isolated canine left ventricle: relationship to mechanical restitution. Circ Res. 56: 340-350, 1985

72. Katz AM, and Repke DI: Calcium-membrane interactions in the myocardium: effects of ouabain, epinephrine, and 3', 5'-cyclic adenosine monophosphate. Am J Cardiol 31: 193-201, 1985

73. Bassani RA, Bassani JW, and Bers DM: Mitochondrial and sarcolemmal $\mathrm{Ca}^{2+}$ transports reduce $[\mathrm{Ca}]_{i}$ during caffeine contractures in rabbit cardiac myocytes. J Physiol 453: 591-608, 1992

74. Bers DM, Lederer WJ, and Berlin JR: Intracellular Ca transients in rat cardiac myocytes: role of $\mathrm{Na}-\mathrm{Ca}$ exchange in excitation-contraction coupling. Am J Physiol Cell Physiol 258: C944-C954, 1990

75. Gibbs CL, and Chapman JB: Cardiac mechanics and energetics: chemomechanical transduction in cardiac muslce. Am J Physiol Hear Circ Physiol 249: H199H206, 1985

76. Hasselbach $W$, and Oetliker $H$ : Energetics and electrogenicity of the sarcoplasmic reticulum calcium pump. Ann Rev Physiol 45: 325-339, 1983

77. Gibbs CL: Cardiac energetics, In: Ter Keurs HEDJ, Tyberg JV (ed) Mechanics of the circulation, Nijhoff, Dordrecht, pp 69-86, 1987

78. Pierce GN, Philipson KD, and Langer GA: Passive calcium-buffering capacity of a rabbit ventricular homogenate preparation. Am J Physiol Cell Physiol 249: C248-255, 1985

79. Wier WG, and Yue DT: Intracellular calcium transients underlying the short-term force-interval relationship in ferret ventricular myocardium. J Physiol (Lond) 376: 507-530, 1986

80. Nozawa T, Yasumura Y, Futaki S, Tanaka N, and Suga $\mathrm{H}$ : No significant increase in $\mathrm{O}_{2}$ consumption of $\mathrm{KCl}$ arrested dog heart with filling and dobutamine. Am J Physiol Heart Circ Physiol 255: H807-H812, 1988

81. Gibbs CL: Modification of physiological determinants of cardiac energy expenditure by pharmacological agents. Pharmacol Ther 18:133-157, 1982

82. Suga H, Yasumura Y, Nozawa T, Futaki S, Tanaka N, and Uenishi M: Pressure-volume relationship around zero transmural pressure in excised cross-circulated dog left ventricle. Circ Res 63: 361-372, 1988

83. Alpert NR, Blanchard EM, and Mulieri LA: Tensionindependent heat in rabbit papillary muscle. J Physiol 414: 433-453, 1989

84. Yaku H, Slinker BK, Mochizuki T, Lorell BH, and Lewinter MM: Use of 2,3-butanedione monoxime to estimate nonmechanical $\mathrm{VO}_{2}$ in rabbit hearts. Am $\mathrm{J}$ Physiol Heart Circ Physiol 265: H834-842, 1993

85. Higashiyama A, Watkins MW, Chen Z, and LeWinter MM: Preload does not influence nonmechanical $\mathrm{O}_{2}$ consumption in isolated rabbit heart. Am J Physiol Heart Circ Physiol 266: H1047-H1054, 1994

86. Blanchard EM, Smith GL, Allen DG, and Alpert NR: The effects of 2,3-butanedione monoxime on initial heat, tension, and aequorin light output of ferret papillary muscles. Pfügers Arch 416: 219-221, 1990

87. Perreault CL, Mulieri, Alpert NR, Ransil BJ, Allen PD, and Morgan JP: Cellular basis of 2,3-butanedione monoxime in human myocardium. Am J Physiol Heart Circ Physiol 263: H503-H510, 1992

88. Gwathmey JK, Hajjar RJ, and Solaro RJ: Contractile deactivation and uncoupling of crossbridges. Effects of 2,3-butanedione monoxime on mammalian myocardium. Circ Res 69: 1280-1292, 1991

89. de Tombe PP, Burkhoff D, and Hunter WC: Comparison between the effects of 2,3-butandione monoxime (BDM) and calcium chloride on myocardial oxygen consumption. J Mol Cell Cardiol 24: 783-797, 1992

90. Baan J, van der Velde ET, de Bruin HG, Smeenk GJ, Koops J, van Dijk AD, Temmerman D, Senden J, and Buis B: Continuous measurement of left ventricular volume in animals and humans by conductance catheter. Circulation 70: 812-823, 1984

91. Burkhoff D, van der Velde E, Kass D, Baan J, Maughan WL, and Sagawa K: Accuracy of volume measurement by conductance catheter in isolated, ejecting 
canine hearts. Circulation 72: 440-447, 1985

92. Nozawa T, Yasumura Y, Futaki S, Tanaka N, Uenishi $M$, and Suga $H$ : Efficiency of energy transfer from pressure-volume area to external mechanical work increases with contractile state and decreases with afterload in the left ventricle of the anesthetized closedchest dog. Circulation 77: 1116-1124, 1988

93. Ito $\mathrm{H}$, Takaki $\mathrm{M}$, Yamaguchi $\mathrm{H}$, Tachibana $\mathrm{H}$, and Suga $\mathrm{H}$ : Left ventricular volumetric conductance catheter for rats. Am J Physiol Heart Circ Physiol 270: H1509_ H1514, 1996

94. Kitagawa $Y$, Yamashita D, Ito $H$, and Takaki M: Reversible effects of isoproterenol-induced hypertrophy on in situ left ventricular function in rat hearts. Am J Physiol Heart Circ Physiol 287: 2004 (in press)

95. Misawa H, Kohzuki H, Sakata S, Ohga Y, and Takaki $\mathrm{M}$ : Oxygen wasting for $\mathrm{Ca}^{2+}$ extrusion activated by partial inhibition of sarcoplasmic reticulum $\mathrm{Ca}^{2+}$-ATPase by cyclopiazonic acid in rat left ventricles. Jpn J Physiol 51: 99-108, 2001

96. Tachibana H, Takaki M, Lee S, Ito H, Yamaguchi $H$, and Suga $\mathrm{H}$ : New mechanoenergetic evaluation of left ventricular contractility in in situ rat hearts. Am J Physiol Heart Circ Physiol 272: H2671-H2678, 1997

97. Lee S, Ohga $Y$, Tachibana $H$, Syuu $Y$, Ito H, Harada M, Suga $H$, and Takaki M: Effects of myosin isozyme shift on curvilinearity of the left ventricular end-systolic pressure-volume relation of in situ rat hearts. Jpn J Physiol 48: 445-455, 1998

98. Suga $H$, Yamada $O$, Goto $Y$, Igarashi $Y$, Yasumura $Y$, Nozawa T, and Futaki S: Left ventricular $\mathrm{O}_{2}$ consumption and pressure-volume area in puppies. Am J Physiol Heart Circ Physiol 253: H770-H776, 1987

99. Hata $Y$, Sakamoto T, Hosogi S, Ohe T, Suga $H$, and Takaki $\mathrm{M}$ : Linear $\mathrm{O}_{2}$ use-pressure-volume area relation from curved end-systolic pressure-volume relation of the blood-perfused rat left ventricle. Jpn J Physiol 48: 197-204, 1998

100. Suga H, Yamada O, Goto Y, and Igarashi Y: Peak isovolumic pressure-volume relation of puppy left ventricle. Am J Physiol Heart Circ Physiol 25: H167-H172, 1986

101. Kishi T, Nakahashi K, Ito H, Taniguchi S, and Takaki M: Effects of milrinone on left ventricular end-systolic pressure-volume relationship of rat hearts in situ. Clin Exp Pharmacol Physiol 28: 737-742, 2001

102. Fabiato A: Myoplasmic free calcium concentration reached during the twitch of an intact isolated cardiac cell and during calcium-induced release of calcium from the sarcoplasmic reticulum of a skinned cardiac cell from the adult rat or rabbit ventricle. J Gen Physiol 78: 457-495, 1981

103. Kentish JC, ter Keurs HEDJ, Ricciardi L, Bucx JJJ, and Noble MIM: Comparison between the sarcomere length-force relations of intact and skinned trabeculae from rat right ventricle. Circ Res 58: 755-768, 1986

104. Suga $H$, Yasumura $Y$, Nozawa T, Futaki S, Igarashi $Y$, and Goto Y: Prospective prediction of $\mathrm{O}_{2}$ consumption and pressure-volume area in dog hearts. Am J Physiol Heart Circ Physiol 252: H1258-H1264, 1987

105. Goto Y, Slinker BK, and Lewinter MM: Similar normalized Emax and oxygen consumption-pressure-volume area relation in rabbit and dog hearts. Am J Physiol
Heart Circ Physiol 255: H366-H374, 1988

106. Goto Y, Slinker BK, and Lewinter MM: Decreased contractile efficiency and increased nonmechanical energy cost in hyperthyroid rabbit heart: relation between $\mathrm{O}_{2}$ consumption and systolic pressure-volume area or force-time integral. Circ Res 66: 999-1011, 1990

107. Wannenburg T, Schulman SP, and Burkhoff D: Endsystolic pressure-volume and $\mathrm{MVO}_{2}$-pressure-volume relations of isolated rat hearts. Am J Physiol Heart Circ Physiol 262: H1287-H1293, 1993

108. Gibbs CL, Papadoyannis DE, Drake AJ, and Noble MIM: Oxygen consumption of the nonworking and potassium chloride-arrested dog heart. Circ Res 47: 408-417, 1980

109. Yasuhara S, Takaki M, Kikuta A, Ito $H$, and Suga $H$ : Myocardial $\mathrm{VO}_{2}$ of mechanically unloaded contraction of rat ventricular slices measured by a new approach. Am J Physiol 270: H1063-H1070, 1996

110. Lewartowski B, and Wolska BM: The effect of thapsigargin on sarcoplasmic reticulum $\mathrm{Ca}^{2+}$ content and contraction in single myocytes of guinea-pig heart. J Mol Cell Cardiol 25: 233-29, 1993a

111. Lewartowski B, and Wolska BM: The effect of thapsigargin on sarcoplasmic reticulum $\mathrm{Ca}^{2+}$ content and contractions of single myocytes of rat ventricular myocardium. J Physiol Pharmacol 44: 243-250, 1993b

112. Negretti N, O'neil SC, and Eisner DA: The effects of inhibitors of sarcoplasmic reticulum function of the systolic $\mathrm{Ca}^{2+}$ transient in rat ventricular myocytes. J Physiol (London) 68: 35-52, 1993

113. Gibbs CL, and Loiselle DS: Cardiac basal metabolism. Jpn J Physiol 51: 399-426, 2001

114. Loiselle DS, and Gibbs CL: Species differences in cardiac energetics. Am J Physiol Heart Circ Physiol 237: H90-H98, 1979

115. Takaki M, Kohzuki H, Kawatani Y, Yoshida A, Ishidate $\mathrm{H}$, and Suga $\mathrm{H}$ : Sarcoplasmic reticulum $\mathrm{Ca}^{2+}$ pump blockade decreases $\mathrm{O}_{2}$ use of unloaded contracting rat heart slices: Thapsigargin and cyclopiazonic acid. J Mol Cell Cardiol 30: 649-659, 1998

116. Ebus JP, and Stienen JM: Origin of concurrent ATPase activities in skinned cardiac trabeculae from rat. J Physiol (London) 492: 675-687, 1996

117. Hata $Y$, Sakamoto T, Hosogi S, Ohe T, Suga $H$, and Takaki M: Effects of thapsigargin and $\mathrm{KCl}$ on the $\mathrm{O}_{2}$ use of the excised blood-perfused rat heart. $\mathrm{J}$ Mol Cell Cardiol 30: 2137-2143, 1998

118. Kass DA, Beyar R, Lankford E, Heard M, Maughan WL, and Sagawa K: Influence of contractile state on curvilinearity of in situ end-systolic pressure-volume relations. Circulation 79: 167-178, 1989

119. Nakayama Y, Takaki M, Kohno K, Araki J, and Suga $\mathrm{H}$ : Mechanoenergetics of the negative inotropism of isoflurane in the canine left ventricle. $\mathrm{No} \mathrm{O}_{2}$ wasting effect. Anesthesiology 87: 82-93, 1997

120. Shimizu J, Araki J, Mizuno J, Lee S, Syuu Y, Hosogi S, Mohri S, Mikane T, Takaki M, Taylor TW, and Suga H: A new integrative method to quantify total $\mathrm{Ca}^{2+}$ handling and futile $\mathrm{Ca}^{2+}$ cycling in failing hearts. Am J Physiol Heart Circ Physiol 275: H 2325-2333, 1998

121. Opie LH: Chap.7 Receptors and signal transduction. In: The Heart. Physiology, from Cell to Circulation. 


\section{TAKAKI}

Lippincott-Raven Press, Philadelphia, New York, pp. 173-207, 1998

122. Banijamali HS, Gao W-D, Macintosh BR, and ter Keurs HEDJ: Force-interval relations of twitches and cold contractures in rat cardiac trabeculae. Effect of ryanodine. Circ Res 69: 937-948, 1991

123. Negretti N, O'neill SC, and Eisner DA: The relative contributions of different intracellular and sarcolemmal systems to relaxation in rat ventricular myocytes. Cardiovasc Res 27: 1826-1830, 1993

124. Sakata S, Ohga Y, Kohzuki H, Misawa H, Mochizuki S, Kajiya F, and Takaki M: Sodium nitroprusside on rat left ventricular mechanoenergetics. J Mol Cell Cardiol 32: A115-P66, 2000 (Abstract)

125. Duwel CMB, and Westerhof N: Feline left ventricular oxygen consumption is not affected by volume expansion, ejection or redevelopment of pressure during relaxation. Pflügers Arch 412: 409-416, 1988

126. Holroyd SM, and Gibbs CL: Is there a shorteningheat component in mammalian cardiac muscle contraction? Am J Physiol Heart Circ Physiol 262: H200H208, 1992

127. Kohzuki H, Misawa $H$, Sakata $S$, Ohga $Y$, Suga $H$, and Takaki M: Energy expenditure by $\mathrm{Ba}^{2+}$ contracture in rat ventricular slices derives from cross-bridge cycling. Am J Physiol Heart Circ Physiol 277: H74-H79, 1999

128. Delbridge LM, and Loiselle DS: An ultrastructural investigation into the size dependency of contractility of isolated cardiac muscle. Cardiovasc Res 15: 2127, 1981

129. Grote J, and Thews G: Die Bedingungen für die Sauerstoff-versorgung des Herzmuskelgewebes. Pflügers Arch 276: 142-165, 1962

130. Loiselle DS: The effects of temperature on the energetics of rat papillary muscle. Pflügers Arch 379: 173-180, 1979

131. Schramm M, Klieber H-G, and Daut J: The energy expenditure of actomyosin-ATPase, $\mathrm{Ca}^{2+}$-ATPase and $\mathrm{Na}^{+}, \mathrm{K}^{+}$-ATPase in guinea-pig cardiac ventricular muscle. J Physiol 481. 3: 647-662, 1994

132. Hata K, Goto Y, Kawaguchi O, Takasago T, Saeki A, Nishioka $\mathrm{T}$, and Suga $\mathrm{H}$ : Hypercapnic acidosis increases oxygen cost of contractility in the dog left ventricle. Am J Physiol Heart Circ Physiol 266: H730740, 1994

133. Agata N, Tanaka H, and Shigenobu K: Possible action of cyclopiazonic acid on myocardial sarcoplasmic reticulum: inotropic effects on neonatal and adult rat heart. Brit J Pharmacol 108: 571-572, 1993

134. Janczewski AM, and Lakatta EG: Thapsigargin inhibits $\mathrm{Ca}^{2+}$ uptake, and $\mathrm{Ca}^{2+}$ depletes sarcoplasmic reticulum in intact cardiac myocytes. Am J Physiol Heart Circ Physiol 265: H517-H522, 1993

135. Lewartowski $B$, and Wolska $B$ : The effect of thapsigargin on sarcoplasmic reticulum $\mathrm{Ca}^{2+}$ content and contractions of single myocytes of rat ventricular myocardium. J Physiol Pharmacol 44: 243-250, 1993

136. Takahashi S, Kato $Y$, Adachi M, Agata N, Tanaka H, and Shigenobu K: Effects of cyclopiazonic acid on rat myocardium: Inhibition of calcium uptake into sarcoplasmic reticulum. J Pharmacol Exp Ther 272: 10951100, 1995
137. Wrzosek A, Schneider H, Grueninger S, and Chiesi M: Effect of thapsigargin on cardiac muscle cells. Cell Calcium 13: 281-292, 1992

138. Sipido KR, and Wier WG: Flux of $\mathrm{Ca}^{2+}$ across the sarcoplasmic reticulum of guinea-pig cardiac cells during excitation-contraction coupling. J Physiol 435: 605-630, 1991

139. Baudet S, Shaoulian R, and Bers DM: Effects of thapsigargin and cyclopiazonic acid on twitch force and sarcoplasmic reticulum $\mathrm{Ca}^{2+}$ content of rabbit ventricular muscle. Circ Res 73: 813-819, 1993

140. Tanaka T, Komukai K, Kawai M, Tanaka E, and Kurihara S: Effects of thapsigargin on aequorin-injected and skinned preparations of ferret ventricular muscles. Cardiovasc Res 30: 357-362, 1995

141. Janiak R, Lewartowski $B$, and Langer GA: Functional coupling between sarcoplasmic reticulum and $\mathrm{Na} / \mathrm{Ca}$ exchange in single myocytes of guinea-pig and rat heart. J Mol Cell Cardiol 28: 253-264, 1996

142. Murphy AM, Kogler H, Georgakopoulos D, McDonough $\mathrm{JL}$, Kass DA, Van Eyk JE, and Marban E: Transgenic mouse model of stunned myocardium. Science 287 : 488-491, 2000.

143. Nerbonne JM, Nichols CG, Schwarz TL, and Escande D: Genetic manipulation of cardiac $\mathrm{K}^{+}$channel function in mice. Circ Res 89: 944-956, 2001

144. Shi S, Chang B, and Brunnert SR. Identification and cloning of a truncated isoform of the cardiac sodiumcalcium exchanger in the BALB/c mouse heart. Biochemical Genetics 36: 119-135, 1998

145. Hilal-Dandan R, Kanter JR, and Brunton LL: Characterization of $\mathrm{G}$-protein signaling in ventricular myocytes from the adult mouse heart: Differences from the rat. J Mol Cell Cardiol 32: 1211-1221, 2000

146. Gao WD, Perez NG, and Marban E: Calcium cycling and contractile activation in intact mouse cardiac muscle. J Physiol 507: 175-184, 1998

147. Georgakopoulos D, and Kass DA: Minimal force-frequency modulation of inotropy and relaxation of in situ murine heart. J Physiol 534: 535-545, 2001

148. Grupp IL, Subramaniam A, Hewett TE, Robbins J, and Grupp G: Comparison of normal, hypodynamic, and hyperdynamic mouse hearts using isolated workperforming heart preparations. Am J Physiol Heart Circ Physiol 265: H1401-H1410, 1993

149. Kass DA, Hare JM, and Georgakopoulos D: Murine cardiac function. A cautionary tail. Circ Res 82: 519 522, 1998

150. Kameyama T, Chen Z, Bell SP, Fabian J, and LeWinter MM: Mechanoenergetic studies in isolated mouse hearts. Am J Physiol Heart Circ Physiol 274: H366H374, 1998

151. Kameyama T, Chen Z, Bell SP, VauBuren P, Maughan $\mathrm{D}$, and LeWinter MM: Mechanoenergetic alterations during the transition from cardiac hypertrophy to failure in Dahl salt-sensitive rats. Circulation 98: 29192929, 1998

152. Harasawa $Y$, de Tombe PP, Sheriff DD, and Hunter WC: Basal metabolism adds a significant offset to unloaded myocardial oxygen consumption per minute. Circ Res 71: 414-422, 1992

153. Higashiyama A, Watkins MW, Chen Z, and LeWinter MM: Estimation of nonmechanical $\mathrm{VO}_{2}$ in isolated rabbit 
heart: comparison of mechanical loading and BDM method. Am J Physiol Heart Circ Physiol 273: H1032H1037, 1997

154. Adams W, Trafford AW, and Eisner DA: 2,3-Butanedione monoxime (BDM) decreases sarcoplasmic rericulum $\mathrm{Ca}$ content by stimulating $\mathrm{Ca}$ release in isolated rat ventricular myocytes. Pflügers Arch 436: 776-781, 1998

155. Maesako M, Araki J, Lee S, Doi Y, Imaoka T, Iribe G, Mohri S, Hirakawa M, Harada M, and Suga H: 2,3Butanedione monoxime suppresses primarily total calcium handling in canine heart. Jpn J Physiol 50: 543-551, 2000

156. Phillips RM, and Altschuld RA. 2,3-Butanedione 2monoxime (BDM) induces calcium release from canine cardiac sarcoplasmic reticulum. Biochem Biophys Res Commun 229: 154-157, 1996

157. Hongo K, Kusakari Y, Kawai M, Konishi M, Kurihara S, and Mochizuki S: Use of tetanus to investigate myofibrillar responsiveness to $\mathrm{Ca}^{2+}$ in isolated mouse ventricular myocytes. Jpn J Physiol 52: 121-127, 2002

158. Hata K, Takasago T, Saeki A, Nishioka T, and Goto Y: Stunned myocardium after rapid correction of acidosis. Circ Res 74: 794-805, 1994

159. Ohgoshi Y, Goto Y, Futaki S, Yaku H, Kawaguchi O, and Suga $\mathrm{H}$ : Increased oxygen cost of contractility in stunned myocardium of dog. Circ Res 69: 975-988, 1991

160. McDonough JL, Arrell DK, and Van Eyk JE: Troponin I degradation and covalent complex formation accompanies myocardial ischemia/reperfusion injury. Circ Res 84: 9-20, 1999

161. Yoshida K, and Harada K: Proteolysis of erythrocytetype and brain-type ankyrins in rat heart after postischemic reperfusion. J Biochem 122: 279-285, 1997

162. Yoshida K, Inui M, Harada K, Saido TC, Sorimachi Y, Ishihara T, Kawasima S, and Sobue K: Reperfusion of rat heart after brief ischemia induces proteolysis of calspectin (nonerythroid spectrin or fodrin) by calpain. Circ Res 77: 603-610, 1995

163. Yoshida K, Sorimachi $Y$, Fujiwara M, and Hironaka K: Calpain is implicated in rat myocardial injury after ischemia or reperfusion. Jpn Circ J 59: 40-48, 1995

164. Iwamoto H, Miura T, Okamura T, Shirakawa K, Iwatate M, Kawamura S, Tatsuno H, Ikeda Y, and Matsuzaki $M$ : Calpain inhibitor-1 reduces infarct size and DNA fragmentation of myocardium in ischemic/reperfused rat heart. J Cardiovasc Pharmacol 33: 580-586, 1999

165. Bennett V: Spectrin-based membrane skeleton:a multipotential adaptor between plasma membrane and cytoplasm. Physiol Rev 70: 1029-1065, 1990

166. Lazarides E, and Nelson WJ: Erythrocyte and brain forms of spectrin in cerebellum: distinct membranecytoskeletal domains in neurons. Science 220: 12951296, 1983

167. Galli A, and DeFelice LJ: Inactivation of L-type $\mathrm{Ca}^{2+}$ channels in embryonic chick ventricle cells: dependence on the cytoskeletal agents colchicine and taxol. Biophys J 67: 2296-2304, 1994

168. Nakamura M, Sunagawa M, Kosugi $T$, and Sperelaki $\mathrm{N}$ : Actin filament disruption inhibits L-type $\mathrm{Ca}^{2+}$ channel current in cultured vascular smooth muscle cells. Am J Physiol Cell Physiol 279: C480-487, 2000
169. Yamaji $\mathrm{T}$, Fukuhara $\mathrm{T}$, and Kinoshita $\mathrm{M}$ : Increased capillary permeability to albumin in diabetic rat myocardium. Circ Res 72: 947-957, 1993

170. Yu Z, Rodrigues B, and Mcneill JH: Intracellular calcium levels are unchanged in the diabetic heart. Cardiovasc Res 34: 91-98, 1997

171. Kawano K, Hirashima T, Mori S, Saito Y, Kurosumi M, and Natori T: Spontaneous long-term hyperglycemic rat with diabetic complications; Otsuka Long-Evans Tokushima Fatty (OLETF) strain. Diabetes 41: 14221428, 1992

172. Mizushige K, Yao L, Noma T, Kiyomoto H, Yu Y, Hosomi $\mathrm{N}$, Ohmori K, and Matsuo $\mathrm{H}$ : Alteration in left ventricular diastolic filling and accumulation of myocardial collagen at insulin-resistant prediabetic stage of a type II diabetic rat model. Circulation 101: 899-907, 2000

173. Ohno M, Cheng CP, and Little WC: Mechanism of altered patterns of left ventricular filling during the development of congestive heart failure. Circulation 89: 2241-2251, 1994

174. Matsubara H, Takaki M, Yasuhara S, Araki J, and Suga $\mathrm{H}$ : Logistic time constant of isovolumic relaxation pressure-time curve in the canine left ventricle. Better alternative to exponential time constant. Circulation 92: 2318-2326, 1995

175. Schaffer SW, Allo S, Punna S, and White T: Defective response to $\mathrm{CAMP}$-dependent protein kinase in noninsulin-dependent diabetic heart. Am J Physiol Endocrinology Metabolism 261: E376-E396, 1991

176. Hoh, JFY, McGrath PA, and Hale PT: Electrophoretic analysis of multiple forms of rat cardiac myosin: Effects of hypophysectomy and thyroxine replacement. J Mol Cell Cardiol 10: 1053-1076, 1977

177. Lompre AM, Mercadier JJ, Wisnewsky C, Bouveret P, Pantaloni C, D'Albis A, and Schwartz K: Species- and age-dependent changes in the relative amounts of cardiac myosin isoenzymes in mammals. Develop Biol 84: 286-290, 1981

178. Holubarsch C, Goulette RP, Litten RZ, Martin BJ, Mulieri $L A$, and Alpert NR: The economy of isometric force development, myosin isoenzyme pattern and myofibrillar ATPase activity in normal and hypothyroid rat myocardium. Circ Res 56: 78-86, 1985

179. Sugiura S, Kobayakawa N, Fujita $H$, Yamashita $H$, Momomura S, Chaen S, Omata M, and Sugi H: Comparison of unitary displacements and forces between 2 cardiac myosin isoforms by the optical trap technique. Molecular basis for cardiac adaptation. Circ Res 82: 1029-1034, 1998

180. Ebrecht $\mathrm{G}$, Rupp $\mathrm{H}$, and Jacob R: Alterations of mechanical parameters in chemically skinned preparations of rat myocardium as a function of isoenzyme pattern of myosin. Basic Res Cardiol 77: 220-234, 1982

181. Black SC, McNeill JH, and Katz S: Cardiac sarcoplasmic reticulum calcium transport activity of thyroidectomized rats: The role of endogenous myocardial acylcarnitines and calcium pump protein. Pharmacology 46: 130-141, 1993

182. Bluhm WF, Meyer M, Sayen MR, Swanson EA, and Dillmann WH: Overexpression of sarcoplasmic reticulum $\mathrm{Ca}^{2+}$-ATPase improves cardiac contractile func- 


\section{TAKAKI}

tion in hypothyroid mice. Cardiovasc Res 43: 382388, 1999

183. Holt E, Sjaastad I, Lunde PK, Christensen G, and Sejersted OM: Thyroid hormone control of contraction and the $\mathrm{Ca}^{2+}$-ATPase/phospholamban complex in adult rat ventricular myocytes. J Mol Cell Cardiol 31: 645-656, 1999

184. Kimura Y, Otsu K, Nishida K, Kuzuya T, and Tada M: Thyroid hormone enhances $\mathrm{Ca}^{2+}$ pumping activity of the cardiac sarcoplasmic reticulum by increasing $\mathrm{Ca}^{2+}$ ATPase and decreasing phospholamban expression. J Mol Cell Cardiol 26: 1145-1154, 1994

185. Kiss E, Brittsan AG, Edes I, Grupp IL, Grupp G, and Kranias EG: Thyroid hormone-induced alterations in phospholamban-deficient mouse hearts. Circ Res 83: 608-613, 1998

186. Kiss E, Jakab G, Kranias EG, and Edes I: Thyroid hormone-induced alterations in phospholamban protein expression. Regulatory effects on sarcoplasmic reticulum $\mathrm{Ca}^{2+}$ transport and myocardial relaxation. Circ Res 75: 245-251, 1994

187. Reed TD, Babu GJ, Ji Y, Zilberman A, Heyen MV, Wuytack F, and Periasamy M: The expression of SR calcium transport ATPase and the $\mathrm{Na}^{+} / \mathrm{Ca}^{2+}$ exchanger are antithetically regulated during mouse cardiac development and in hypo/hyperthyroidism. J Mol Cell Cardiol 32: 453-464, 2000

188. Rohrer D and Dillmann WH: Thyroid hormone markedly increases the mRNA coding for sarcoplasmic reticulum $\mathrm{Ca}^{2+}$-ATPase in the rat heart. J Biol Chem 263: 6941-6944, 1988

189. Suga H, Tanaka N, Ohgoshi $Y$, Saeki $Y$, Nakanishi $T$, Futaki S, Yaku H, and Goto Y: Hyperthyroid dog left ventricle has the same oxygen consumption versus pressure-volume area (PVA) relation as euthyroid dog. Heart Vessels 6: 71-83, 1991

190. Pillar TM, and Seitz HJ: Thyroid hormone and gene expression in the regulation of mitochondrial respiratory function. Eur J Endocrinol 136: 231-239, 1997

191. Paradies G, Petrosillo G, and Ruggiero FM: Cardiolipin-dependent decrease of cytochrome c oxidase activity in heart mitochondria from hypothyroid rats. Biochim Biophys Acta 1319: 5-8, 1997

192. Kaasik A, Minajeva A, Paju K, Eimre M, and Seppet EK: Thyroid hormones differentially affect sarcoplasmic reticulum function in rat atria and ventricles. Mol Cell Biochem 176: 119-126, 1997

193. Cernohorsky J, Kolár F, Pelouch V, Korecky B, and Vetter R: Thyroid control of sarcolemmal $\mathrm{Na}^{+} / \mathrm{Ca}^{2+}$ exchanger and $\mathrm{SR} \mathrm{Ca}^{2+}$-ATPase in developing rat heart. Am J Physiol Heart Circ Physiol 275: H264-H273, 1998

194. Shenoy R, Klein I, and Ojamaa K: Differential regulation of SR calcium transporters by thyroid hormone in rat atria and ventricles. Am J Physiol Heart Circ Physiol 281: H1690-H1696, 2001

195. Arai M, Otsu K, MacLennan DH, Alpert NR, and Periasamy M: Effect of thyroid hormone on the expression of mRNA encoding sarcoplasmic reticulum proteins. Circ Res 69: 266-276, 1991

196. del Monte F, Williams E, Lebeche D, Schmidt U, Rosenzweig A, Gwathmey JK, Lewandowski ED, and Hajiar RJ: Improvement in survival and cardiac metabolism after gene transfer of sarcoplasmic reticu- lum $\mathrm{Ca}^{2+}$-ATPase in a rat model of heart failure. Circulation 104: 1424-1429, 2001

197. del Monte F, and Hajjar RJ: Targeting calcium cycling proteins in heart failure through gene transfer. J Physiol (Lond) 546: 49-61, 2002

198. Gwathmey JK, and Morgan JP: Altered calcium handling in experimental pressure-overload hypertrophy in the ferret. Circ Res 57: 836-843, 1985

199. Gwathmey JK, Bentivegna LA, Ransil BJ, Grossman W, and Morgan JP: Relationship of abnormal intracellular calcium mobilisation to myocyte hypertrophy in human ventricular myocardium. Cardiovasc Res 27: 199-203, 1993

200. Gwathmey JK, and Hajjar RJ: Relation between steadystate force and intracellular $\left[\mathrm{Ca}^{2+}\right]$ in intact human myocardium. Index of myofibrillar responsiveness to $\mathrm{Ca}^{2+}$. Circulation 82: 1266-1278, 1990

201. Davidoff AJ, and Gwathmey JK: Pathophysiology of cardiomyopathies: Part I. Animal models and humans. Curr Opin Cardiol 9: 357-368, 1994

202. Force T, Hajjar R, del Monte F, Rosenzweig A, and Choukroun G: Signaling pathways mediating the response to hypertrophic stress in the heart. Gene Expr 7: 337-348, 1999

203. Hajjar RJ, Schwinger RH, Schmidt U, Kim CS, Lebeche D, Doye AA, and Gwathmey JK: Myofilament calcium regulation in human myocardium. Circulation 101: 1679-1685, 2000

204. Hajjar RJ, del Monte F, Matsui T, and Rosenzweig A: Prospects for gene therapy for heart failure. Circ Res 86: 616-621, 2000

205. del Monte F, Williams E, Lebeche D, Schmidt U, Rosenzweig A, Gwathmey JK, Lewandowski DE, and Hajjar RJ: Improvement in survival and cardiac metabolism following gene transfer of SERCA2a in a rat model of heart failure. Circulation 104: 1424-1429, 2001

206. del Monte F, Harding SE, Dec GW, Gwathmey JK, and Hajjar RJ: Targeting phospholamban by gene transfer in human heart failure. Circulation 105: 904-907, 2002

207. Bers DM: Cardiac Na/Ca exchange function in rabbit, mouse and man: What's the difference? J Mol Cell Cardiol 34: 369-373, 2002

208. Wier WG, and Balke CW: $\mathrm{Ca}^{2+}$ release mechanisms, $\mathrm{Ca}^{2+}$ sparks, and local control of excitation-contraction coupling in normal heart muscle. Circ Res 85: 770-776, 1999

209. Luo W, Grupp IL, Harrer J, Ponniah S, Grupp G, Duffy JJ, Doetschman T, and Kranias EG: Targeted ablation of the phospholamban gene is associated with markedly enhanced myocardial contractility and loss of agonist stimulation. Circ Res 75: 401-409, 1994

210. Koss KL, and Kranias EG: Phospholamban: A prominent regulator of myocardial contractility. Circ Res 79: 1059-1063, 1996

211. Wu KD, Lee WS, Wey J, Bungard D, and Lytton J: Localization and quantification of endoplasmic reticulum $\mathrm{Ca}^{2+}$-ATPase isoform transcripts. Am J Physiol Cell Physiol 269: C775-C784, 1995

212. Arai M, Matsui H, and Periasamy M: Sarcoplasmic reticulum gene expression in cardiac hypertrophy and heart failure. Circ Res 74: 555-564, 1994 
213. Loukianov E, Ji Y, Baker DL, Reed T, Babu J, Loukianova $T$, Greene A, Shull $G$, and Periasamy $M$ : Sarco(endo)plasmic reticulum $\mathrm{Ca}^{2+}$-ATPase isoforms and their role in muscle physiology and pathology. Ann N Y Acad Sci 853: 251-259, 1998

214. Yamashita D, Kohzuki H, Kitagawa Y, Nakashima T, Kikuta A, and Takaki M: Oxygen consumption of mechanically unloaded contractions of mouse left ventricular myocardial slices. Am J Physiol Heart Circ Physiol 287: H54-H62, 2004

215. Li L, Desantiago J, Chu G, Kranias EG, and Bers DM: Phosphorylation of phospholamban and troponin I in beta-adrenergic-induced acceleration of cardiac relaxation. Am J Physiol Heart Circ Physiol 278: H769$\mathrm{H} 779,2000$

216. Li Y, Kranias EG, Mignery GA, and Bers DM: Protein kinase $A$ phosphorylation of the ryanodine receptor does not affect calcium sparks in mouse ventricular myocytes. Circ Res 90: 309-316, 2002

217. Bers DM: Cardiac excitation-contraction coupling. Nature 415, 198-205, 2002

218. Hasenfuss G, Pieske B, Holubarsch C, Alpert NR, and Just $\mathrm{H}$ : Excitation-contraction coupling and contractile protein function in failing and nonfailing human myocardium. Adv Exp Med Biol 346: 91-100, 1993

219. Bers DM: Calcium and cardiac rhythms: physiological and pathophysiological. Circ Res 90: 14-17, 2002

220. Pieske B, Maier LS, Bers DM, and Hasenfuss G: $\mathrm{Ca}^{2+}$ handling and sarcoplasmic reticulum $\mathrm{Ca}^{2+}$ content in isolated failing and nonfailing human myocardium. Circ Res 85: 38-46, 1999

221. Pogwizd SM, Qi M, Yuan W, Samarel AM, and Bers DM: Upregulation of $\mathrm{Na}^{+} / \mathrm{Ca}^{2+}$ exchanger expression and function in an arrhythmogenic rabbit model of heart failure. Circ Res 85: 1009-1019, 1999

222. Pogwizd SM, Schlotthauer K, Li L, Yuan W, and Bers DM: Arrhythmogenesis and contractile dysfunction in heart failure: Roles of sodium-calcium exchange, inward rectifier potassium current, and residual beta-adrenergic responsiveness. Circ Res 88: 1159-1567, 2001

223. Hagihara $H$, Yoshikawa $Y$, Takenaka C, Taniguchi S, and Takaki M: Similar left ventricular (LV) mechanoenergetics in ischemic-reperfused hearts to high $\mathrm{Ca}^{2+}$-infused hearts in rats. $\mathrm{J}$ Mol Cell Cardiol 35: A21-O-17, 2003 (Abstract)

224. Hajjar RJ, Kang JX, Gwathmey JK, and Rosenzweig A: Physiological effects of adenoviral gene transfer of sarcoplasmic reticulum calcium ATPase in isolated rat myocytes. Circulation 95: 423-429, 1997

225. Hajjar RJ, Schmidt U, Kang JX, Matsui T, and Rosenzweig A: Adenoviral gene transfer of phospholamban in isolated rat cardiomyocytes. Rescue effects by concomitant gene transfer of sarcoplasmic reticulum $\mathrm{Ca}^{2+}$ ATPase. Circ Res 81: 145153, 1997

226. Hajjar RJ, Schmidt U, Matsui T, Guerrero JL, Lee KH, Gwathmey JK, Dec GW, Semigran MJ, and Rosenzweig A: Modulation of ventricular function through gene transfer in vivo. Proc Natl Acad Sci USA 95: 52515256, 1998

227. del Monte F, Harding SE, Schmidt U, Matsui T, Kang ZB, Dec GW, Gwathmey JK, Rosenzweig A, and Hajjar $\mathrm{RJ}$ : Restoration of contractile function in isolated cardiomyocytes from failing human hearts by gene transfer of SERCA2a: Circulation 100: 2308-2311, 1999

228. del Monte F, Butler K, Boecker W, Gwathmey JK, and Hajjar RJ: Novel technique of aortic banding followed by gene transfer during hypertrophy and heart failure. Physiol Genomics 9: 49-56, 2002

229. Miyamoto MI, del Monte F, Schmidt U, Matsui T, Guerrero JL, Gwathmey JK, Rosenzweig A, and Hajjar RJ: Adenoviral gene transfer of SERCA2a improves left ventricular function in aortic-banded rats in transition to heart failure. Proc Natl Acad Sci USA 97: 793798,2000

230. He H, Meyer M, Martin JL, McDonough PM, Ho P, Lou $X$, Lew WY, Hilal-Dandan R, and Dillmann WH: Effects of mutant and antisense RNA of phospholamban on SR $\mathrm{Ca}^{2+}$-ATPase activity and cardiac myocyte contractility. Circulation 100: 974-980, 1999

231. Minamisawa S, Hoshijima M, Chu G, Ward CA, Frank K, Gu Y, Martone ME, Wang Y, Ross J Jr, Kranias EG, Giles WR, and Chien KR: Chronic phospholambansarcoplasmic reticulum calcium ATPase interaction is the critical calcium cycling defect in dilated cardiomyopathy. Cell 99: 313-322, 1999

232. Hoshijima M, Ikeda $Y$, Iwanaga $Y$, Minamisawa S, Date MO, Gu Y, Iwatate M, Li M, Wang L, Wilson JM, Wang $Y$, Ross $J \mathrm{~J}$, and Chien KR: Chronic suppression of heart-failure progression by a pseudophosphorylated mutant of phospholamban via in vivo cardiac rAAV gene delivery. Nat Med 8: 864-871, 2002

233. Yoshikawa $Y$, and Takaki M: Energy utilization in failing hearts. Folia Pharmacol Jpn 123: 77-86, 2004 (in Japanese) 